\title{
An overview of the ORACLES (ObseRvations of Aerosols above CLouds and their intEractionS) project: aerosol-cloud-radiation interactions in the southeast Atlantic basin
}

Jens Redemann ${ }^{1}$, Robert Wood ${ }^{2}$, Paquita Zuidema ${ }^{3}$, Sarah J. Doherty ${ }^{2}$, Bernadette Luna $^{4}$, Samuel E. LeBlanc ${ }^{5,4}$, Michael S. Diamond ${ }^{2}$, Yohei Shinozuka ${ }^{7}$, Ian Y. Chang ${ }^{1}$, Rei Ueyama ${ }^{4}$, Leonhard Pfister ${ }^{4}$, Ju-Mee Ryoo ${ }^{4,36}$, Amie N. Dobracki ${ }^{3}$, Arlindo M. da Silva ${ }^{6}$, Karla M. Longo ${ }^{6,7}$, Meloë S. Kacenelenbogen ${ }^{4}$, Connor J. Flynn ${ }^{1}$, Kristina Pistone ${ }^{5,4}$, Nichola M. Knox ${ }^{8}$, Stuart J. Piketh ${ }^{9}$, James M. Haywood ${ }^{10}$, Paola Formenti ${ }^{11}$, Marc Mallet ${ }^{12}$, Philip Stier ${ }^{13}$, Andrew S. Ackerman ${ }^{14}$, Susanne E. Bauer ${ }^{14}$, Ann M. Fridlind ${ }^{14}$, Gregory R. Carmichael ${ }^{15}$, Pablo E. Saide ${ }^{16,17}$, Gonzalo A. Ferrada ${ }^{15}$, Steven G. Howell ${ }^{18}$, Steffen Freitag ${ }^{18}$, Brian Cairns ${ }^{14}$, Brent N. Holben ${ }^{6}$, Kirk D. Knobelspiesse ${ }^{6}$, Simone Tanelli ${ }^{20}$, Tristan S. L'Ecuyer ${ }^{20}$, Andrew M. Dzambo ${ }^{20}$, Ousmane O. Sy ${ }^{19}$, Greg M. McFarquhar ${ }^{1,39}$, Michael R. Poellot ${ }^{21}$, Siddhant Gupta ${ }^{1}$, Joseph R. O'Brien ${ }^{21}$, Athanasios Nenes ${ }^{22,37,38}$, Mary Kacarab $^{22}$, Jenny P. S. Wong ${ }^{22,23}$, Jennifer D. Small-Griswold ${ }^{24}$, Kenneth L. Thornhill ${ }^{25,34}$, David Noone ${ }^{26,35}$, James R. Podolske ${ }^{4}$, K. Sebastian Schmidt ${ }^{27}$, Peter Pilewskie ${ }^{27}$, Hong Chen ${ }^{27}$, Sabrina P. Cochrane ${ }^{27}$, Arthur J. Sedlacek ${ }^{28}$, Timothy J. Lang ${ }^{29}$, Eric Stith ${ }^{30}$, Michal Segal-Rozenhaimer ${ }^{4,5,31}$, Richard A. Ferrare ${ }^{25}$, Sharon P. Burton ${ }^{25}$, Chris A. Hostetler ${ }^{25}$, David J. Diner ${ }^{19}$, Felix C. Seidel ${ }^{19}$, Steven E. Platnick ${ }^{6}$, Jeffrey S. Myers ${ }^{32}$, Kerry G. Meyer ${ }^{6}$, Douglas A. Spangenberg ${ }^{34}$, Hal Maring ${ }^{33}$, and Lan Gao ${ }^{1}$

${ }^{1}$ School of Meteorology, University of Oklahoma, Norman, OK, USA

${ }^{2}$ Department of Atmospheric Sciences, University of Washington, Seattle, WA, USA

${ }^{3}$ Department of Atmospheric Sciences, University of Miami, Miami, FL, USA

${ }^{4}$ NASA Ames Research Center, Moffett Field, CA, USA

${ }^{5}$ Bay Area Environmental Research Institute, Moffett Field, CA, USA

${ }^{6}$ NASA Goddard Space Flight Center, Greenbelt, MD, USA

${ }^{7}$ Universities Space Research Association, Columbia, MD, USA

${ }^{8}$ Department of Geo-Spatial Sciences and Technology, Namibia University of Science and Technology, Windhoek, Namibia

${ }^{9}$ Unit for Environmental Science and Management, North-West University, Potchefstroom, North-West, South Africa

${ }^{10}$ College of Engineering, Mathematics and Physical Science, University of Exeter, Exeter, EX4 4QE, UK

${ }^{11}$ Laboratoire Interuniversitaire des Systèmes Atmosphériques (LISA), UMR CNRS 7583, Université Paris-Est-Créteil,

Université de Paris, Institut Pierre Simon Laplace, Créteil, France

${ }^{12}$ Centre National de Recherches Météorologiques, Météo-France-CNRS, Toulouse, France

${ }^{13}$ Atmospheric, Oceanic and Planetary Physics, Department of Physics, University of Oxford, Oxford, UK

${ }^{14}$ NASA Goddard Institute for Space Studies, New York, NY, USA

${ }^{15}$ Center for Global and Regional Environmental Research, University of Iowa, Iowa City, IA, USA

${ }^{16}$ Department of Atmospheric and Oceanic Sciences, University of California, Los Angeles, CA, USA

${ }^{17}$ Institute of the Environment and Sustainability, University of California, Los Angeles, CA, USA

${ }^{18}$ Department of Oceanography, University of Hawai' $i$ at Mānoa, Honolulu, HI, USA

${ }^{19}$ Jet Propulsion Laboratory, California Institute of Technology, Pasadena, CA, USA

${ }^{20}$ Department of Atmospheric and Oceanic Sciences, University of Wisconsin-Madison, Madison, WI, USA

${ }^{21}$ Department of Atmospheric Sciences, University of North Dakota, Grand Forks, ND, USA

${ }^{22}$ Georgia Institute of Technology, Atlanta, GA, USA

${ }^{23}$ Department of Chemistry and Biochemistry, Mount Allison University, Sackville, Canada

${ }^{24}$ Department of Atmospheric Sciences, University of Hawai 'i at Mānoa, Honolulu, HI, USA

${ }^{25}$ NASA Langley Research Center, Hampton, VA, USA

${ }^{26}$ College of Earth, Ocean, and Atmospheric Sciences, Oregon State University, Corvallis, OR, USA 
${ }^{27}$ Department of Atmospheric and Oceanic Sciences, University of Colorado, Boulder, CO, USA

${ }^{28}$ Brookhaven National Laboratory, Upton, NY, USA

${ }^{29}$ NASA Marshall Space Flight Center, Huntsville, AL, USA

${ }^{30}$ National Suborbital Research Center, Moffett Field, CA, USA

${ }^{31}$ Department of Geophysics and Planetary Sciences, Porter School of the Environment and Earth Sciences,

Tel Aviv University, Tel Aviv, Israel

${ }^{32}$ University of California Santa Cruz, Santa Cruz, CA, USA

${ }^{33}$ NASA Headquarters, Washington, D.C., USA

${ }^{34}$ Science Systems and Applications, Inc., Hampton, VA, USA

${ }^{35}$ Department of Physics, University of Auckland, Auckland, New Zealand

${ }^{36}$ Science and Technology Corporation, Moffett Field, CA, USA

${ }^{37}$ Ecole Polytechnique Federale de Lausanne, Lausanne, Switzerland

${ }^{38}$ Foundation for Research and Technology - Hellas, Heraklion, Greece

${ }^{39}$ Cooperative Institute for Mesoscale Meteorological Studies (CIMMS) and School of Meteorology, University of Oklahoma, Norman, OK, USA

Correspondence: Jens Redemann (jredemann@ou.edu)

Received: 8 May 2020 - Discussion started: 16 June 2020

Revised: 9 October 2020 - Accepted: 1 November 2020 - Published: 4 February 2021

Abstract. Southern Africa produces almost a third of the Earth's biomass burning (BB) aerosol particles, yet the fate of these particles and their influence on regional and global climate is poorly understood. ORACLES (ObseRvations of Aerosols above CLouds and their intEractionS) is a 5-year NASA EVS-2 (Earth Venture Suborbital-2) investigation with three intensive observation periods designed to study key atmospheric processes that determine the climate impacts of these aerosols. During the Southern Hemisphere winter and spring (June-October), aerosol particles reaching 3-5 km in altitude are transported westward over the southeast Atlantic, where they interact with one of the largest subtropical stratocumulus (Sc) cloud decks in the world. The representation of these interactions in climate models remains highly uncertain in part due to a scarcity of observational constraints on aerosol and cloud properties, as well as due to the parameterized treatment of physical processes. Three ORACLES deployments by the NASA P-3 aircraft in September 2016, August 2017, and October 2018 (totaling $\sim 350$ science flight hours), augmented by the deployment of the NASA ER-2 aircraft for remote sensing in September 2016 (totaling 100 science flight hours), were intended to help fill this observational gap. ORACLES focuses on three fundamental science themes centered on the climate effects of African BB aerosols: (a) direct aerosol radiative effects, (b) effects of aerosol absorption on atmospheric circulation and clouds, and (c) aerosol-cloud microphysical interactions. This paper summarizes the ORACLES science objectives, describes the project implementation, provides an overview of the flights and measurements in each deployment, and highlights the integrative modeling efforts from cloud to global scales to address science objectives. Signif- icant new findings on the vertical structure of BB aerosol physical and chemical properties, chemical aging, cloud condensation nuclei, rain and precipitation statistics, and aerosol indirect effects are emphasized, but their detailed descriptions are the subject of separate publications. The main purpose of this paper is to familiarize the broader scientific community with the ORACLES project and the dataset it produced.

\section{Introduction}

The radiative and cloud-altering impacts of anthropogenic aerosol particles constitute the largest source of uncertainty in anthropogenic climate forcing (IPCC, 2013). Aerosol particles interact directly with solar radiation through scattering and absorption of radiation, which leads to a direct radiative forcing whose sign depends on the ratio of the absorption to the total aerosol extinction and on the albedo of the underlying surface-atmosphere system (Coakley and Chylek, 1975). Heating of the atmosphere by aerosol absorption can induce changes in atmospheric circulation and mixing that can either enhance or decrease cloudiness (Ackerman et al., 2000; Koch and Del Genio, 2010). Aerosol particles also serve as cloud condensation nuclei $(\mathrm{CCN})$, which can enhance cloud albedo by increasing the concentration of cloud droplets and reducing their size when aerosol concentrations increase at fixed liquid water content (Twomey, 1974), and also potentially drive changes in cloud condensate or cloud cover by altering cloud lifetimes (Simpson and Wiggert, 1969; Albrecht, 1989; Ackerman et al., 2004; Wood, 2007). The magnitudes of all effects and even the sign of the latter two aerosol ef- 
fects are not well quantified globally (IPCC, 2013) and are expected to be geographically and seasonally heterogeneous because the total aerosol forcing is dependent upon the nature and amount of different aerosol species, cloud type and cover, and surface albedo, all of which vary on such scales.

Biomass burning (BB) is one of the largest sources of absorbing aerosol globally (Bond et al., 2013). BB aerosol particles contain black carbon, the most strongly absorbing of all aerosol constituents found in the atmosphere. The sign of the direct aerosol forcing is highly dependent upon the relative vertical locations of aerosol and clouds, with forcing changing from negative to positive when BB aerosol layers overlie low clouds rather than a dark ocean surface (Chand et al., 2009). BB aerosols also contain oxidized organic carbon and other soluble inorganic species that can act as effective $\mathrm{CCN}$ if transported into clouds.

The southeast Atlantic (SEA) region has some of the highest optical depths of BB aerosol on the planet. It is also the location of large inter-model differences in aerosol forcing assessments (Schulz et al., 2006; Stier et al., 2013; Zuidema et al., 2016). The neighboring southern African biomass burning (BB) source regions account for almost one third of the Earth's BB emissions (550 $\mathrm{Tg} \mathrm{C} \mathrm{yr}^{-1}$; van der Werf et al., 2010), producing optically thick BB aerosol layers that are routinely transported across much of the South Atlantic basin (Chand et al., 2009; Zuidema et al., 2016). While burned areas are decreasing in size globally, burned areas in Africa are increasing, raising interesting questions about $\mathrm{BB}$ aerosol interactions with climate in that region in the future (Andela et al., 2017).

The SE Atlantic is also home to one of the Earth's largest subtropical stratocumulus $(\mathrm{Sc})$ cloud decks, which plays a key role in the energetic balance of the region. The physical processes governing the feedbacks between sea surface temperature (SST) and cloud properties in these Sc decks are poorly represented in climate models (Bony and Dufresne, 2005). In the Austral spring (July to October), the Sc deck interacts with the African BB aerosols that have been transported westward by prevailing mid-tropospheric tropical easterly winds. These aspects of the SE Atlantic attracted several international field experiments on aerosolcloud-climate interactions in the region. These projects were based out of deployment sites distributed throughout the SE Atlantic (Fig. 1) and were scheduled between 2016 and 2018 to allow for collaborative science. These experiments include the NASA ORACLES project described in this paper, deploying from Walvis Bay, Namibia, in 2016 and São Tomé in 2017 and 2018; the UK CLARIFY (Clouds and Aerosol Radiative Impacts and Forcing), deploying from Ascension Island in 2017; the French AEROCLO-sA (Aerosol, Radiation and Clouds in southern Africa) project, deploying from Walvis Bay, Namibia, in 2017; and the DOE Atmospheric Radiation Measurement mobile facility LASIC (Layered Atlantic Smoke Interactions with Clouds) deployment to As- cension Island in 2016-2017, all described in more detail in Sect. 3.4.

The southern and central African fires producing BB aerosol occur during the warm, dry season over the continent, so emissions are lofted in the convective boundary layer to an altitude of several kilometers. As they advect offshore, the BB aerosol layers form a plume that initially overlays the cloud deck over the Atlantic (Fig. 2; see also Adebiyi and Zuidema, 2016; Zuidema et al., 2016; Deaconu et al., 2019 ) and exerts a direct radiative forcing (RF) whose sign and magnitude depend upon the reflectance and coverage of the clouds below and on the absorptivity of the aerosols (Keil and Haywood, 2003; Chand et al., 2009). Depending on the relative vertical location of the aerosols and the cloud deck, cloud condensate may increase or decrease in response to aerosol absorption and subsequent changes in atmospheric stability, relative humidity, and subsidence (semi-direct forcing). Cloud optical thickness and areal coverage may also be influenced by aerosol-induced changes in cloud microphysics (forcing from aerosol-cloud interactions) when BB aerosols are mixed into the marine boundary layer (MBL). This is expected to occur more frequently offshore as the MBL deepens in response to warming sea surface temperatures (e.g., Eastman et al., 2017), raising cloud top heights (Zuidema et al., 2009) and easing entrainment of the overlying aerosol, and as BB aerosol layers descend in response to prevailing large-scale subsidence (Fig. 2).

Satellite- and model-based assessments of aerosol-cloudclimate interactions in this region (e.g., Chand et al., 2009; Wilcox, 2012; Stier et al., 2013; De Graaf et al., 2014; Zhang et al., 2016; Adebiyi and Zuidema, 2018; Zhang and Zuidema, 2019; Kacenelenbogen et al., 2019; Sayer et al., 2019) indicate that improved observations of aerosol properties and loading, cloud fraction, albedo, and liquid water path (LWP) are needed to constrain the local aerosol radiative impacts. Such studies are hampered by problematic aerosol retrievals in regions of extensive low clouds and difficulties retrieving cloud microphysical properties underneath dense aerosol layers (Haywood et al., 2004; Coddington et al., 2010; Deaconu et al., 2017). The observations used in these studies often have severe limitations and require significant assumptions about aerosol and cloud properties (Yu et al., 2012; Yu and Zhang, 2013; Jethva et al., 2014; Knobelspiesse et al., 2015; Meyer et al., 2015; Sayer et al., 2016).

An example of a satellite-based retrieval of both aerosols and clouds is given in Fig. 2, which shows the altitude of aerosol and cloud layers during 3 months as a function of longitude, as operationally retrieved from the Cloud-Aerosol Lidar with Orthogonal Polarization (CALIOP) space-based lidar. Multiple filters have been applied for quality assurance of these data. However, the simple message this figure conveys, of an elevated aerosol layer that is typically far above the low cloud, is somewhat misleading because (i) there could be multiple aerosol layers above the uppermost cloud and (ii) the CALIOP-derived aerosol layer base 


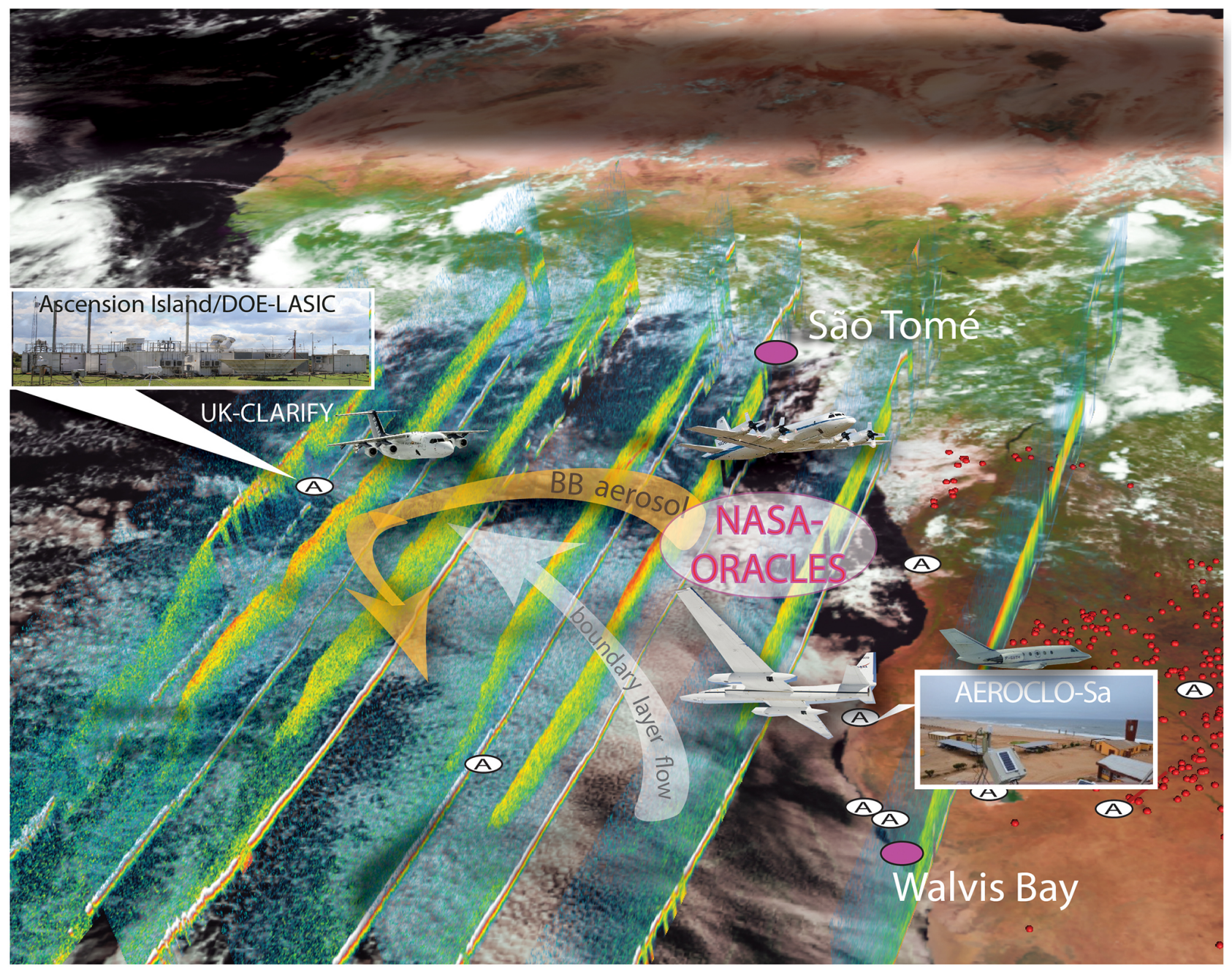

Figure 1. Deployment sites for the 2016-2018 ORACLES field experiments and collaborative international deployment activities (see text), along with CALIOP curtain data visualized by Charles Trepte (NASA Langley), adapted from @ Google Maps 2020. The ovals with the letter A indicate new or refurbished AERONET sites (Holben et al., 2018).

height has been found to be biased high, based on airborne measurements made during ORACLES as well as CALIOP retrievals that have been constrained by above-cloud aerosol optical thickness derived from the CALIOP data. The latter results from the fact that, especially for the daytime retrievals from CALIOP, there is a significant reduction in the signalto-noise ratio in the presence of optically thick aerosol layers. Hence, the separation between clouds and overlying aerosols (Fig. 2, yellow bars) is also likely biased high (see also Rajapakshe et al., 2017). Such observational uncertainty and the differing conclusions one may draw based on the separation between the BB aerosol layer and the underlying Sc clouds in this region were a significant contributing impetus for the ORACLES project. We include the CALIOP-derived Fig. 2 here to provide the scientific information available at the ORACLES proposal stage, which partially motivated the project in the first place and greatly influenced its design (WatsonParris et al., 2018).

Surface-based measurements also have limitations. AERONET (Aerosol Robotic Network) sky radiance observations (Holben et al., 1998) are used frequently to tune global model estimates of aerosol absorption (Bond et al., 2013) but can be routinely performed only from land and in the absence of clouds. Although historically a number of AERONET stations existed near the main African BB sources, just prior to ORACLES, there were no operational AERONET stations in the main $\mathrm{BB}$ region, with the exception of Ascension Island far downwind.

Airborne instruments provide measurements of aerosols and clouds under co-varying meteorological conditions that are currently impossible to obtain from space. Highresolution airborne observations, over scales that resolve processes of interest, provide critical constraints for parame- 

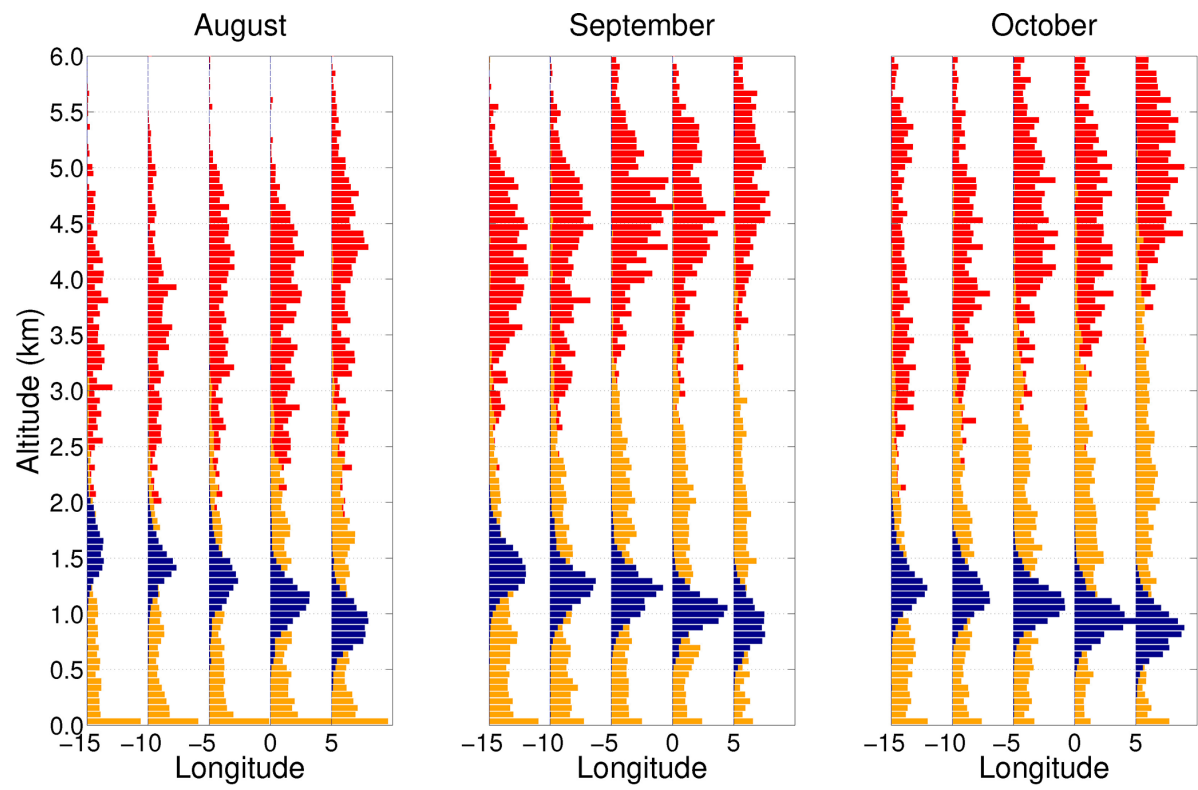

Figure 2. Distributions of aerosol top height (red), cloud top height (blue), and the separation between clouds and overlying aerosols (yellow) as a function of longitude, between $10-22.5^{\circ} \mathrm{S}$. Observations are taken from the Cloud-Aerosol Lidar with Orthogonal Polarization (CALIOP) version 3 aerosol profile product from 2006 to 2012 (7 years).

terizing aerosol-cloud-climate interactions in models. They can also be used to enhance satellite-based remote sensing, by resolving in situ characteristics and variability within a particular scene, by providing a direct test of retrieved properties, and in the long term by guiding the development of new and improved remote-sensing techniques. Because previous efforts to study BB emissions in South Africa (e.g., SAFARI-2K, Swap et al., 2003; TRACE-A, Fishman et al., 1996) were focused over land or in close proximity to the coastal zone (e.g., Haywood et al., 2003), prior to ORACLES, there was a dearth of measurements over the SE Atlantic Ocean, where the major radiative impacts of $\mathrm{BB}$ aerosols are taking place.

In response to the need for new measurement constraints, in 2014 NASA funded the ORACLES project as one of the Earth Venture Suborbital-2 investigations. The goal of ORACLES is to provide a process-level understanding of the role of aerosols in climate by providing observations of all relevant aerosol effects over the SE Atlantic, a region with some of the largest aerosol loadings on the planet that is readily accessible with airborne platforms. The overarching ORACLES science goals, which encompass the specific science themes and questions in the abstract and Table 1 below, are as follows.

1. Determine the impact of African BB aerosol on cloud properties and the radiation balance over the South Atlantic, using state-of-the-art in situ and remote-sensing instruments to generate datasets that can also be used to verify and refine current and future observation meth- ods, including instrument concepts with potential for deployment to space.

2. Acquire a process-level understanding of aerosolcloud-radiation interactions and resulting cloud adjustments that can be applied in global models.

In this paper, we provide an overview of all three ORACLES deployments, highlighting aerosol absorptive and cloud-nucleating properties, their vertical distribution relative to clouds, the locations and degree of aerosol mixing into clouds, and cloud changes in response to such mixing. We make an initial assessment of the differences and similarities of the BB plume and cloud properties as observed from the 2016 deployment site (Walvis Bay, Namibia) at the plume's southern edge and from the 2017 and 2018 deployment site (São Tomé and Príncipe) near the plume's northern edge. We conclude with an outlook for the integrative work we envision to address the overarching science questions regarding aerosol-radiation-climate interactions in the SE Atlantic and how these suborbital observations will aid long-term modeling and satellite remote-sensing efforts.

\section{Project background}

\subsection{Motivation for 3-year field deployment}

Prior to the ORACLES implementation stage, an analysis of satellite data in the study area had revealed pronounced shifts in aerosol altitude, concentration, and optical properties through the July to October BB season. That com- 
bined body of work suggested that aerosol loadings peak in September (Fig. 3, see also Adebiyi et al., 2015), whereas single-scattering albedo (SSA) increases over the season, reflecting either a change in BB aerosol composition (Eck et al., 2013) or the mix of aerosol types present (Bond et al., 2013). Another striking seasonal change is that, on average, the gap between cloud top and the aerosol layer increases dramatically (Fig. 2), primarily due to higher aerosol layers.

The closer vertical proximity of $\mathrm{BB}$ aerosol layers to clouds early in the season (shown in Fig. 2) suggested that studies of aerosol-cloud interactions would be most feasible then, while larger gaps later in the season would suggest weaker indirect effects. Observing and quantifying these seasonal changes and the changing importance of the aerosol semi-direct and indirect effects over the BB season required either an impractically extended deployment or separate deployments spread across the season. The ORACLES team decided on separate deployments in September 2016, August 2017, and October 2018, a decision that was aided by a relative lack of interannual variability in meteorology. This variability was predominantly linked to SST variations known as Benguela Niños that mainly occur in boreal spring, not fall, and are much less frequent than the better-known Pacific El Niños (Rouault, 2012). Interannual variability in fire emissions was expected to be low as well (van der Werf et al., 2010). As a result, aerosol loading in the ORACLES region was expected to be repeatable, with Moderate Resolution Imaging Spectroradiometer (MODIS) clear-sky aerosol optical depth (AOD) retrievals implying year-to-year variability through the burning season of only $20 \%$ of the mean. In reality, recently developed above-cloud AOD retrievals reveal a significant interannual variability in the properties of the above-cloud aerosol plume (see Sect. 4.2-4.3 below); investigations into the particular reasons are ongoing. Finally, a practical consideration for the attempt to cover the BB seasonal cycle with three separate deployments was based on the fact that airborne instrument performance has a tendency to significantly decrease as mission durations extend beyond 4 weeks.

\subsection{Science questions and objectives}

ORACLES science questions and related objectives are generally focused on direct, semi-direct, and indirect aerosol effects on climate. Table 1 summarizes science questions and objectives as originally posed. The general approach for developing these objectives was to include goals that were highly achievable first and to increase the complexity of objectives gradually. The objectives related to science questions 1 and 2, i.e., direct and semi-direct effects, constituted the "threshold" (for success) science mission. The science objectives associated with question 3, i.e., indirect effect assessments, were part of the "baseline" science mission, which in NASA terminology indicates the full mission scope.

\subsection{Project implementation}

\subsubsection{Logistics and deployment details}

The Walvis Bay airport in western Namibia was originally considered the ideal location for ORACLES due to its proximity to the ocean and cloud deck, runway length and hangar size for the ER-2, and due to its use during the SAFARI-2K campaign by the University of Washington CV-580 aircraft. The runway had been extended to $\sim 3350 \mathrm{~m}$, but certification of the extension was still in progress as ORACLES began. It was our intention to deploy only one aircraft in the first year and grow the activity after acclimating to the locality and airspace. However, during the ORACLES-2016 deployment planning, the UK CLARIFY team announced plans to fly its airborne assets in 2016 as well. In response, leadership re-ordered ORACLES deployments to bring both aircraft to Walvis Bay in 2016, so as to maximize their impact in a concerted effort with the international partners.

In the event that the facilities were found to be inadequate or unready or unavailable, alternate airfields were investigated. Specifically, Upington (FAUP), South Africa, and São Tomé (FPST) were pursued with due diligence until country approval was obtained from Namibia. Upington had no usable hangar but an extremely long runway, little competing traffic, and the benefit of a long-standing collaborative relationship with the USA and NASA. São Tomé's runway length and hangars could not accommodate the ER-2 requirements, but officials were very enthusiastic about a NASA collaboration. Both locations could support a P-3-only deployment. A temporary hangar in Upington, South Africa, or Windhoek, Namibia, might have supported the ER-2. Ascension Island also had no hangar and posed significant constraints to the commercial import/transport of people and equipment. In later years, Ascension Island was subject to runway construction, but it did serve as an overnight transit stop for the P-3 in 2016 and 2017 and as the target for suitcase (overnight stay) flights in 2017.

ORACLES experiment requirements dictated deployment of up to 80 people (110 in 2016) for three 5-week periods, centered on the months of September 2016, August 2017, and October 2018.

\subsubsection{Choice of measurement platforms: envisioned versus realized capabilities}

The revised ORACLES project implementation plan called for the operation of two aircraft in 2016 and the operation of only one aircraft in 2017 and 2018. The choice to deploy the ER-2 aircraft in 1 year only was solely based on funding considerations, as its operations are considerably more complicated and costly.

The ORACLES platforms and instruments were selected to efficiently and quantitatively address the science questions outlined above through measurements of radiative fluxes, 

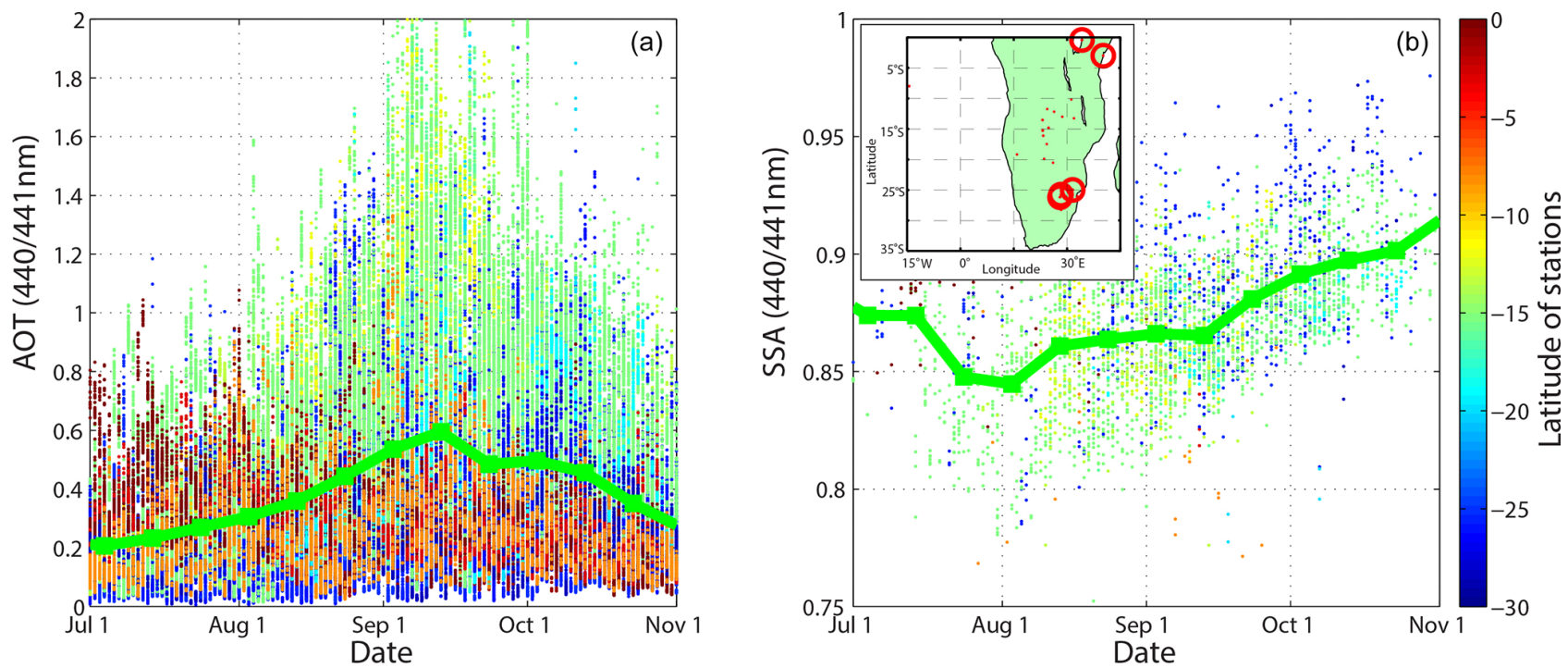

Figure 3. Aerosol optical depth at 440/441 nm (a) from AERONET sites in southern Africa peaks in early September, while SSA at $440 / 441 \mathrm{~nm}$ (b) shows a significant increase between August and November. Red circles in the inset indicate the few stations operating between 2011 and 2013. Both panels contain data from 1995 to 2013 to represent the state of knowledge prior to the ORACLES deployments.

Table 1. A summary of ORACLES science questions and related objectives.

\begin{tabular}{|c|c|}
\hline Science questions & Related science objectives \\
\hline $\begin{array}{l}\text { Q1: what is the direct radiative effect } \\
\text { of the African biomass burning (BB) } \\
\text { aerosol layer in clear- and cloudy-sky } \\
\text { conditions over the SE Atlantic? }\end{array}$ & $\begin{array}{l}\text { O1-1 (aerosol spatial evolution): determine the evolution of the BB aerosol mi- } \\
\text { crophysical and spectral radiative properties as the aerosol is transported across } \\
\text { the South Atlantic. } \\
\text { O1-2 (aerosol-induced radiative fluxes): measure aerosol-induced spectral ra- } \\
\text { diative fluxes as a function of cloud albedo and aerosol properties. } \\
\text { O1-3 (seasonal aerosol variation): assess the key factors that control the sea- } \\
\text { sonal variation in aerosol direct effects. }\end{array}$ \\
\hline $\begin{array}{l}\text { Q2: how does absorption of solar radia- } \\
\text { tion by African biomass burning (BB) } \\
\text { aerosol change atmospheric stability, } \\
\text { circulation, and ultimately cloud prop- } \\
\text { erties? }\end{array}$ & $\begin{array}{l}\text { O2-1 (relative vertical distribution): determine the seasonally varying relative } \\
\text { vertical distributions of aerosol and cloud properties as a function of distance } \\
\text { from shore. } \\
\text { O2-2 (aerosol-cloud heating rates): constrain aerosol-induced heating rates for } \\
\text { aerosol layers above, within, and below cloud. } \\
\text { O2-3 (cloud changes due to aerosol-induced heating): investigate the sensitivity } \\
\text { of cloud structure and condensate to aerosol-induced heating rates. }\end{array}$ \\
\hline $\begin{array}{l}\text { Q3: how do BB aerosols affect cloud } \\
\text { droplet size distributions, precipitation, } \\
\text { and the persistence of clouds over the } \\
\text { SE Atlantic? }\end{array}$ & $\begin{array}{l}\text { O3-1 (mixing survey): survey the location and extent of aerosol mixing into the } \\
\text { boundary layer (BL) and its seasonal variation. } \\
\text { O3-2 (cloud changes due to aerosol mixing): measure changes in cloud micro- } \\
\text { physical properties, albedo, and precipitation as a function of aerosol mixing } \\
\text { into the BL. } \\
\text { O3-3 (cloud changes due to aerosol-suppressed precipitation): investigate the } \\
\text { sensitivity of cloud structure and condensate to aerosol-induced suppression in } \\
\text { precipitation. }\end{array}$ \\
\hline
\end{tabular}

derivation of heating rates, observations of aerosol and cloud microphysical and radiative properties, atmospheric thermodynamics, and chemistry. The desired flight plans were driven by expected aerosol-cloud features and their interactions within the region, by regional model forecasts, and by recent (same-flight or previous-flight) observations. When the P-3 was the sole NASA aircraft deployed (August 2017 and October 2018), Research Scanning Polarimeter (RSP) and High Spectral Resolution Lidar (HSRL-2) instruments (Table A4) were added to its payload to capture relevant sci- 
ence data by flying above, within, and below aerosol layers and clouds. When both the P-3 and ER-2 were present (September 2016), the ER-2 served in a remote-sensing role, obviating the need for the P-3 to fly above both cloud and aerosol layers.

It was known from the planning stage that the range of the P-3 aircraft was dependent on payload and flight pattern flown; spirals and low-altitude flight reduce flight time. Based on DISCOVER-AQ's successful inclusion of spirals from 1000 to $5000 \mathrm{ft}$ ( 305 to $1525 \mathrm{~m}$ ) during $8 \mathrm{~h}$ flights, ORACLES flights were expected to be similar in duration and character. From Walvis Bay, Namibia, this covered the target science zone (5 to $35^{\circ} \mathrm{S}$, westward from the coast to approximately the prime meridian), transit to Ascension Island for suitcase flights and for coordination with the UK's CLARIFY team, and transit to São Tomé Island, located near the northern edge of the climatological BB plume, with margins for headwinds, profiles, and low-altitude flight.

During the 2016 deployment, it became obvious that there was merit in P-3 flights that extended beyond the originally estimated $8 \mathrm{~h}$ duration. The NASA P- 3 crew accommodated this request as far as crew rest considerations permitted; the average flight duration for local P-3 science flights (excluding transits) in 2016 was $8.3 \mathrm{~h}$ (see Sect. 4.4). In 2017 and 2018, while flying from São Tomé, a larger P-3 flight crew was able to average 9.1 and 8.3 flight hours respectively for similar flights, with the 2018 average affected by increased safety margins due to expected inclement weather.

For ORACLES, ER-2 flights were envisioned to be up to $8 \mathrm{~h}$ in duration, similar to the prior Studies of Emissions and Atmospheric Composition, Clouds and Climate Coupling by Regional Surveys (SEAC4RS) campaign. Due to the $2 \mathrm{~h}$ pre-flight hands-off period and pilot $12 \mathrm{~h}$ duty day, there were concerns that weather delays (e.g., low ceilings) would result in flight duration limitations and therefore limitations in the final geographical coverage. The ER-2 deployed only once for ORACLES, to Walvis Bay, Namibia, during September 2016. The payload consisted of the Enhanced MODIS Airborne Simulator (eMAS), Airborne Multiangle SpectroPolarimetric Imager (AirMSPI), RSP, and HSRL-2 (Table B2) for various aspects of cloud composition, aerosol properties, and the overall cloud/aerosol morphology, as well as the Solar Spectral Flux Radiometer (SSFR) for radiative flux measurements. The aircraft operated as expected, and the average flight duration from Walvis Bay was $8.1 \mathrm{~h}$. Especially during the second half of the campaign, the ER-2 pilots were extremely accommodating, frequently extending individual flight duration to $9 \mathrm{~h}$.

\subsubsection{Choice of instrumentation}

In this section, we discuss the choice of instrumentation for each platform and deployment. Depending on ORACLES deployment year, the P-3 carried 8 to 11 instruments or instrument suites, with the following included for all deploy- ments: cloud suite (UND/OU); phase Doppler interferometer (PDI); Hawaii Group for Environmental Aerosol Research (HiGEAR) in situ measurement suite for aerosols; SSFR/CG-4 for radiative fluxes; Spectrometer for SkyScanning, Sun-Tracking Atmospheric Research (4STAR) for aerosol optical depth, cloud, and sky radiances; Airborne Third Generation Precipitation Radar (APR-3) for cloud and precipitation observations; Research Scanning Polarimeter (RSP); $\mathrm{CO}$ Measurements and Analysis (COMA) for CO, $\mathrm{CO}_{2}$, and $\mathrm{H}_{2} \mathrm{O}$ mixing ratios; $\mathrm{CCN}$ spectrometer for cloud condensation nuclei; and Water Isotope System for Precipitation and Entrainment Research (WISPER) for water isotope measurements. In certain years there were targeted additions/deletions, listed as follows.

- The HSRL-2 was added to the P-3 payload for deployments without the ER-2, i.e., 2017 and 2018.

- Advanced Microwave Precipitation Radiometer (AMPR) was included in the first deployment year only (2016), when the ER-2 also carried the HSRL-2 and RSP.

- The PTI (photothermal interferometer) was included in the 2016 and 2018 deployments only, as it suffered a failure before the 2017 deployment.

- The counterflow virtual impactor (CVI) was added for 2017 and 2018 as part of WISPER to enable cloud residual aerosol and droplet water isotope ratio measurements.

- An aerosol filter system (AFS) for trapping aerosol particles for post-flight analysis was added in 2017 and 2018.

- In 2017 and 2018, a duplicate cloud droplet probe (CDP) was mounted in a position more forward relative to the leading edge of the wing, in an attempt to determine whether proximity to the leading edge affected cloud particle measurements.

- In 2018, two customized versions of the sunshine pyranometer (Badosa et al., 2014) were added to the P-3, as was a nadir-viewing geo-referenced and radiometrically calibrated fish-eye camera.

As part of ORACLES, two new AERONET stations were established, i.e., the "Namibe" site in Namibe, Angola, and the "SEGC_Lope_Gabon" site near Libreville, Gabon. Many other sites in the region were revamped or established with separate funding and are shown in Fig. 1 (see https: //aeronet.gsfc.nasa.gov/cgi-bin/site_info_v3, last access: December 2019, for a list of sites).

Tables B1 to B3 in Appendix B provide full payload tables, including instrument names, instrument descriptions, primary measurements, and derived geophysical observables for each instrument. 


\subsubsection{Experiment strategy: dry-run exercise}

ORACLES conducted a 2-week "dry-run" activity from 1428 September 2015, prior to its first deployment in 2016. Project meteorologists, platform scientists, pilots, and the leadership team met by phone and Cisco Webex to examine daily weather forecasts, chemical weather predictions, and flight conditions. In response to these forecasts, detailed flight plans were developed for the upcoming 1 or 2 possible flight days, using a flight planning tool that was specifically designed for multi-aircraft flight operations (LeBlanc, 2018). Longer-range forecasts up to $5 \mathrm{~d}$ were used to plan for extended flight strategies relative to overarching flight objectives. Satellite data, primarily Meteosat-10 Spinning Enhanced Visible and Infrared Imager (SEVIRI) visible imagery and Cloud-Aerosol-Transport System (CATS) and CALIPSO vertical feature mask and attenuated backscatter profiles, were used to evaluate the likely success of a given flight plan for a given day. The process familiarized the science team with items that impacted real flight planning: aircraft limitations, staff fatigue limits (e.g., down days, crew rest), aviation authority coordination timelines, the availability and latency of meteorological forecasts, and the use of the flight planning tool. This practice time made ORACLES actual deployments more efficient, although the complexity and scope of actual chemical and meteorological forecasts in the field ended up being well beyond the scope of the dryrun exercise. This increased complexity was undoubtedly the result of lessons learned during the dry-run exercise itself.

\subsubsection{Experiment strategy: forecasting and flight planning}

The forecasting effort for ORACLES deployments in the field entailed both meteorological and chemical weather predictions. The meteorological forecasting effort for the ORACLES mission consisted of three components: (i) forecasting for flight planning, (ii) nowcasting during flights for realtime flight direction, and (iii) forecasting local weather for flight operations. Each of the three ORACLES deployments featured daily planning meetings. On non-flight days, the flight planning team met at 08:00 local time to discuss the weather and chemical weather forecasts for a period of up to $5 \mathrm{~d}$, with special emphasis on the upcoming 1 or 2 flight days. On flight days, the team would assemble at 05:00 local time to assess whether the latest forecasts warranted any changes to flight plans made the day prior. Also on flight days, the forecast team would provide in-flight nowcasting that often led to significant adjustments of flight plans, usually to respond to actual cloud conditions that materialized on a given flight day or in response to changing local conditions.

Clouds were the primary focus of the meteorological forecasting effort for both flight planning and nowcasting. Low clouds (i.e., stratocumulus at the inversion) were of primary scientific interest for their interaction with the African smoke plume. However, middle and high clouds were also important since the presence of these clouds complicated the radiation measurements of some instruments (e.g., 4STAR, SSFR). Verification studies prior to the ORACLES deployments showed that the European Centre for Medium Range Weather Forecasts (ECMWF; Pappenberger et al., 2008; ECMWF Newsletter, 2012; Ye et al., 2014) and United Kingdom Meteorological Office (UKMO; Ran et al., 2018) global forecast models provided the best performance for cloud forecasts. ECMWF digital data were available at $0.125^{\circ}$ longitude $\times$ latitude resolution and included the primary meteorological variables (relative humidity and horizontal winds at $925,850,800,700,600,500,400,300,150$, and $100 \mathrm{hPa}$ levels; $1000-500 \mathrm{hPa}$ layer thickness; surface wind speed; mean sea level pressure; boundary layer height; precipitation; convective available potential energy) as well as 3-D ice and liquid water mass. We also used the 2-D ECMWF products of cloud fraction and cloud base for the low, middle, and high clouds, which were found to be adequate for our forecasting requirements. The ECMWF cloud forecasts were supplemented by low, middle, and high cloud distribution forecasts from the UKMO global forecast model. In order to forecast the overall circulation over the southeast Atlantic, with an emphasis on wind and relative humidity distributions from the surface to $500 \mathrm{hPa}$, we used a suite of forecast products from ECMWF, UKMO, Global Forecasting System (GFS) from the National Centers for Environmental Prediction (Environmental Modeling Center, 2003), and the NASA Goddard Earth Observing System, Version 5 (GEOS-5) model (Molod et al., 2012).

Our primary nowcasting tool during the flights was the geostationary satellite imagery from the SEVIRI instrument aboard Meteosat-10 and Meteosat-11. Raw imagery from the infrared and visible channels was useful for establishing the evolution and distribution of clouds during flight. Satellite cloud properties described by Minnis et al. $(2008,2020)$ were calculated from SEVIRI raw radiances by NASA Langley, including cloud altitude, water path, and effective radius, and were also used in real-time flight direction. For forecasting local weather for flight operations, particularly during the October 2018 deployment in São Tomé, we primarily relied on satellite imagery over the past $12-24 \mathrm{~h}$ for a short-term (i.e., a day or less) outlook of heavy precipitation at the airport, as precipitation forecasts from the models were largely unreliable.

Chemical forecasts were done using both global and regional models, with the regional models providing a lot of the detail required for flight planning on a daily basis. We used three global systems: GEOS5 (https://gmao.gsfc.nasa.gov/ GEOS/, last access: May 2020), the Copernicus Atmosphere Monitoring Service (CAMS, https://atmosphere.copernicus. eu/, last access: May 2020), and a bespoke three-component aerosol (carbonaceous, mineral dust, and industrial pollution) modeling system developed by the UK Met Office for their CLARIFY deployment in 2017. Five-day aerosol fore- 
casts provided the expected spatial and vertical location of the main smoke coming from the African continent. These models were also useful in identifying times when the smoke was expected to be mixed with dust aerosols, especially during the 2016 deployment from Walvis Bay.

For regional model forecasts, two configurations of the Weather Research and Forecasting Model (WRF; Skamarock et al., 2008) were employed. One of them used WRF coupled to chemistry (WRF-Chem, Grell et al., 2005) using the physics package from the Community Atmosphere Model version 5 (CAM5, Ma et al., 2014), run by a team from the University of Iowa (WRF-CAM5, PI: Gregory Carmichael). This model provided daily $72 \mathrm{~h}$ aerosol forecasts for similar purposes as for the global models by using a full chemistry suite with hundreds of chemical species considered. WRF was also configured using an aerosol-aware microphysics (AAM) scheme (Saide et al., 2016) maintained by a team from NCAR/UCLA (PI: Pablo E. Saide). The Weather Research and Forecasting aerosol-aware microphysics (WRFAAM) model provided forecasts for lead times of up to $4 \mathrm{~d}$ at $12 \mathrm{~km}$ resolution. The system included a near-real-time emission constraint using satellite-based aerosol optical depth (Saide et al., 2016), which to our knowledge corresponds to the first near-real-time system to perform such tasks. Two simulations were performed per forecasting cycle turning smoke emissions on and off in the model. Since WRF-AAM resolves aerosol-cloud-radiation interactions, these simulations allowed assessment of the effects of smoke on weather in forecasting mode by taking the difference between the two forecasts. The forecasts also included tracers tagged to each day of smoke emissions from the African continent, which were used to provide a distribution of smoke age based on the tracer concentrations and the days since emissions. Statistics such as mean and mode were extracted from the age distribution and used for flight planning to target plumes with different ages to explore the temporal evolution of aerosol properties.

Another task performed during the planning meetings was near-real-time evaluation of the forecasts. These were focused on assessing forecast performance in predicting clouds and the aerosol plume location, and relied mostly on the latest SEVIRI cloud retrievals, and clear-sky and above-cloud AOD from MODIS. This exercise allowed the team to track forecast failures and successes and provided a sense of reliability when making decisions based on forecasts.

\subsubsection{Routine flights vs. target-of-opportunity flights}

The ORACLES investigation concept featured a combination of routine flights to facilitate comparisons with climate models and to ensure sampling of a wide range of aerosol loadings and cloud conditions, with other flights addressing "targets of opportunity". The "routine" flights all took place along a fixed latitude-longitude line with sampling at a range of altitudes and remote sensing of the full column. In 2016, the routine flight track was along a diagonal with endpoints of $20^{\circ} \mathrm{S} / 10^{\circ} \mathrm{E}$ and $10^{\circ} \mathrm{S} / 0^{\circ} \mathrm{E}$; in 2017 and 2018 the routine flight track extended from the Equator to $\sim 15^{\circ} \mathrm{S}$ along $5^{\circ} \mathrm{E}$. See Fig. 11 in Sect. 4.4 for a complete set of flight tracks.

In situ observations of aerosol microphysical and optical properties during the routine flights were envisioned to map the evolution of BB aerosol radiative properties during transport. HSRL-2 (High Spectral Resolution Lidar) observations from the P-3 or ER-2 helped map the spatial extent of the layers, while SSFR (Solar Spectral Flux Radiometer) and 4STAR (Spectrometer for Sky-Scanning, Sun-Tracking Atmospheric Research) observations provided additional insights into the in situ-derived aerosol properties via optical and radiative closure experiments. Measurements to address seasonal variations in direct aerosol radiative effects and their controlling factors were derived from the routine flights. The routine flight requirements were derived based on the assumption that the statistics of important observed aerosol and cloud properties, given sampling and measurement uncertainties, are sufficiently constrained to distinguish between climate model estimates. For this, we assumed that the variability in aerosol properties at model-relevant scales $\left(100 \mathrm{~km}^{2}\right)$ can be extrapolated from the analysis of Shinozuka and Redemann (2011) to be less than $20 \%$ and that such variability is well below the inter-model differences on such scales.

Another motivation for the routine flights was to ensure sampling of a wide range of aerosol loadings and cloud conditions. The five to six envisioned routine flights (equaling $\sim 40-50$ flight hours per deployment) that comprise the ORACLES threshold science objectives were intended to yield aerosol and cloud data in about $200100 \mathrm{~km}^{2}$ climate model grid boxes. Prior to the start of the campaign, we investigated probability density functions (PDFs) of MODIS daily $1 \times 1^{\circ}$ averaged AOD between $10-20^{\circ} \mathrm{S}$ and $5^{\circ} \mathrm{W}-5^{\circ} \mathrm{E}$ for September 2001 derived from the then-available dark target algorithm. We randomly subsampled the roughly $30001 \times 1^{\circ}$ MODIS AOD boxes with the planned 200 airborne observations and found that the resulting PDFs were a good representation of the parent population of MODIS AOD. We concluded that the number of threshold science flight hours was adequate to compile probability density functions of aerosol properties that allow assessments of climate model differences at these spatial scales. This was confirmed by analysis after the first deployment (Shinozuka et al., 2020).

About half of the flight hours in each campaign focused on targets of opportunity, as detailed in Tables A1-A3 in Appendix A. These flights targeted specific science goals (e.g., capturing a range of aerosol ages, or contrasting conditions in terms of aerosol-cloud interactions). Flight patterns (e.g., "radiation walls", square spirals) were optimized to leverage the measurement capabilities of the range of instruments on board the P-3 and to allow for later comparison of different methods of measuring a common parameter (e.g., aerosol SSA). During the 2017 and 2018 deployments, the target-of- 
opportunity flights were planned to be near the routine flight track whenever possible to improve sampling statistics.

\subsubsection{Considerations for 2016 deployment with ER-2 and P-3}

The planning for the 2016 field deployment in Namibia started in early 2015, with multiple site visits to the Walvis Bay airport, logistics and hotel providers, Namibian science partners, and representatives of various Namibian government organizations. This planning started early because the unexpected change to deploy both ORACLES aircraft in 2016 brought along a significant set of challenges due to the large contingency of scientific and aircraft support equipment needed, with this being the first of the three ORACLES deployments. The ORACLES team gratefully acknowledges the help provided by the Honorable Thomas F. Daughton, US Ambassador to Namibia from 2014 to 2017, and the support by the US embassy staff led by John Kowalski. The US embassy proved instrumental in receiving flight permissions and in arranging the student program in August 2016. The ORACLES team also received invaluable feedback and support from the Namibia University of Science and Technology (NUST), led by its rector, Tjama Tjivikua, and Dean Lameck Mwewa. In addition to NUST, the Gobabeb Training and Research Center led by Gillian Maggs-Kolling, the University of Namibia represented by Martin Hipondoka and Michael Backes as well as North-West University (South Africa) represented by Stuart Piketh provided information and logistics support throughout the 2016 campaign. As we describe in Sect. 3.5 below, these contacts were the springboard for the outreach efforts that led to the deployment of seven graduate students in the 2016 field campaign, including five students from NUST and the University of Namibia. In their totality, we hope that the efforts expended by the Namibian government and the Namibian and South African science community, as well as the reciprocating efforts by the ORACLES science team, can be considered a transformational effort in the context of science diplomacy (Annegarn and Swap, 2012), at least in so far as the experience for the individual students that participated in the outreach efforts are concerned.

\subsection{Linkage with international deployment efforts (LASIC, CLARIFY, AEROCLO-SA)}

ORACLES was not the only recent experimental investigation in the southeast Atlantic (see Fig. 1). The UK CLARIFY project, which deployed their BAe-146 plane from Ascension Island in August-September 2017 (Haywood et al., 2020), and the French AEROCLO-sA project, which deployed a Falcon-20 plane from Walvis Bay, Namibia, in August 2017 (Formenti et al., 2019), shared similar science objectives with ORACLES, as did the DOE Atmospheric Radiation Measurement mobile facility deployment to Ascension
Island from June 2016 through October 2017 for the LASIC project (Zuidema et al., 2015). All four campaigns were active in August-September 2017, and a "suitcase" flight to Ascension Island by the NASA P-3 plane included a direct instrument intercomparison flight with the CLARIFY BAe146 on 18 August 2017. Collaboration between all four campaigns continued through a joint data workshop held in Paris in April 2019, prior to a joint session at the annual meeting of the European Geophysical Union. The excitement generated from sharing insights and points of view, some similar and some not, from the individual campaigns led to a decision to hold another joint workshop in May 2020, planned for the United States but held virtually due to the COVID19 pandemic. In one example, a different view of the relationship of the single-scattering albedo to aerosol aging was noted, with ORACLES scientists focusing more on the vertical structure (Fig. 12) and CLARIFY scientists interested in investigating the change in SSA with distance from the continent. The latter is an excellent example of the synergism afforded between the two campaigns, with ORACLES sampling air closer to the continent and the CLARIFY campaign sampling $\sim 1700 \mathrm{~km}$ offshore.

\subsection{Outreach efforts}

\subsubsection{Namibia - 2016}

During the field campaign held in Namibia in 2016, the gathering of science data not only benefited the scientists directly involved in the project; through an outreach program the science was extended to the Namibian population (and to some extent the broader southern African region). The outreach effort was multi-tiered and aimed to inform the public, develop young scientists, and encourage children to enter into STEM fields of study. Outreach activities included public lectures, interviews with local radio and newspapers, and open days at the airfield. In addition, ORACLES scientists traveled to northern Namibia for several days to participate in the Ongwediva Annual Trade Fair (OATF) together with students, staff, and faculty from the University of Namibia (UNAM), the Namibia University of Science and Technology (NUST), and the Gobabeb Research and Training Center. The OATF showcased collaborative environmental research from participating research institutes and was attended by Ongwedivaarea students, business leaders, and local dignitaries.

In addition to these broader public engagement outreach activities, a targeted science development program was initiated with support from the US Embassy in Namibia and NUST. This 3-week full immersion outreach program was developed to provide promising local and regional young scientists with an opportunity to experience different components of a large complex airborne research field campaign. In total, seven post-graduate students (master's and $\mathrm{PhD}$ level), from Namibia (five students) and South Africa (two students), participated in the student guest program (Fig. 4). 
Student guests were exposed to the planning, modeling, and instrumentation used within the ORACLES field campaign. In addition to these broad field campaign skills, they received a solid foundation in basic atmospheric science through tutorials from the participating campaign scientists, some introductory programming tutorials, and an opportunity to interact with scientists aligned with their field of research. Within the duration of the program they also all had an opportunity to join a science flight. Further regional expansion of this student guest program was planned for the 2017 and 2018 field campaigns in collaboration with the CLARIFY and AEROCLO-sA campaigns, but with the move of the ORACLES field campaigns to São Tomé this expansion outreach effort could not be implemented.

\subsubsection{São Tomé and Príncipe (STP) - 2017 and 2018}

To understand the challenges of implementing an outreach program as part of a scientific project like ORACLES in São Tomé and Príncipe (STP), one needs to know a little about the history of this young country of just over 200000 inhabitants. Previously uninhabited, the STP Archipelago was colonized by Portugal throughout the 16th century, when it served as a warehouse for the slave trade and established itself as a producer of sugarcane, coffee, and cocoa. STP independence from Portugal came in 1975, keeping Portuguese as its official language, although minority groups also speak at least four other dialects.

During an initial exploratory visit in 2015, built on a previous NSF-sponsored site visit, the ORACLES team contacted the Instituto Nacional de Meteorologia (INM) to establish collaborations. The INM operates at STP airport facilities and showed great initial enthusiasm for ORACLES deployments from STP. During the 2 years of ORACLES operations in 2017 and 2018, INM kindly issued daily weather reports tailored to ORACLES needs. There were several visits from the ORACLES team to INM, and Aristómenes Amadeu do Nascimento of INM attended various ORACLES weather briefings.

The only public university in STP and the most important one, the University of STP (USTP), was established only in 2014. The creation of USTP came to address fundamental and emergency problems of the country, which included training of personnel for the health and education sectors, agriculture, and food production. When the ORACLES team deployed to STP in 2017, USTP had, in its current format, only 2 years of existence, still consolidating its vocations and priorities. Nevertheless, the institution represented by Aires Bruzaca (dean), João Pontífice (vice dean), and Manuel do Sacramento Ramos Penhor was enthusiastic about establishing scientific collaborations with NASA.

The ORACLES team organized a series of seminars about ORACLES scientific objectives for the USTP and INM communities. The seminar themes also included the AERONET (Aerosol Robotic Network) and Pandora NASA projects, global networks of spectrometers designed to retrieve, respectively, aerosol optical depth and microphysical parameters (Holben et al., 1998; Dubovik and King, 2000), and total columns of ozone and other trace gases in the atmosphere from direct-Sun measurements (Herman et al., 2009, 2015; Tzortziou et al., 2012). All lectures were presented by ORACLES science team members in Portuguese to address potential language barriers.

A Pandora Spectrometer Instrument (PSI) and an AERONET instrument were brought to STP as part of the ORACLES deployment. The main goal, especially for the PSI deployment, was to assess whether mutual goodwill, interest, and capabilities exist for NASA, USTP, and INM to collaborate scientifically long term. The team was successful in training professors of the USTP to operate the PSI and the AERONET instruments (Fig. 5), and this resulted in additional aerosol measurements beyond the campaign periods. Moreover, it laid the foundation to have STP as one of the sites of the Pandora network, with an official agreement between NASA and the USTP signed in 2018.

The ORACLES team found in STP a community open to and eager for the establishment of a fruitful scientific cooperation. Our experience points out that involvement with the local community is of extreme importance, not only for the dissemination of scientific knowledge but also to facilitate engagement between the young scientists from both communities. Collaboration with local scientific communities during field deployments such as ORACLES has the dual benefits of enhancing local scientific capabilities in under-resourced areas of the world and producing tangible benefits for this and future missions in the region.

\section{Description of deployments}

\subsection{Meteorological context}

The key feature of the circulation that transports fire emissions from the African continent over the southeast Atlantic is the easterly flow above about $2 \mathrm{~km}$. Figure 6 shows the $4 \mathrm{~km}$ flow and relative humidity (RH) from the ERAInterim reanalysis, along with the southerly limit of significant rainfall from the monthly $0.25^{\circ}$ satellite-based 3B 43 dataset (Huffman et al., 2007) for the 19-year September mean (2000-2018). The easterly flow maximizes around $8^{\circ} \mathrm{S}$, reaching minima near $4^{\circ} \mathrm{N}$ and $18^{\circ} \mathrm{S}$. This flow is maintained by the thermally direct circulation over the continent, which is driven by heating of the elevated African plateau south of $10^{\circ} \mathrm{S}$ (Adebiyi and Zuidema, 2016). The moister regions to the north are cooler, consistent with the thermal wind relation and the easterly shear below the jet. The jet is similar in character to the northern African Easterly Jet (NAEJ; consistent with the temperature gradient between the hot Sahara desert and the cooler equatorial region), if not as pronounced. Since there is no heating source over 


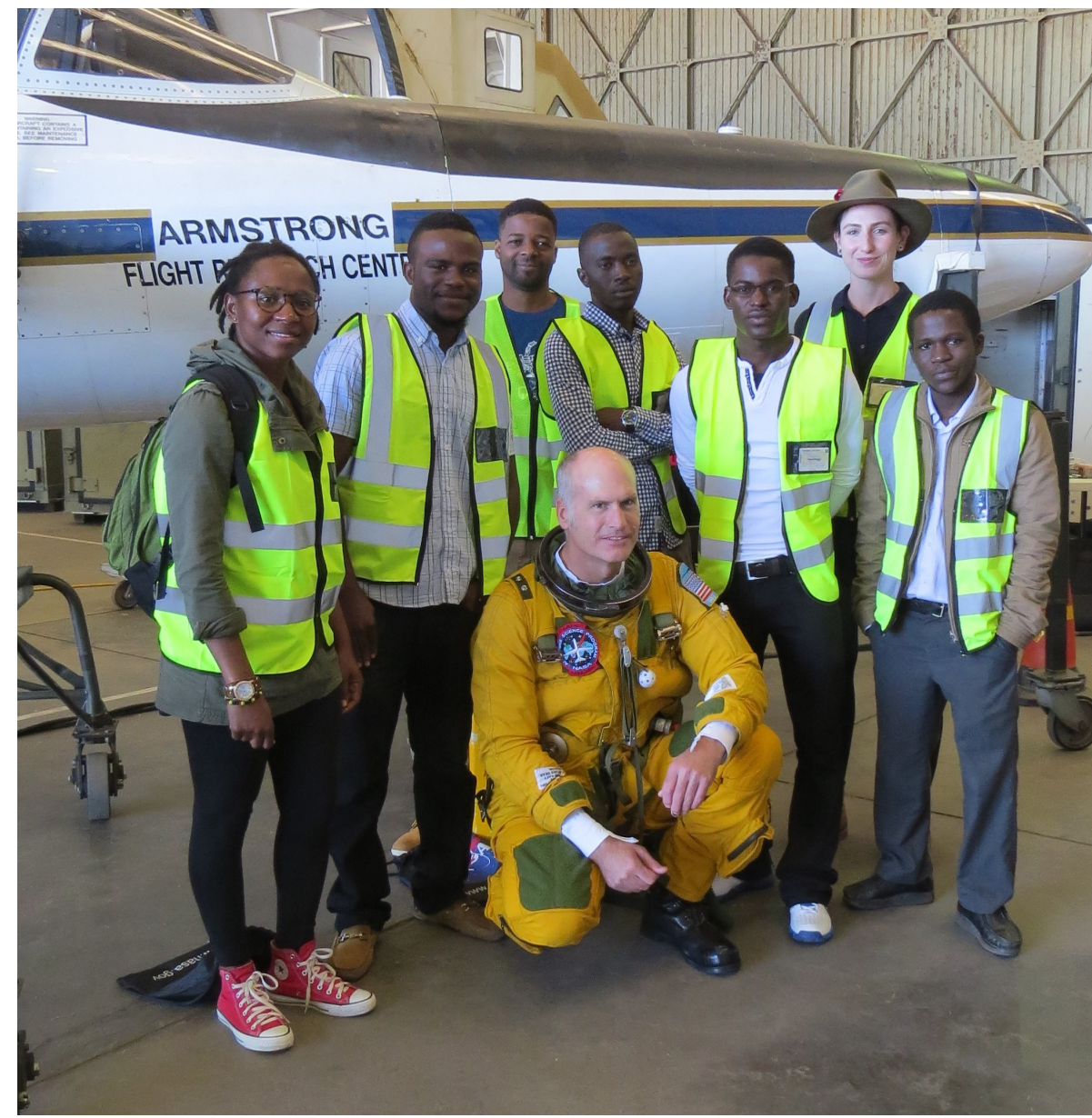

Figure 4. The ORACLES guest students, together with ER-2 pilot, James Gregory Nelson, at the Walvis Bay airport.

the southeast Atlantic, the jet decreases in intensity as soon as the winds leave the continent. The mean $4 \mathrm{~km}$ flow then curls anticyclonically near $10-20^{\circ} \mathrm{W}$ and merges with the midlatitude jet, most pronounced in September-October. Smoke associated with this flow has been observed as far away as the South Pacific (Chatfield et al., 2002).

The $\mathrm{RH}$ at $4 \mathrm{~km}$ altitude provides a useful qualitative indicator of the effects of upward vertical motion (Fig. 6). North of about $3^{\circ} \mathrm{S}$, rainfall is substantial (averaging $0.25 \mathrm{~mm} \mathrm{~h}^{-1}$ ), and the enhanced $\mathrm{RH}$ is almost certainly due to moist convection. The $4 \mathrm{~km} \mathrm{RH}$ decreases south of $3^{\circ} \mathrm{S}$, with a secondary maximum near $10-11^{\circ} \mathrm{S}$. This feature is present in other analyses as well (e.g., Modern Era-Retrospective Analysis for Research and Applications, MERRA-2, not shown) and occurs at the boundary between the Congo River basin (about $300 \mathrm{~m}$ ) and the elevated African plateau (up to $1500 \mathrm{~m}$ ). Though moist convection is present in this region, most of the vertical mixing is probably due to dry convection. The effects of this dry convection on the temperature and RH profile have been seen in the occasional radiosondes over south central Africa and downstream over St. Helena Island.
Figure $7 \mathrm{a}$ and $\mathrm{b}$ show latitudinal and longitudinal cross sections along the lines indicated in cyan in Fig. 6, also for the 19 -year September mean. Figure 7a clearly shows the southern African Easterly Jet (SAEJ) near $4 \mathrm{~km}$ and $8^{\circ} \mathrm{S}$, just offshore at $9.75^{\circ} \mathrm{E}$. The enhanced $\mathrm{RH}$ extends up to about 5$6 \mathrm{~km}$ between 10 and $20^{\circ} \mathrm{S}$, at times moist enough to support mid-level clouds (Adebiyi et al., 2020). Notably, even though the flow is easterly (though weaker) above $6 \mathrm{~km}$, the air is dry, indicating that convection is not reaching those levels on a consistent basis. Farther north, moist convection is maintaining RH exceeding $80 \%$ up to $7 \mathrm{~km}$ (and higher, not shown). Another notable feature is the dry tongue extending to $10-15^{\circ} \mathrm{S}$ at $1-2 \mathrm{~km}$, just above the moist boundary layer. At low levels, there is a strong southerly jet associated with the St. Helena high-pressure system. Potential temperature surfaces slope downward and northward to about $15^{\circ} \mathrm{S}$, implying subsidence and drying of the northward flow (Fig. 6a).

The longitudinal cross section at $9.75^{\circ} \mathrm{S}$, the approximate meridional center of the SAEJ, indicates that the SAEJ is strongest at the coastline. The top of the moist layer is roughly consistent with the top of the daytime boundary layer 


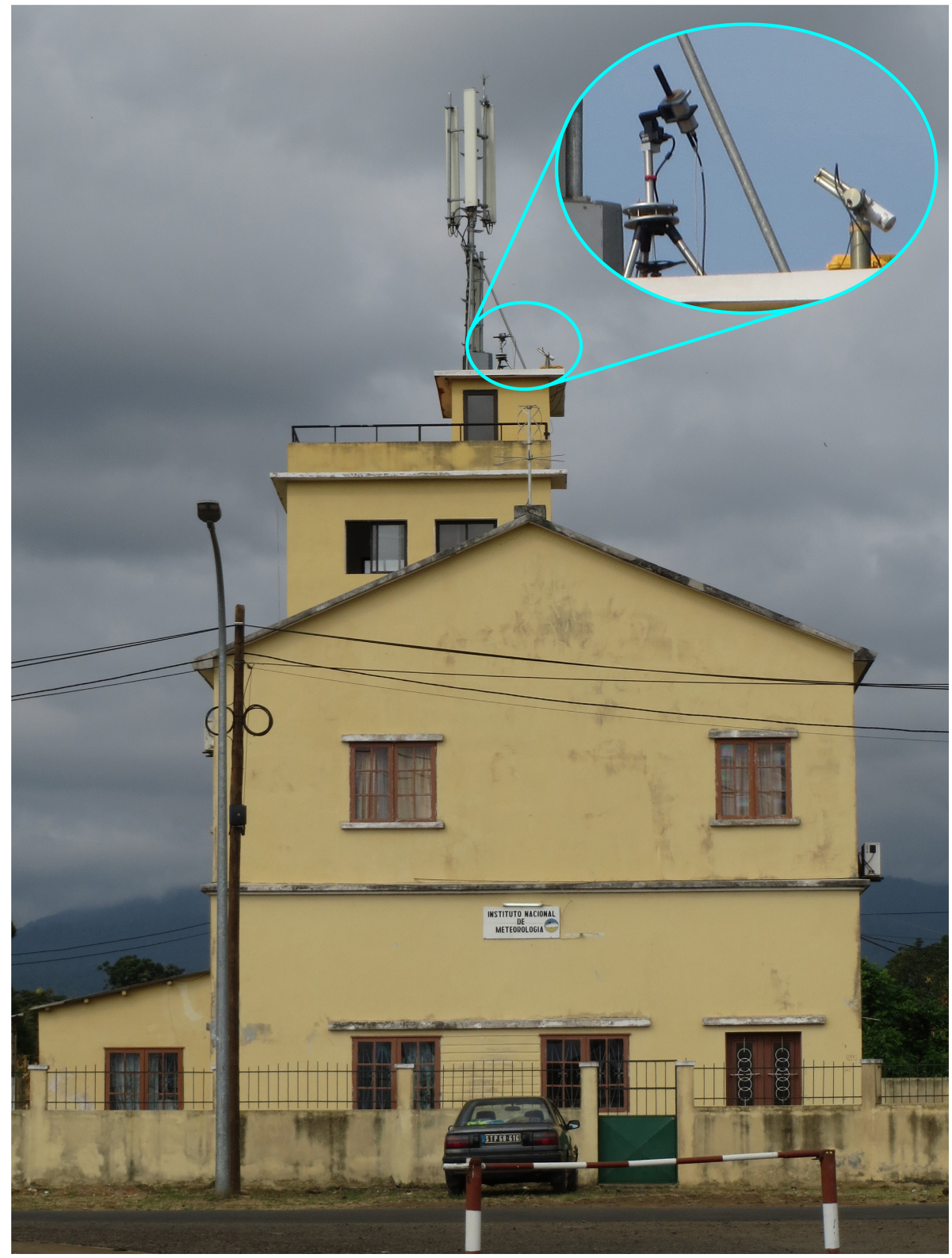

Figure 5. A picture of the STP Instituto Nacional de Meteorologia (INM), with an inset of the Pandora and AERONET instruments temporarily installed on the rooftop. Photo credit: James Podolske.

over the continent near $16^{\circ} \mathrm{E}$ (Fig. 6b). The RH decreases in the mean as the air flows westward, consistent with the overall subsidence over the SE Atlantic. This subsidence is consistent with modest radiative cooling in this region.

An analysis of the SAEJ (averaged over a volume the white rectangle in Fig. 6 and the upper left panels in Fig. 7a and b) shown in Fig. 7c reveals that some months during deployment years deviated substantially from the average (such as October 2016). The actual deployment months varied - the SAEJ strength in September 2016 is $\sim 0.7 \mathrm{~m} \mathrm{~s}^{-1}$ weaker than the climatological mean, the SAEJ strength in August 2017 is weaker than the climatological mean, and the SAEJ strength in October 2018 is very similar to the climatological jet intensity. The individual August-October months of the three ORACLES deployment years are compared to the climatological means of RH and winds at $4 \mathrm{~km}$ altitude (represented as the SAEJ) in Fig. 8.

Clearly apparent is the southward progression of the regions of significant rainfall as the seasons change and the strengthening of the SAEJ. Note that the basic westward circulation at $4 \mathrm{~km}$ is present for all 3 months but is only about half as strong in August as in the other 2 months. The other rows represent the three ORACLES years (2016-2018), with the relevant deployment months outlined in magenta. A num- 


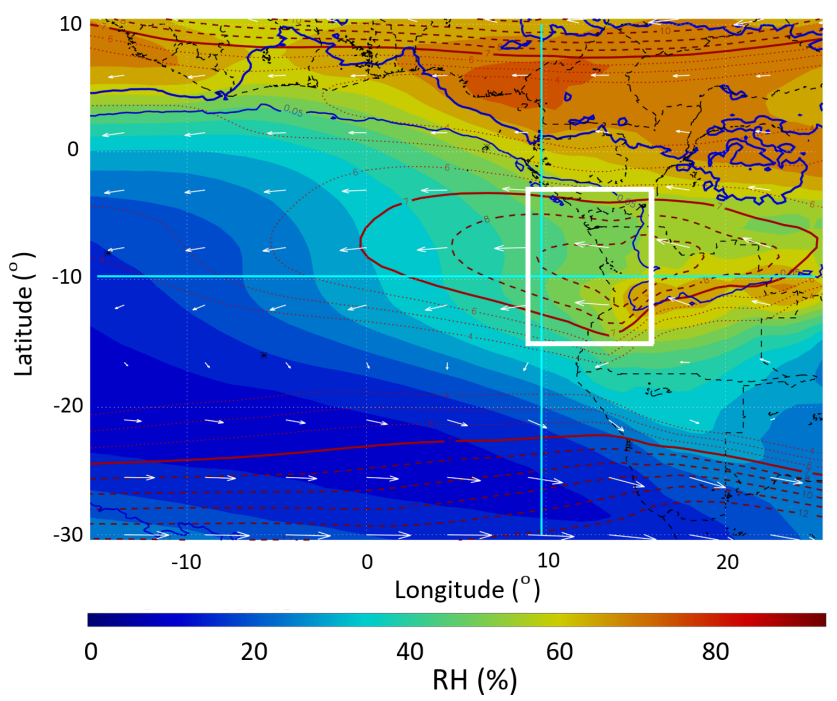

Figure 6. September-mean relative humidity ( $\mathrm{RH}-$ color fill) and horizontal winds at $4 \mathrm{~km}$ (averaged over $600-650 \mathrm{hPa}$ - red contours and white arrows), and the southerly limit of significant rainfall averaged over 19 years (2000-2018 - blue contour). Heavy solid and dashed red contours indicate elevated wind speeds $\left(7 \mathrm{~m} \mathrm{~s}^{-1}-\right.$ solid; 8 and $9 \mathrm{~m} \mathrm{~s}^{-1}$ - dashed). The white rectangle encompasses $8-16^{\circ} \mathrm{E}$ and $14-3^{\circ} \mathrm{S}$. The cyan lines refer to $9.75^{\circ} \mathrm{S}$ and $9.75^{\circ} \mathrm{E}$, respectively (see Fig. 7). RH and winds are from the ERA-Interim analyses, and the rainfall is from the monthly $0.25^{\circ}$ satellite-based $3 \mathrm{~B} 43$ dataset.

ber of features are apparent. Rainfall in September 2016 was greater in the SAEJ region than typical, and RH values were higher. The strength of the SAEJ in 2016 was about average. The August SAEJ strength was about average during the 2017 deployment year, though RH values were lower than climatology. The October 2018 SAEJ strength was also about average, rainfall was about typical, and $\mathrm{RH}$ values were lower than the climatology.

Similar to the SAEJ feature, the southeasterly low-level jet and boundary layer flow intensity during deployment years are within the range of climatological mean, even though some months deviated substantially from the average. The most important feature of the boundary layer height (BLH) over the area that ORACLES sampled is an overall decrease in BLH from August to October (not shown), consistent with climatological monthly-mean radiosonde profiles at St. Helena Island (Adebiyi et al., 2015).

\subsection{Aerosol and cloud context}

As pointed out above, the interannual variability in fire emissions in southern Africa was expected to be low (van der Werf et al., 2010), and as a result, aerosol loading in the ORACLES region was expected to be repeatable, with analyses of MODIS clear-sky AOD retrievals in the project planning stage implying year-to-year variability through the burning season of only $20 \%$ of the mean. Since the beginning of the
ORACLES project, a number of MODIS- and SEVIRI-based retrieval algorithms for above-cloud aerosol optical depth (ACAOD) have been developed (Meyer et al., 2015; Jethva et al., 2016, 2018; Peers et al., 2019; Sayer et al., 2019), allowing a study of the interannual variability of the aerosol loading above clouds, which is more relevant for ORACLES science objectives than clear-sky AOD. In this section, we describe the interannual variability of MODIS-detected fire counts, ACAOD, and Sc cloud fractions in August, September, and October for the three ORACLES flights years, i.e., 2016-2018. We compare them to the climatologies of the same quantities for the period of 2003 to 2018 for context (Fig. 9). MODIS data are a composite of Terra and Aqua, where available.

Within each panel, Fig. 9 shows monthly averages of fire counts as blue-to-red shading over land, ACAOD as yellowto-red shading over ocean (Meyer et al., 2015), and low cloud fractions as black contours over ocean, for August, September, and October. The top row of panels shows the 2003 to 2018 climatological means, while the second, third, and fourth row of plots provide the August, September, and October means for the 3 deployment years, i.e., 2016 to 2018 .

Overall, Fig. 9 corroborates the initial assumption that the interannual variability in fire locations and fire counts is relatively small. While there are differences from month to month, both in a given year and in the climatology, the fire counts in the three deployment years are very similar to the climatologies, with minor differences discussed below. We attribute this to the interannual consistency in agricultural practices in the various burning regions. The extent of the Sc cloud deck exhibits some interannual variability. The August Sc cloud distributions in 2016 to 2018 appear quite similar to the August climatologies, while some of the September and October distributions appear to extend slightly farther south or west. The largest interannual differences of any of the quantities shown in Fig. 9 are in the ACAOD. The August 2016 and 2018 plumes appear stronger than the climatological plume, while the August 2017 plume appears weaker than the climatology; the September 2016 and 2018 plumes appear slightly weaker than the climatologies, while the September 2017 plume appears slightly stronger than the climatological plume; the October plumes in 2016 to 2018 are somewhat reproducible year to year, but they all appear slightly stronger than the October climatology. Overall, this supports the conclusion of an earlier and possibly prolonged presence of the BB plume over the SE Atlantic in recent years, relative to the 2003 to 2018 climatology.

As far as the specific ORACLES deployment months are concerned (black outlined panels in Fig. 9), September 2016 shows a slightly weaker ACAOD plume than the climatology. We attribute this mainly to slightly weaker free troposphere (FT) winds in the SAEJ and slightly lower RH at plume level (see RH contours, and $7 \mathrm{~m} \mathrm{~s}^{-1}$ contours not extending as far westward in Fig. 8). August 2017 also has a slightly weaker ACAOD plume than the climatology; since fires are as strong 
(a)

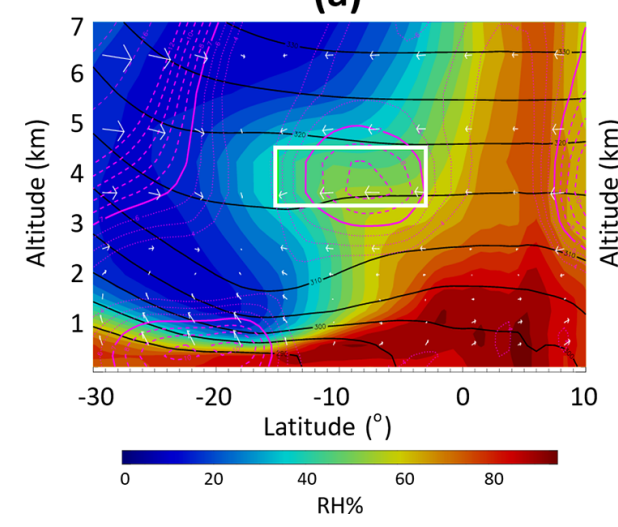

(b)

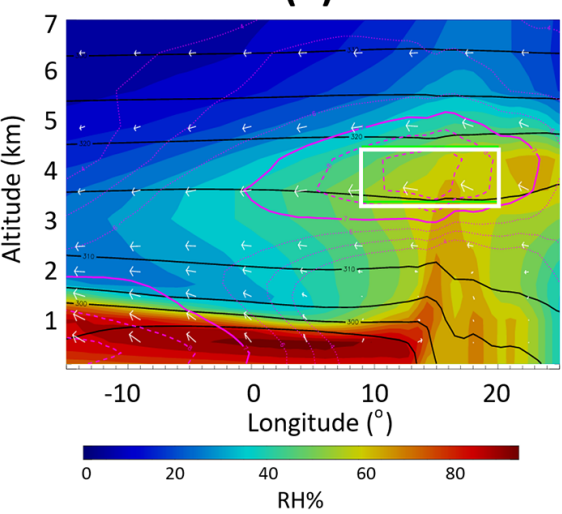

(c)

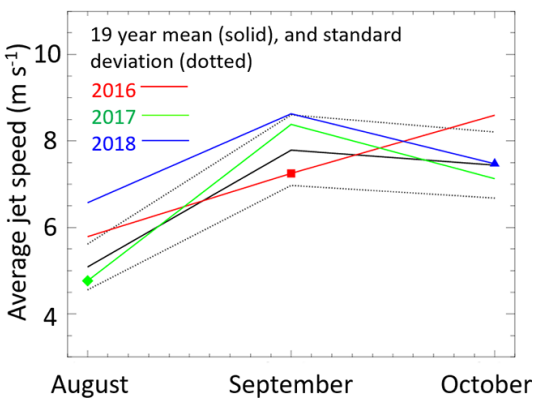

Figure 7. September-mean (a) meridional and (b) zonal cross sections of RH (shading), potential temperature (black contours), and horizontal winds (white barbs), with wind speeds exceeding $7 \mathrm{~ms}^{-1}$ outlined in magenta contours $\left(7 \mathrm{~m} \mathrm{~s}^{-1}-\right.$ solid; 8 and $\left.9 \mathrm{~ms}^{-1}-\mathrm{dashed}\right)$, at (a) $9.75^{\circ} \mathrm{E}$ and (b) $9.75^{\circ} \mathrm{S}$, respectively, averaged over 19 years (2000-2018). (c) Strength of the SAEJ averaged over the volume defined by the white rectangles in panels (a) and (b). The solid lines represent the individual and 19-year (2000-2018) means; the dashed lines represent the standard deviation during the 19-year period.

or even stronger than the climatology, we again attribute this to a slightly weaker SAEJ than the climatological mean. October 2018 has a slightly stronger plume than the climatology: the SAEJ winds are very similar to the climatology, but fires in southern Angola appear to be slightly stronger and a more expansive area of elevated $\mathrm{RH}$ is present by comparison to the climatology, likely giving rise to the more expansive $\mathrm{BB}$ plume in this month.

\subsection{Cloud droplet number concentrations and boundary layer winds}

As ORACLES science objectives encompassed direct, semidirect, and indirect effects, we were keenly aware of the interannual variability of marine boundary layer pollution levels, as well as boundary layer wind strengths and directions. In analogy to Sect. 4.2, this section summarizes our current assessment of the interannual variability of boundary layer winds and of cloud droplet number concentrations, $N_{\mathrm{c}}$, the latter as a proxy for BL pollution.

Cloud droplet number concentrations are derived following Painemal and Zuidema (2011) as

$N_{\mathrm{c}}=1.4067 \times 10^{-6}\left[\mathrm{~cm}^{-1 / 2}\right] \times \frac{(\mathrm{COD})^{1 / 2}}{(\mathrm{CER})^{5 / 2}}$,

where COD is the cloud optical depth and CER is the cloud droplet effective radius near cloud top. Equation (1) assumes an adiabatic liquid water content profile and a vertically uniform $N_{\mathrm{c}}$ (Szczodrak et al., 2001). $N_{\mathrm{c}}$ is computed from COD and CER products that have accounted for the above-cloud AOD (Meyer et al., 2015). These products are used instead of those from the MODIS standard product (i.e., MXD06) where CODs are typically underestimated in the retrievals due to the top of atmosphere (TOA) shortwave reflectance absorption by overlying smoke aerosols (Haywood et al., 2004; Coddington et al., 2010; Meyer et al., 2013).

Within each panel, Fig. 10 shows monthly averages of $N_{\mathrm{c}}$ calculated from MODIS Aqua and Terra cloud optical depth (COD) and effective radius (CER) retrievals as yellow-to-red shaded contours, along with $925 \mathrm{mb}$ wind data from the $\mathrm{Na}$ tional Centers for Environmental Prediction (NCEP) reanalysis. As in Fig. 9, the top row of plots shows the climatological mean from 2003 to 2018 for August, September, and October, while the second, third, and fourth row show the monthly means for the same months in 2016, 2017, and 2018, respectively. Overall, there are striking deviations in the $N_{\mathrm{c}}$ averages in every year relative to the climatological mean. August 2016 and August 2017 show significantly larger $N_{\mathrm{c}}$, while August 2018 shows a lower $N_{\mathrm{c}}$ relative to climatology. By contrast, the September $N_{\mathrm{c}}$ values in 2016 to 2018 resemble the climatological mean quite closely. October 2016 and October 2017 are again quite similar to the October climatology while the October $2018 N_{\mathrm{c}}$ values are significantly elevated relative to climatology. MBL winds in most months were similar to the climatological means, with the notable exception of the 2018 October ORACLES deployment, when the MBL winds were somewhat weaker than the climatological means.

To summarize our findings regarding the general plume and MBL pollution levels during the ORACLES deployment months (September 2016, August 2017, and October 2018), we note that the September 2016 FT plume and boundary layer $N_{\mathrm{c}}$ values were quite similar to the climatologies of these quantities. August 2017 featured a FT BB plume with notably lower ACAOD but an MBL with significantly elevated $N_{\mathrm{c}}$ relative to the climatologies. October 2018 featured a markedly more expansive FT ACAOD plume and a simultaneously more polluted MBL with significantly elevated 

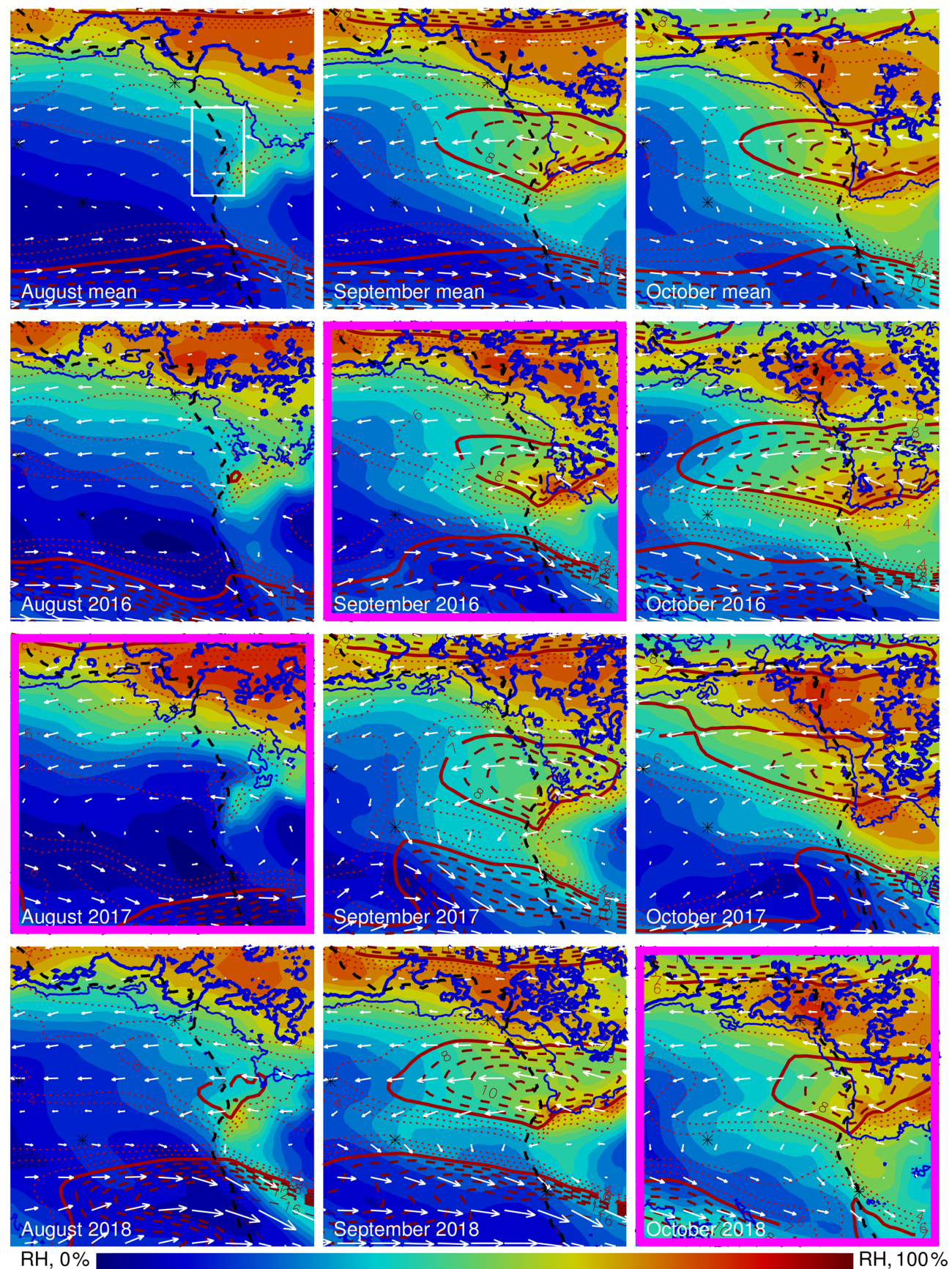

Figure 8. The same as Fig. 6 except for the 19-year mean (2000-2018) and 3 years of the ORACLES deployment (2016, 2017, and 2018). The boxes with magenta frames indicate the ORACLES deployment months. The white rectangle represents the area over $8-16^{\circ} \mathrm{E}$ and $14-3^{\circ} \mathrm{S}$.

$N_{\mathrm{c}}$. Detailed explanations for these interannual variations are currently the subject of at least one ORACLES-related investigation. Taking all 3 years together, mean ACAOD values were slightly lower than their climatological mean values for August-October and $N_{\mathrm{c}}$ values slightly higher than climatology. These deviations are substantially smaller than the day-to-day variability sampled in the three campaigns, and we therefore consider the ORACLES measurements to have captured representative conditions overall. Detailed assessment of the representativeness of the actual aircraft observations, which only sampled a fraction of the days within each of the three measurement months, has been undertaken in the model-observation intercomparison studies (Shinozuka et al., 2020). This assessment indicates that the airborne sampling provides averages sufficiently representative of the monthly means to be able to characterize and test model 

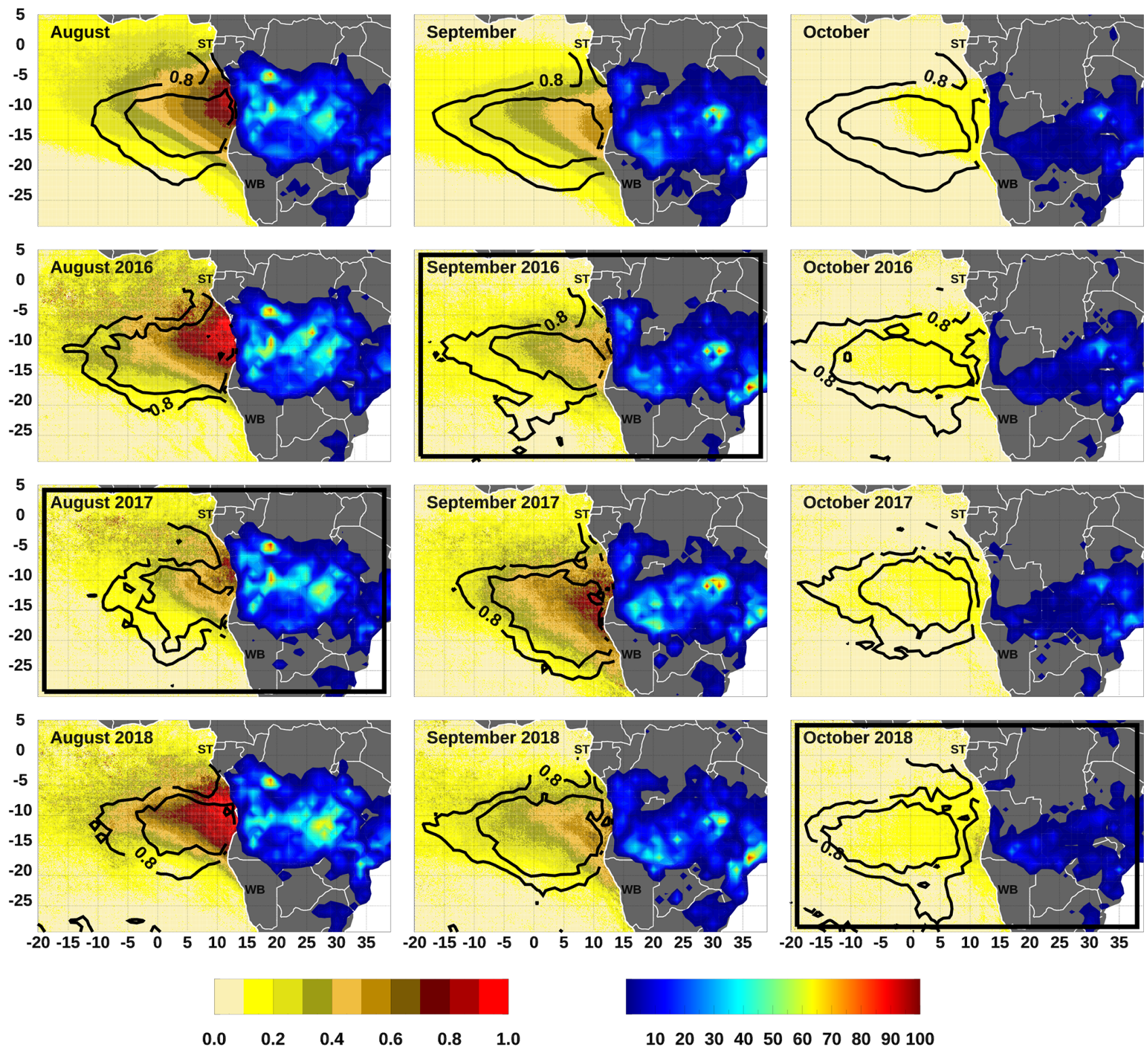

Above-cloud aerosol optical thickness

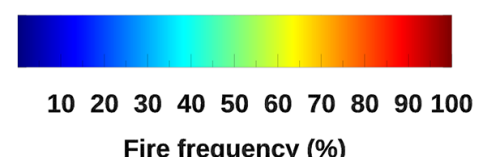

Figure 9. Combined Terra-Aqua data for August, September, and October, aggregated at $0.1^{\circ}$. Yellow to red shading over water indicates above-cloud AOD, black open contours indicate low-level (cloud top below $2.5 \mathrm{~km}$ ) cloud fraction of 0.8 and 0.9 , and color shading over land indicates MODIS fire frequency for fires with detection confidence above 70\%. Top row: climatologies computed over 2003-2018 (coinciding with the Aqua record). Second through fourth row: monthly averages for August through October 2016, 2017, and 2018, respectively. ST and WB stand for São Tomé and Walvis Bay. Bold black frames indicate ORACLES deployment months.

skill at representing geographical gradients in climatological mean plume structure. The wide range of varying aerosolcloud vertical structures sampled are sufficient for addressing all of the originally postulated objectives.

\subsection{Description of flights and links to data}

In total, the P-3 aircraft flew 350.6 flight hours in 44 flights for science operations between September 2016 and Octo- ber 2018, while the ER-2 flew 97.3 flight hours in 12 science flights in 2016. Both tallies include transit flights with science data collections into and out of the deployment sites, because on many occasions valuable science data were collected during these flights. The P-3 flight hours and flight counts exclude an attempt at a transit flight from Ascension Island in 2017, which had to be aborted due to an aircraft malfunction. 

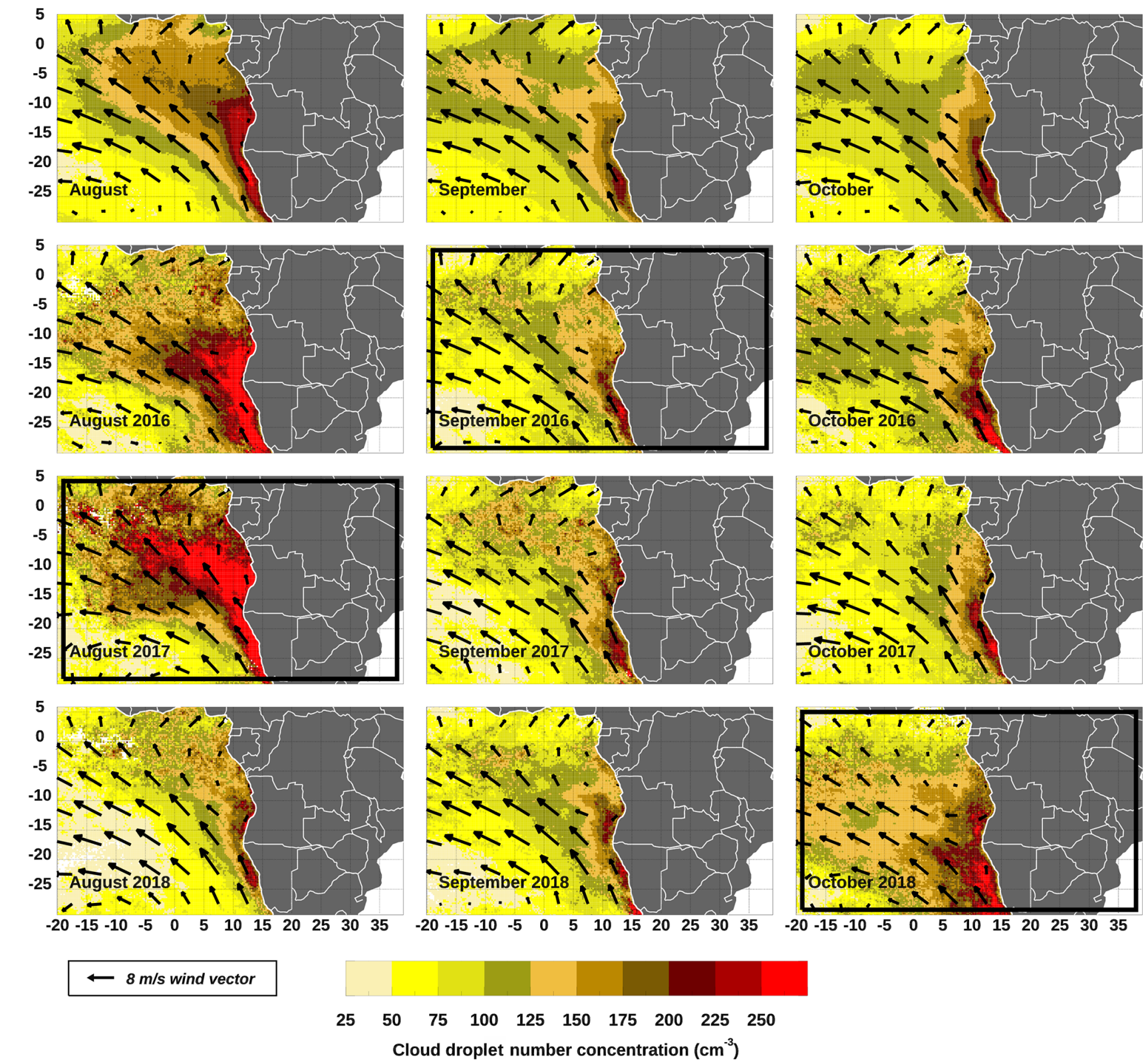

Figure 10. As in Fig. 9, but for $N_{\mathrm{c}}$ from combined Terra-Aqua retrievals for August, September, and October, aggregated at $0.1^{\circ}$. Black arrows denote $925 \mathrm{mb}$ wind vectors with $8 \mathrm{~m} \mathrm{~s}^{-1}$ wind vector scale shown in the black box. The bold black frames indicate ORACLES deployment months.

Figure 11 shows the flight tracks of the three P-3 ORACLES deployments in 2016 (light blue), 2017 (orange), and 2018 (dark blue) and the ER-2 flights in 2016 (green). In each of the flight years, about half of the P-3 flights lie on top of each other along the routine flight track as described above. For clarity, the $2018 \mathrm{P}-3$ flight tracks have been offset by $0.1^{\circ}$ in longitude to allow distinction from 2017 P-3 flight tracks. In their totality, these flight tracks cover a vast portion of the climatological SE Atlantic Sc cloud deck and the overlying BB plume.
Table 2 summarizes eight types of flight maneuvers conducted during research flights and briefly describes the purpose for each maneuver. Figure 12 provides a schematic representation of each of these flight maneuvers.

Tables A1-A3 in Appendix A summarize the flights of both ORACLES aircraft in 2016, 2017, and 2018. They include a brief flight synopsis and the number of each of the eight flight maneuvers described in Table 2 for every flight. Detailed flight reports for each of the flights listed in Tables A1-A3 can be found at the project web page: https://espo.nasa.gov/oracles/mission-flight-docs (last 


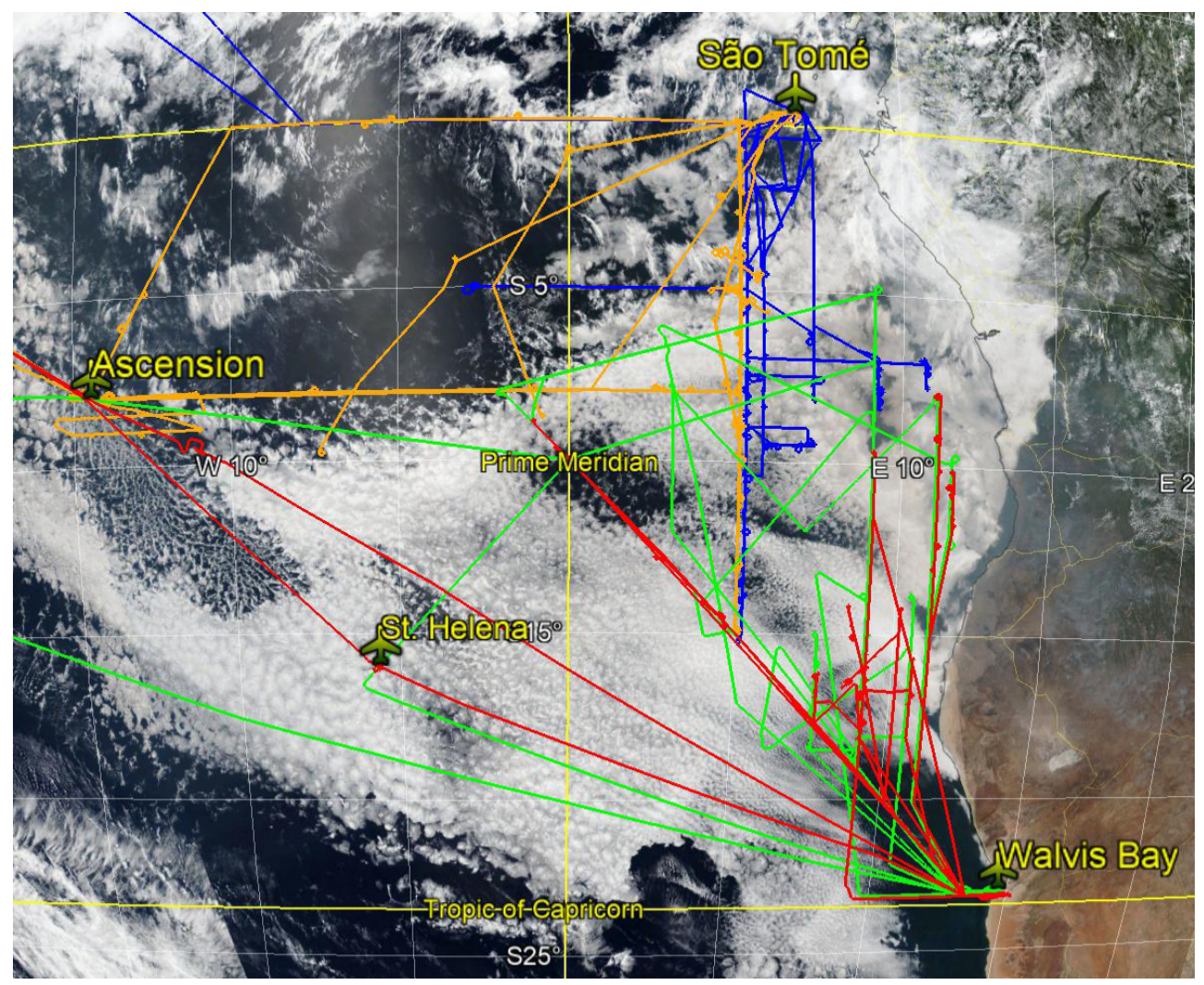

Figure 11. Flight tracks of the ORACLES aircraft in 2016 to 2018, overlain on a MODIS-Aqua True Color Image acquired on 13 September 2018. ER-2 flight tracks in 2016 (only deployment year) are shown in green, adapted from ( $)$ Google Maps 2020 . P-3 flight tracks in 2016, 2017, and 2018 are shown in red, orange, and blue, respectively. The 2018 P-3 flight tracks are offset by $0.1^{\circ}$ in longitude to allow distinction from 2017 flight tracks.
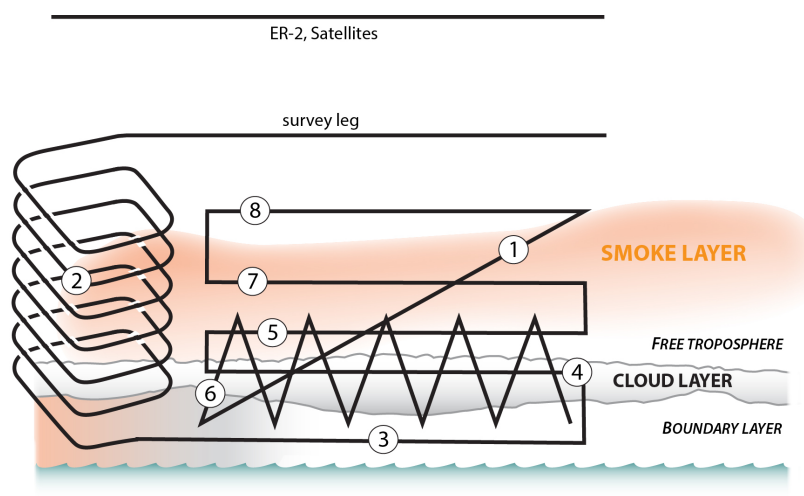

Figure 12. Schematic of flight maneuvers during research flight linked to descriptions in Table 2 and flight synopses in Tables A1A3.

access: May 2020). ORACLES data are archived permanently with separate digital objective identifiers (DOIs) for each deployment year and separate DOI for the two aircraft participating in the 2016 deployment (see references for ORACLES Science Team, 2020-2016 P-3 data, 2016 ER2 data, 2017 P-3 data, and 2018 P-3 data). A link to images and KMZ files for flight tracks, data from ground-based instruments, and other auxiliary information can be found at https://espo.nasa.gov/home/oracles/content/ ORACLES_Science (last access: May 2020). Video footage from the P-3 front and nadir cameras is available at https: //asp-archive.arc.nasa.gov/Oracles/N426NA/Video/ (last access: May 2020).

\section{Preliminary science findings and implications}

\subsection{List of golden days for various objectives}

The target-of-opportunity flights, described in Sect. 4.4, usually were designed to address more focused scientific objectives within the context of the general science objectives. Broadly, these objectives can be characterized as pertaining to (i) the radiative interactions of aerosols and clouds (radiation flights); (ii) the microphysical interactions of aerosols and clouds as they are affected by vertical mixing, drizzle suppression, etc. (cloud microphysics flights); and (iii) the spatiotemporal evolution of aerosol microphysics in the BB plume (plume evolution flights). In addition, a number of 
Table 2. P-3 flight maneuvers conducted during research flights, and their primary purpose.

\begin{tabular}{|c|c|}
\hline Flight maneuver & Primary purpose \\
\hline 1. Ramp - RA & $\begin{array}{l}\text { Continuous profile of thermodynamic state variables, aerosol, } \\
\text { and cloud properties from in situ measurements, often con- } \\
\text { ducted to maximize the geographic extent of a given flight, } \\
\text { while also sampling vertical gradients. }\end{array}$ \\
\hline 2. Square spiral - SS & $\begin{array}{l}\text { A spiral descent (or ascent) for localized radiation and in situ } \\
\text { profile measurements, modified to include four } 20-30 \mathrm{~s} \text { level } \\
\text { segments every } 90^{\circ} \text { heading for radiation measurements, giv- } \\
\text { ing the pattern the appearance of a box with rounded edges. }\end{array}$ \\
\hline 3. MBL leg - ML & $\begin{array}{l}\text { A constant-altitude leg in the MBL to assess aerosol properties } \\
\text { and trace gas concentrations, usually below cloud. }\end{array}$ \\
\hline 4. In-cloud leg - ICL & $\begin{array}{l}\text { A nearly-constant-altitude leg, deliberately placed at an altitude } \\
\text { of specific cloud interest, e.g., in the thickest part of the cloud } \\
\text { or near cloud top for remote-sensing validation. }\end{array}$ \\
\hline 5. Above-cloud Leg - ACL & $\begin{array}{l}\text { A constant-altitude leg, usually just above cloud top, to ascer- } \\
\text { tain the presence of a clear slot and to measure full-column } \\
\text { above-cloud aerosol plume with remote-sensing/radiation in- } \\
\text { struments. Sometimes this leg was optimized in altitude to pro- } \\
\text { vide sufficient standoff for radar observations. }\end{array}$ \\
\hline 6. Sawtooth leg - STL & $\begin{array}{l}\text { A flight segment that continuously profiles from just above } \\
\text { cloud top to just below cloud base, to ascertain the cloud vertical } \\
\text { structure; also useful for quick above-cloud aerosol assessments } \\
\text { at the top of each sawtooth. }\end{array}$ \\
\hline 7. In-plume leg - IPL & $\begin{array}{l}\text { A constant-altitude leg deliberately placed at a specific alti- } \\
\text { tude to assess aerosol properties with in situ measurements; fre- } \\
\text { quently in the heaviest aerosol loading to provide the largest } \\
\text { signal-to-noise ratio. }\end{array}$ \\
\hline 8. Above-plume leg - APL & $\begin{array}{l}\text { A constant-altitude leg above the BB aerosol layer, usually in- } \\
\text { tended for full-column lidar assessments with HSRL- } 2 \text {. }\end{array}$ \\
\hline
\end{tabular}

flights provided an excellent dataset for the evaluation of remote-sensing concepts (see Sect. 5.3.7), often on the basis of successful coordination of the P-3 with the ER-2 in 2016 or with satellite assets in 2017 and 2018 . Table 3 provides a list of "golden days" for each observational focus, to be interpreted as the likely best start of exploration of the ORACLES dataset for an uninitiated science user. The ordering of flights within each category is based on a preliminary assessment of the utility and quality of the data to address the observational objective. Flights with coordinated P-3 and ER-2 sampling in 2016 are postulated to provide superior data and hence appear before any single-aircraft flights. Future analyses are likely to provide a revised list of useful flight days in the context of detailed and overarching ORACLES objectives.

\subsection{Examples of significant findings}

\subsubsection{HSRL-2 statistics on contact of plume and cloud tops}

An important line of inquiry and indeed a major motivation for the ORACLES project was the question of how frequently Sc clouds in the SE Atlantic MBL are in physical contact with the BB plume emanating from the southern African continent. The only prior work in the area using in situ aircraft measurements (Haywood et al., 2003) found frequent separation between cloud and aerosol close to the coast of Namibia and Angola but potential interactions between cloud and aerosol in the vicinity of Ascension Island. However, the statistical relevance of those findings is impossible to establish given the scarcity of the available in situ data. For a large number of coincident CALIOP and MODIS aerosol and cloud retrievals in the SE Atlantic region, Costantino and Bréon (2013) found that more than half of the vertical profiles they studied indicated "well-separated" aerosol 
Table 3. ORACLES golden flight days by observational focus.

\begin{tabular}{|c|c|}
\hline Observational focus & Dates $(\mathrm{mm} / \mathrm{dd} / \mathrm{yyyy})$ - P-3/ER-2 flight number \\
\hline \multirow{8}{*}{ Radiation } & 09/20/2016 - PRF11Y16/ERF06Y16 \\
\hline & 09/14/2016 - PRF09Y16/ERF03Y16 \\
\hline & 09/27/2016 - ERF10Y16 \\
\hline & 09/02/2016 - PRF03Y16 \\
\hline & 08/13/2017 - PRF02Y17 \\
\hline & 08/26/2017 - PRF09Y17 \\
\hline & 09/30/2018 - PRF02Y18 \\
\hline & 10/05/2018 - PRF05Y18 \\
\hline \multirow{11}{*}{ Cloud microphysics } & 09/20/2016 - PRF11Y16/ERF06Y16 \\
\hline & 09/14/2016 - PRF09Y16/ERF03Y16 \\
\hline & 09/06/2016 - PRF05Y16 \\
\hline & 09/25/2016 - PRF13Y16 \\
\hline & 08/28/2017 - PRF10Y17 \\
\hline & 08/13/2017 - PRF02Y17 \\
\hline & 09/02/2017 - PRF13Y17 \\
\hline & 10/03/2018 - PRF04Y18 \\
\hline & 10/02/2018 - PRF03Y18 \\
\hline & 10/23/2018 - PRF13Y18 \\
\hline & 10/12/2018 - PRF08Y18 \\
\hline \multirow{8}{*}{ Plume evolution } & 09/18/2016 - PRF10Y16/ERF05Y16 \\
\hline & 09/24/2016 - PRF12Y16/ERF08Y16 \\
\hline & 09/06/2016 - PRF05Y16 \\
\hline & 08/17/2017 - PRF04Y17 \\
\hline & 08/21/2017 - PRF07Y17 \\
\hline & 08/31/2017 - PRF12Y17 \\
\hline & 10/17/2018 - PRF10Y18 \\
\hline & 10/19/2018 - PRF11Y18 \\
\hline Remote-sensing test bed data & 09/20/2016 - PRF11Y16/ERF06Y16 \\
\hline
\end{tabular}

and cloud layers, i.e., an "aerosol-free gap" above cloud top. They went on to attribute the differences in cloud effective radii between separated and unseparated cases to the probable paucity of aerosols in the MBL in the separated cases. ORACLES observations show that the separation of aerosol and cloud layers in an instantaneous profile is a poor indicator for the concentration of aerosol in the MBL, because there are many other pathways for the aerosol to reach the MBL at a given location. However, the physical contact of the $\mathrm{BB}$ plume and Sc cloud tops is indicative of active entrainment of $\mathrm{BB}$ aerosol into the MBL and is often associated with significant BB aerosol in the MBL. The relatively low signal-to-noise ratio (SNR) in CALIOP vertical profiles after traversing a BB plume with significant optical attenuation, also alluded to in Sect. 2.1, raises the question of how accurate the CALIOP-indicated frequent separation between the BB plume and Sc cloud tops (shown in Fig. 2) really is.

To help address this question, we investigate here how frequently the HSRL-2 aerosol extinction profiles in the three
ORACLES deployments indicate separation or lack thereof between the BB plume base and the Sc cloud tops. The left panel of Fig. 13 shows mean aerosol extinction profiles at $532 \mathrm{~nm}$ for each ORACLES deployment year, along with mean cloud top heights as horizontal solid lines. Because ORACLES-2016 had a somewhat different geographic focus from ORACLES-2017 and ORACLES-2018, Fig. 13 only shows data for the geographic box bounded by $5-15^{\circ} \mathrm{S}$ and $2.5-7.5^{\circ} \mathrm{E}$, where there are data present in all 3 flight years.

The mean extinction profiles show that the BB plume in ORACLES-2017 (August) has a local maximum of aerosol extinction at altitudes between $2-3 \mathrm{~km}$, while the ORACLES-2016 (September) and ORACLES-2018 (October) mean profiles have maximum aerosol loading between 3.0 and $4.5 \mathrm{~km}$ in altitude, albeit with somewhat lower values. In all 3 years, there is a relative minimum in aerosol loading near the location of the mean cloud tops. This suggests that the air mass just above cloud top may indeed be significantly older, more processed, and scavenged than the 

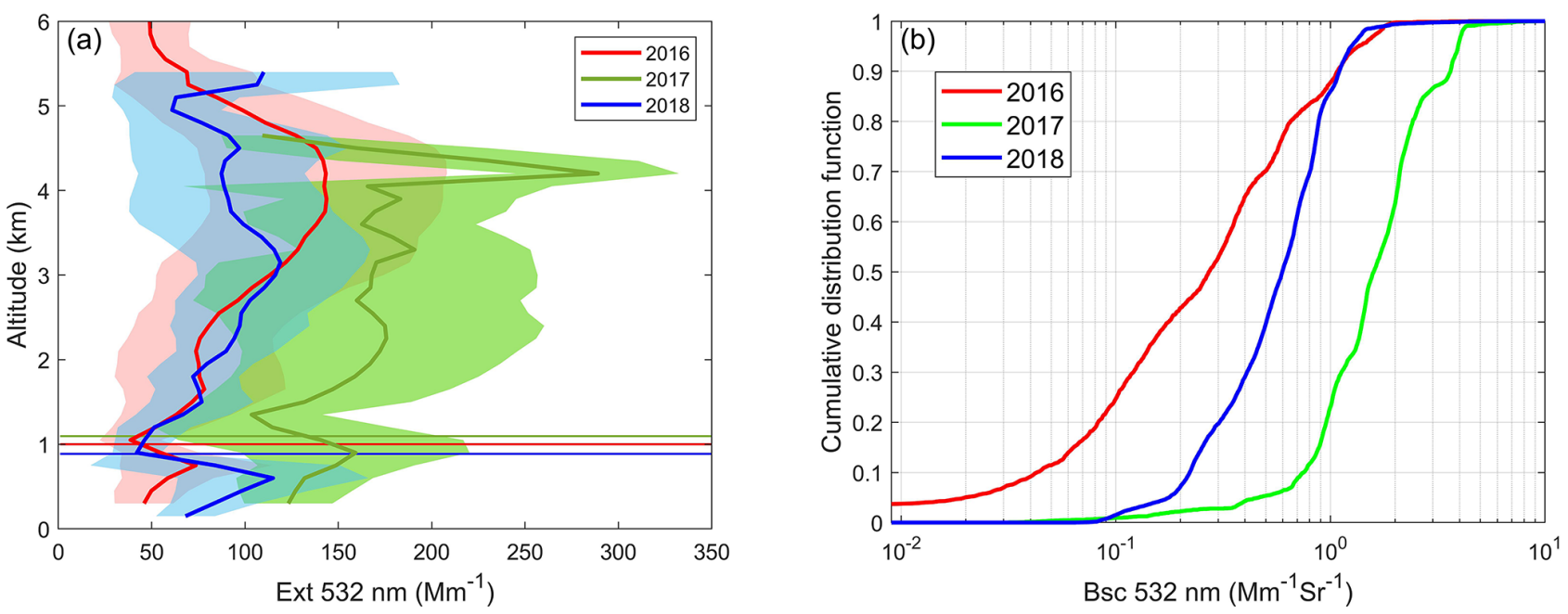

Figure 13. (a) A composite of vertical profiles of aerosol extinction at $532 \mathrm{~nm}$, derived from HSRL- 2 measurements for each of the deployment months bounded by $5-15^{\circ} \mathrm{S}$ and $2.5-7.5^{\circ}$ E. Shaded regions represent 1 standard deviation of extinction measurements. Solid horizontal lines indicate the mean cloud top heights for each dataset. (b) Cumulative distribution function for mean aerosol backscattering in the $300 \mathrm{~m}$ layer above cloud top.

FT above and possibly even the BL below, which may have been subject to entrainment of FT air upstream of the BL flow, to the south of the bounding box.

The separation between the BB plume base and the cloud tops for each year is indicated in the right hand panel in Fig. 13. It shows the cumulative distribution of HSRLderived aerosol backscattering coefficient at $532 \mathrm{~nm}$ in the $300 \mathrm{~m}$ layer just above cloud top for the same geographic region as the left panel. The cumulative distribution of aerosol backscatter values near the cloud top varies sigmoidally, without any discontinuity that would indicate an unambiguous lower edge to the aerosol layer. Instead, it is apparent that the assessment of an aerosol-free gap depends entirely on the definition of the aerosol loading. For example, the August 2017 and October 2018 deployments featured a relatively low fraction of profiles with less than $0.25 \mathrm{M} \mathrm{m}^{-1} \mathrm{Sr}^{-1}$ aerosol backscatter coefficient in the first $300 \mathrm{~m}$ above cloud, i.e., $3 \%$ and $15 \%$ for 2017 and 2018, respectively. The September 2016 profiles in this region on the other hand show less than $0.25 \mathrm{M} \mathrm{m}^{-1} \mathrm{Sr}^{-1}$ aerosol backscatter coefficient, and hence an aerosol-free gap, almost $50 \%$ of the time. Regardless of the exact threshold chosen, September 2016 showed by far the highest frequency of aerosol-free gaps above clouds when compared to the 2017 and 2018 deployments. The representativeness of this September maximum in aerosol-free gaps above clouds is unknown and will need to be explored with future satellite lidar observations of sufficient accuracy. Overall, we found significant spatial and temporal variability in the degree of contact between BB aerosol and Sc clouds in the SEA region and that the frequency of occurrence of aerosol-free gaps is likely much lower than previously assumed (Costantino and Bréon, 2013). These findings need to be considered when interpreting previous results on aerosol-cloud interactions in the region.

ORACLES data provide a useful test bed for algorithm development in support of future satellite missions, for example NASA's ACCP (Aerosols, Clouds, Convection and Precipitation) mission. For instance, ORACLES observations are currently being used to develop joint polarimeter-lidar retrievals of aerosol and cloud properties. Whether such observations will successfully detect features such as the clear-air layers in the SEA will depend on specific instrument characteristics, but the ORACLES measurements should provide useful benchmarks for the testing of candidate observing concepts.

\subsubsection{Vertical plume structure and chemical composition}

The lidar-derived increase in extinction with height for September (2016) in Fig. 13 is accompanied by a similar increase with height of the mean in situ SSA (derived from the in situ PSAP absorption paired with nephelometer scattering at $530 \mathrm{~nm}$ ) from 0.84 to 0.87 (Fig. 14, middle of top row). The SSA values are in reasonable agreement with values of $\sim 0.83$ for dry conditions in Davies et al. (2019) derived using state-of-the-art photoacoustic and cavity ringdown instrumentation. Pistone et al. (2019) compare the ORACLES absorption-scattering measurements with SSA derived by several different airborne remote-sensing methods at wavelengths between 400 and $995 \mathrm{~nm}$ and found reasonable agreement both for specific case studies and for the range of measured spectral SSA over the full ORACLES-2016 deployment.

Black carbon is the primary absorber of sunlight within BB aerosol (e.g., Bond et al., 2013). Although a correspond- 
ing decrease with height of the refractory black carbon (BC) mass concentration relative to the mean organic aerosol (OA) mass concentration is not clearly apparent in Fig. 14, (middle of middle row), an example from an individual profile from the 24 September 2016 flight indicates more nitrate and organic aerosol above $3.5 \mathrm{~km}$ than below it, relative to the black carbon mass concentration (Fig. 14, middle of bottom row). This is consistent with an increase in SSA with height. Examples of individual profiles are shown from each year, broken down by aerosol species - black carbon, organic aerosol, nitrate $\left(\mathrm{NO}_{3}\right)$, ammonium $\left(\mathrm{NH}_{4}\right)$ and sulfates $\left(\mathrm{SO}_{4}\right)$, indicate distinct vertical structures (Fig. 14 bottom row).

Profiles from August 2017 also indicate some vertical structure to the SSA without a clear mapping to the BC/OA ratio, while the mean SSA from the October 2018 deployment increases even more sharply with altitude than does the mean SSA from September (2016). For October 2018, the increase of SSA with height is clearly consistent with the proportional increase in organic aerosol relative to black carbon. Work is ongoing to attribute changes in SSA to both thermodynamically driven changes in gas-particle phase partitioning (e.g., Wu et al., 2020) and more irreversibly driven changes related to forms of photodegradation in this nearequatorial, sun-exposed environment. Overall the SSA values are less than has been previously assumed, with that implication further explored within the modeling study of Mallet et al. (2020).

Some of the differences between the individual profiles in Fig. 14, bottom row, can be related to differences in the prevailing meteorology shown in Fig. 8. The distinctive twolayer aerosol structure profiled on 24 September 2016 reflects the ability of strong winds at $4 \mathrm{~km}$ (see also Fig. 6) to disperse aerosol westward, with the aerosol lower down, at 2-3 km, resulting from an anticyclonic circulation (Fig. 8). The strong $4 \mathrm{~km}$ zonal winds are much less apparent in August, consistent with a lower-lying, less layered aerosol vertical structure. The free-tropospheric winds remain strong into October, but by then the fire emissions have reduced considerably and less aerosol appears to reach the altitude at which the zonal winds are strongest.

\subsubsection{Chemical aging}

Ongoing analysis of the ORACLES dataset is relating the observed vertical structure in aerosol composition and optical properties to aerosol aging. Rather than using an aircraft to track the evolution of a smoke plume as it advects, or using an aerosol chemical component as a "chemical clock" to determine aerosol age, an alternative approach links a modelderived mean aerosol age to in situ aerosol characteristics. Particles, including at fire emission sources, are marked at the time of the model initialization and tracked in time thereafter (Saide et al., 2016), with the particle ages subsequently extracted along the flight legs and these modeled ages combined with the in situ datasets. An example is shown in
Fig. 15 for 24 September 2016 (a profile from this flight is also shown in Fig. 14), using aerosol age derived from one of the ORACLES in-field aerosol forecasting models, WRFAAM (see Sect. 3.3.5). The model-derived mean aerosol age height-latitude cross section is overlaid with measurements of $\mathrm{f} 44$, the mass-to-charge ratio $\mathrm{m} / \mathrm{z} 44$ relative to total organics. Higher fractions of $\mathrm{f} 44$ reflect the formation of carboxylic acids, which coincide with older aerosol ages up to approximately $10 \mathrm{~d}$. The ORACLES f44 values shown here are on par with those reported for Siberian biomass burning aerosol after trans-Pacific transport to Alaska. Notable is that younger aerosol overlies older aerosol on this day, coinciding with the altitude range of strong zonal winds (not shown, but consistent with Fig. 6). This figure also highlights the wide range of aerosol ages beyond $4 \mathrm{~d}$ that ORACLES sampled during its flights, marking another unique contribution by the ORACLES campaign. Ongoing work is relating the modelderived aerosol aging to a continuous depletion of non-blackcarbon aerosols.

\subsubsection{Boundary layer clouds - CCN, cloud, and rain statistics}

ORACLES scientific objective 3 (Table 1) seeks to understand the extent to which smoke aerosol from southern Africa mixes into the MBL and impacts marine low cloud microphysical processes. Smoke may enhance the population of cloud condensation nuclei (CCN), which can lead to increases in cloud droplet concentration and smaller droplet sizes. It can also potentially induce changes in cloud condensate through suppressing precipitation rates, enhancing cloud top entrainment, and otherwise influencing cloud macrophysical properties. These indirect effects lead to significant increases in albedo in global models, but little in situ data are available over the SE Atlantic to test these models.

According to HSRL-2 observations (Fig. 13), a denser, more frequent smoke layer in the FT occurred in 2017 than in 2016 or 2018. CCN measurements made on all three ORACLES deployments (Kacarab et al., 2020) provide evidence that FT CCN concentrations were also higher in 2017 (Fig. 16a). Despite the frequent contact of the smoke with the sub-cloud planetary boundary layer (PBL) top, concentrations of CCN in the PBL are much lower than those in the FT (compare panels a and b in Fig. 16). Also, despite very similar FT CCN concentrations in 2016 and 2018, PBL CCN levels were actually significantly higher in 2018 than in 2016 (Fig. 16b), suggesting that the FT CCN concentration alone is not a unique determinant of microphysical properties in the PBL. As noted in Diamond et al. (2018), it is the history of subsidence and entrainment of smoke into the PBL, rather than the instantaneous presence of aerosol immediately above clouds, that sets the MBL CCN level and therefore cloud droplet concentration $\left(N_{\mathrm{c}}\right)$. Seasonally, satellite evidence (Fig. 10) indicates that the highest $N_{\mathrm{c}}$ values offshore occurred in 2017, and this is consistent with the high- 
(a) August 2017

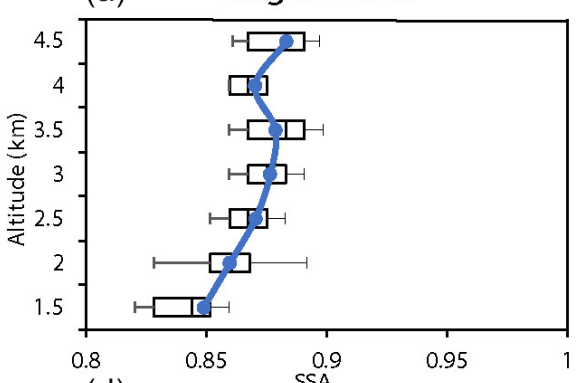

(d)

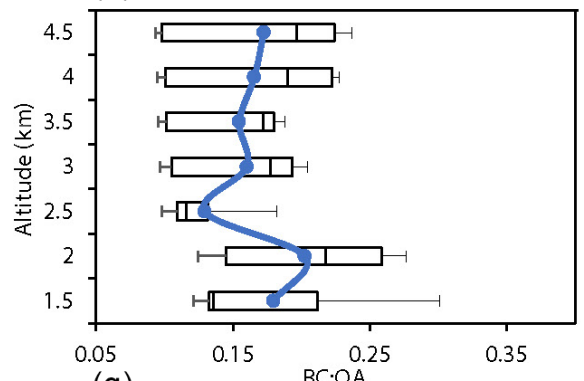

(g)

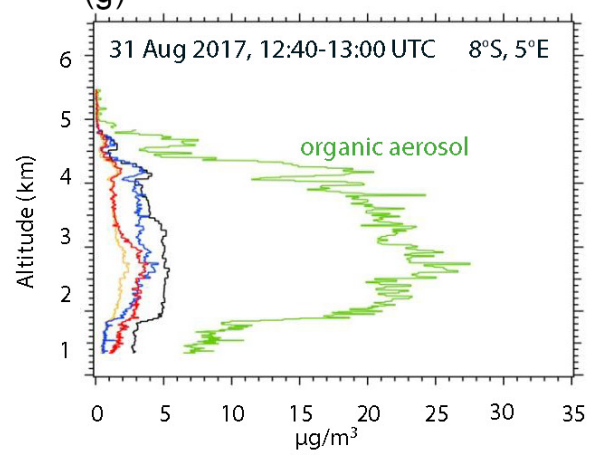

(b) September 2016

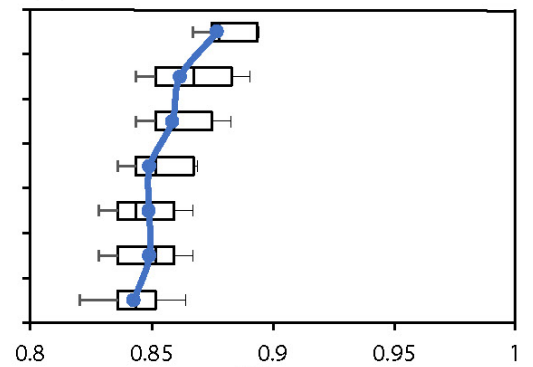

(e)

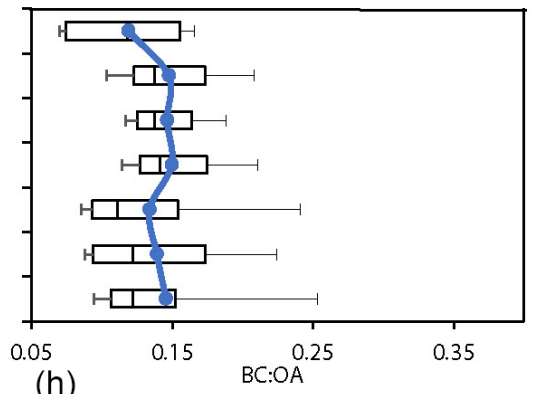

(h)

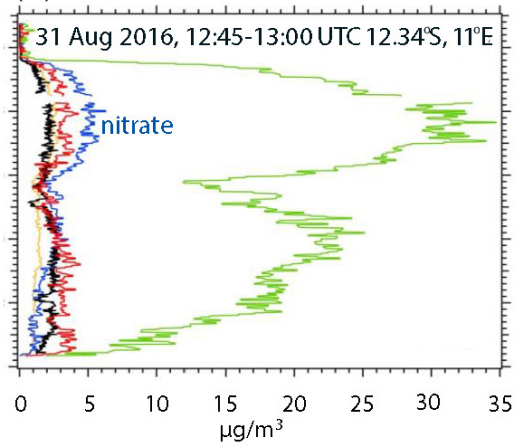

(c) October 2018

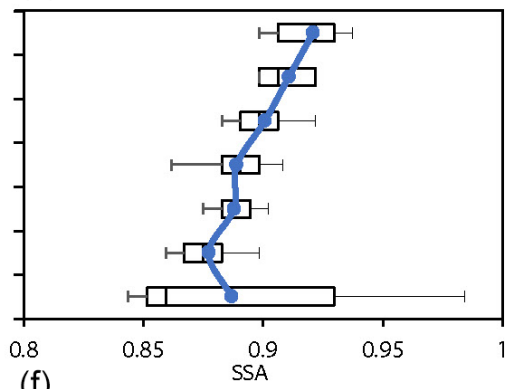

(f)

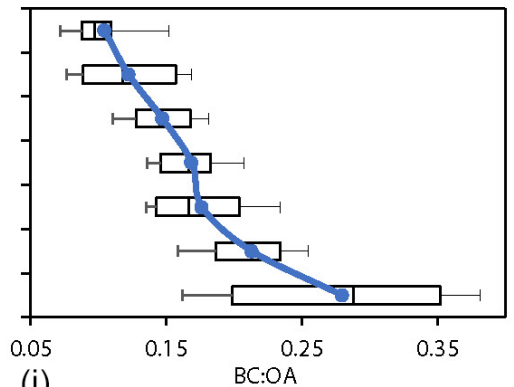

(i)

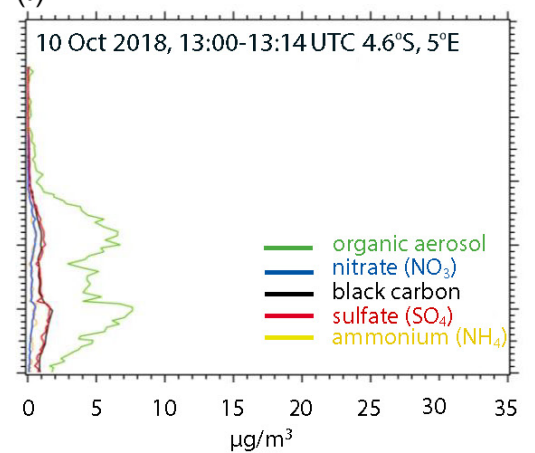

Figure 14. (a-c) Deployment-mean $530 \mathrm{~nm}$ SSA vertical profiles for each year for the August (2017), September (2016), and October (2018) deployments. (d-f) The corresponding mean black carbon to organic aerosol ratio (BC: OA) profiles. (g-i) Example profiles of individual aerosol species, from left to right: 30 August 2017, 12:40-13:00 UTC, $8^{\circ} \mathrm{S} /{ }^{\circ} \mathrm{E} ; 24$ September 2016, 12:45-13:00 UTC, 12.34 ${ }^{\circ} \mathrm{S} / 11^{\circ} \mathrm{E}$; and 4 October $2018,13: 00-13: 15 \mathrm{UTC}, 4.6^{\circ} \mathrm{S} / 5^{\circ} \mathrm{E}$. A blue line connects mean values, with box-whisker plots indicating the 10 th, 25 th, 50 th, 75 th, and 90th percentile values.

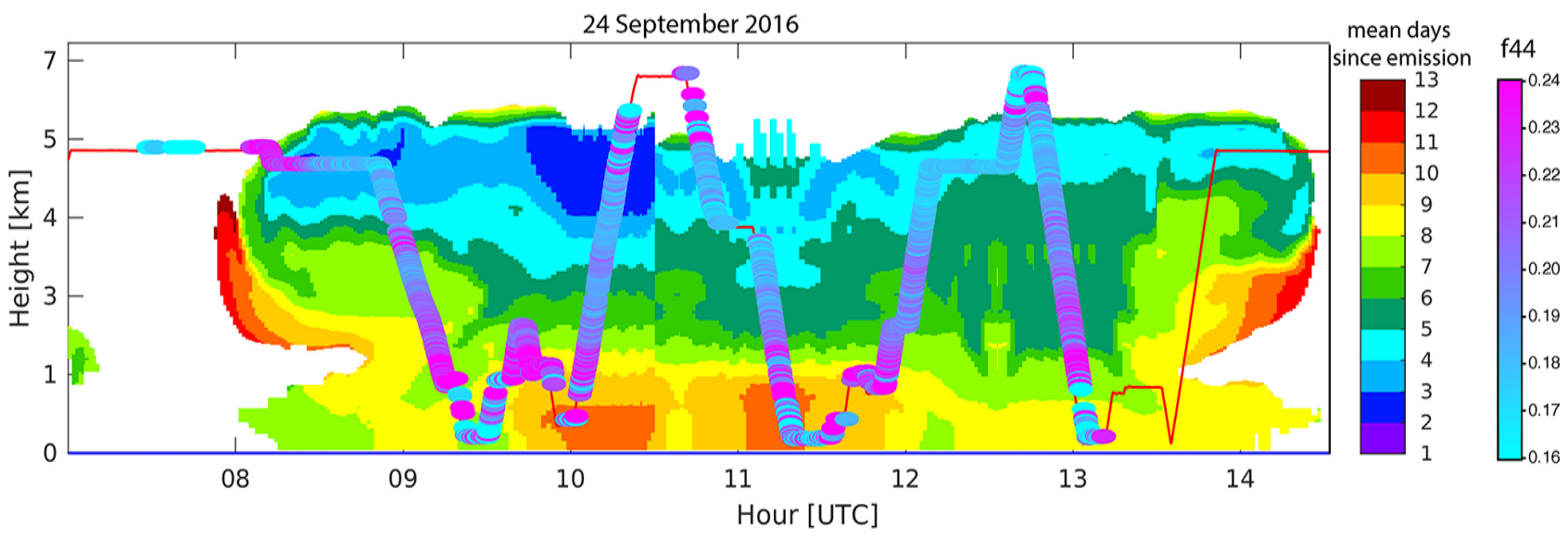

Figure 15. The WRF-AAM model-derived mean aerosol age along the P-3 flight track for 24 September 2016, overlain with a measure of aerosol oxidation derived from in situ $\mathrm{f} 44$ measurements on the P-3 aircraft. 


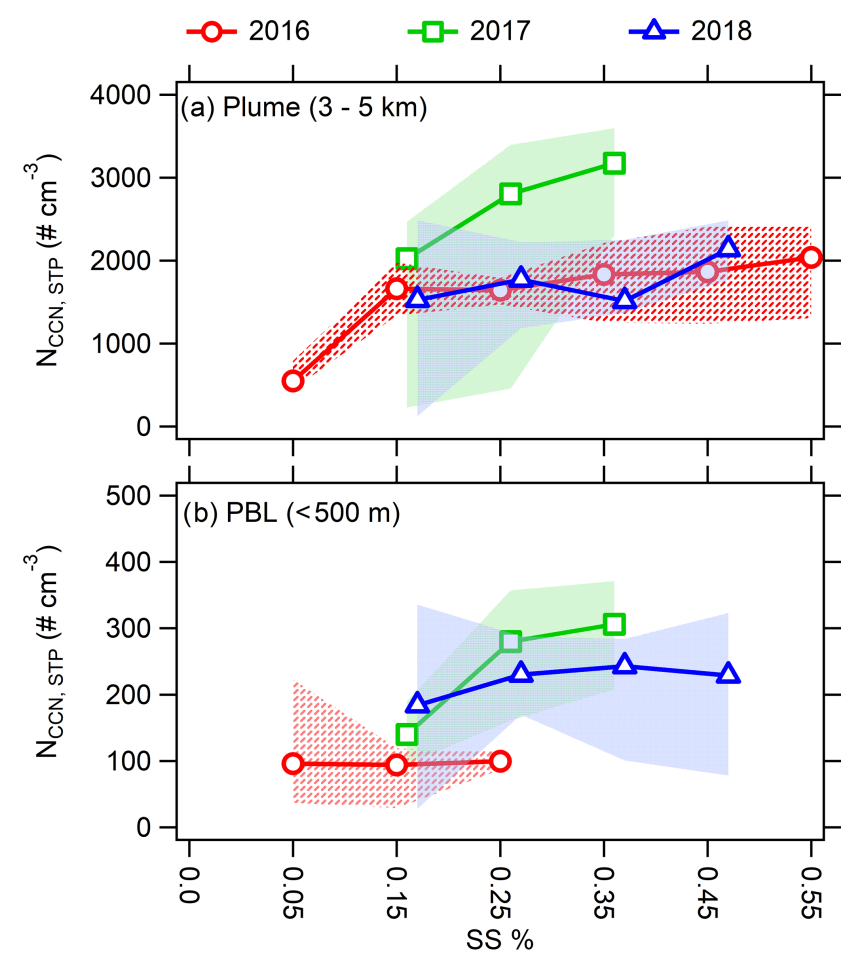

Figure 16. Composite $\mathrm{CCN}$ supersaturation spectra (concentration of $\mathrm{CCN}$ as a function of the applied supersaturation, SS) for (a) the free-tropospheric BB plume and (b) the MBL within a region (5$15^{\circ} \mathrm{S}$ and $2.5-7.5^{\circ} \mathrm{E}$ ) sampled during all three deployments.

est measured PBL CCN concentrations (at supersaturations $>0.25 \%$ ) occurring during 2017. October 2018 also showed high $N_{\mathrm{c}}$ values offshore consistent with the higher measured $\mathrm{CCN}$ concentrations.

In addition to entrainment of smoke from the FT, the concentration of $\mathrm{CCN}$ and resulting droplet concentrations in the marine PBL are also modulated strongly by coalescence scavenging by light precipitation (Wood et al., 2012). In addition, evidence suggests that precipitation can be suppressed in clouds with high $\mathrm{CCN}$ and $N_{\mathrm{c}}$ (e.g., Sorooshian et al., 2009). The APR-3 radar on the P-3 is sufficiently sensitive to detect this light precipitation. Measurements of precipitation from the APR-3 indicated significant differences in precipitation during the three campaigns (Fig. 17). Comparing the two campaigns flown out of São Tomé (2017 and 2018), precipitation was significantly lighter in 2017 (Fig. 17), which may indicate suppression due to higher droplet concentrations, but additional analysis of cloud thickness and liquid water path differences between the campaigns is underway to quantify these impacts (see also Dzambo et al., 2020).

\subsubsection{Evidence of aerosol indirect effects}

Observations obtained by in situ probes installed on the NASA P-3 are being used to investigate cloud-aerosol interactions. Over the 3-year period of ORACLES, 397 ver- tical profiles were flown through clouds during either sawtooth profiles (see Fig. 11) or in individual cloud profiles isolated in time-space from other profiles. The vertical dependence of cloud properties in a common reference frame is examined using a normalized altitude $Z_{\mathrm{N}}$, defined as $\left(Z-Z_{\mathrm{b}}\right) /\left(Z_{\mathrm{t}}-Z_{\mathrm{b}}\right)$, where $Z$ is altitude, $Z_{\mathrm{t}}$ cloud top altitude and $Z_{\mathrm{b}}$ cloud base altitude. This allows us to composite the vertical microphysical structure of cloud decks from many different clouds.

We select 397 vertical profiles through the cloud layer when accumulation-mode $(0.1<D<3 \mu \mathrm{m})$ aerosol concentration $\left(N_{\mathrm{a}}\right)$ was measured at least $100 \mathrm{~m}$ above and below cloud using the Passive Cavity Aerosol Spectrometer Probe (PCASP). Each profile was classified as "Contact" or "Separated" based on whether the layer of enhanced above-cloud aerosol concentration (defined as PCASP $N_{\mathrm{a}}>500 \mathrm{~cm}^{-3}$ ) was in contact with cloud top or separated from it by at least $100 \mathrm{~m}$. Each of the "Contact" and "Separated" profiles was further classified based on whether the average PCASP $N_{\mathrm{a}}$ within the $100 \mathrm{~m}$ layer below cloud base was greater than or less than $250 \mathrm{~cm}^{-3}$. Four different regimes were thus defined based on the below-cloud boundary layer $N_{\mathrm{a}}$ and by whether or not the cloud layer was in contact with an overlying biomass burning aerosol (BBA) plume or separated from it.

Figure 18 shows the mean cloud droplet concentration $N_{\mathrm{c}}$ as a function of $Z_{\mathrm{N}}$ for the four regimes. The average boundary layer $N_{\mathrm{a}}$ values for the regimes are as follows: Contact $/ N_{\mathrm{a}}<250,184 \mathrm{~cm}^{-3}$; Contact $/ N_{\mathrm{a}}>250$, $507 \mathrm{~cm}^{-3}$; Separated $/ N_{\mathrm{a}}<250,113 \mathrm{~cm}^{-3} ;$ Separated $/ N_{\mathrm{a}}>$ $250,318 \mathrm{~cm}^{-3}$. The average boundary layer $N_{\mathrm{a}}$ is a good predictor of the vertical mean $N_{\mathrm{c}}$ across the four regimes, consistent with the primary source for droplets being aerosols ingested into cloud base (Diamond et al., 2018). Although $N_{\mathrm{c}}$ is approximately constant with height for the two Separated regimes and the Contact $/ N_{\mathrm{a}}<250 \mathrm{~cm}^{-3}$ regime, consistent with many previous studies (Nicholls and Leighton, 1986; Martin et al., 1994; Miles et al., 2000; Painemal and Zuidema, 2011; Wood, 2012), it experiences a significant and unexpected increase with $Z_{\mathrm{N}}$ for the Contact $/ N_{\mathrm{a}}>250 \mathrm{~cm}^{-3}$ case. The highest $N_{\mathrm{c}}$ values occur where the MBL has both high $N_{\mathrm{a}}$ and is in contact with overlying BB aerosol layers. The lowest boundary layer $N_{\mathrm{a}}$ is found where there is separation from the overlying aerosol. It is perhaps surprising that clouds within boundary layers with higher $N_{\mathrm{a}}$ but not overlain by aerosol, or clouds within boundary layers with lower $N_{\mathrm{a}}$ but overlain by aerosol, possess very similar $N_{\mathrm{c}}$. This further suggests that clouds' history of interacting with aerosol within the prior days (Mauger and Norris, 2007; Diamond et al., 2018) can have an impact on $N_{\mathrm{c}}$ but that aerosols entrained from above cloud top also have an impact on $N_{\mathrm{c}}$. These findings are further described by Gupta et al. (2020). 
(a)

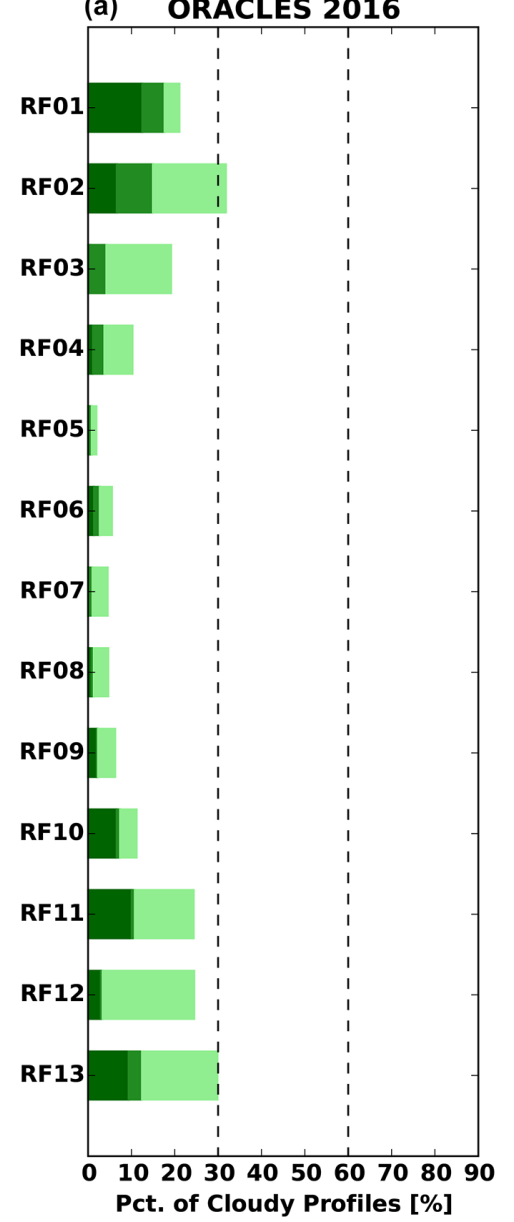

(b) ORACLES 2017

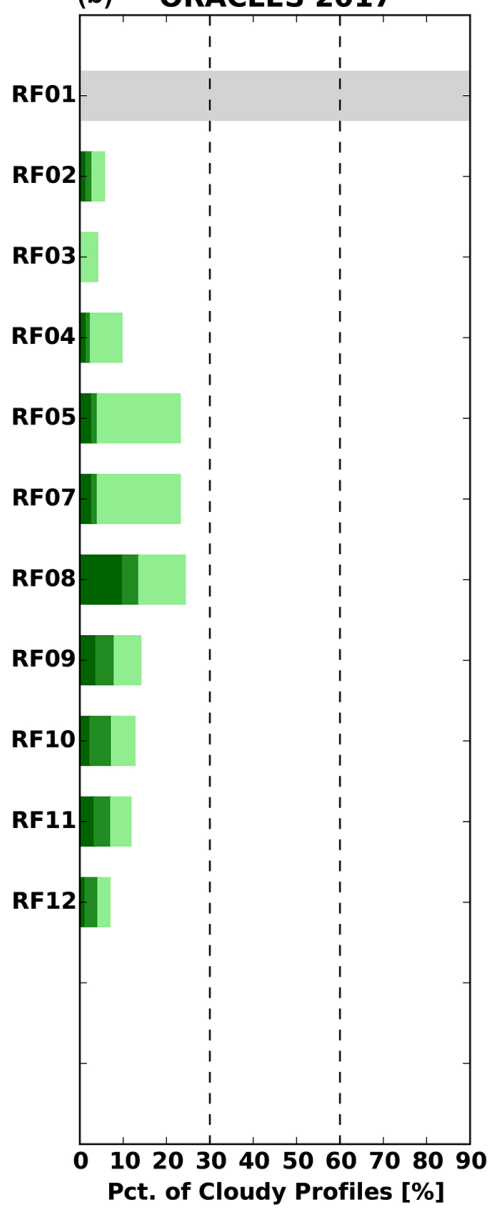

(c) ORACLES 2018

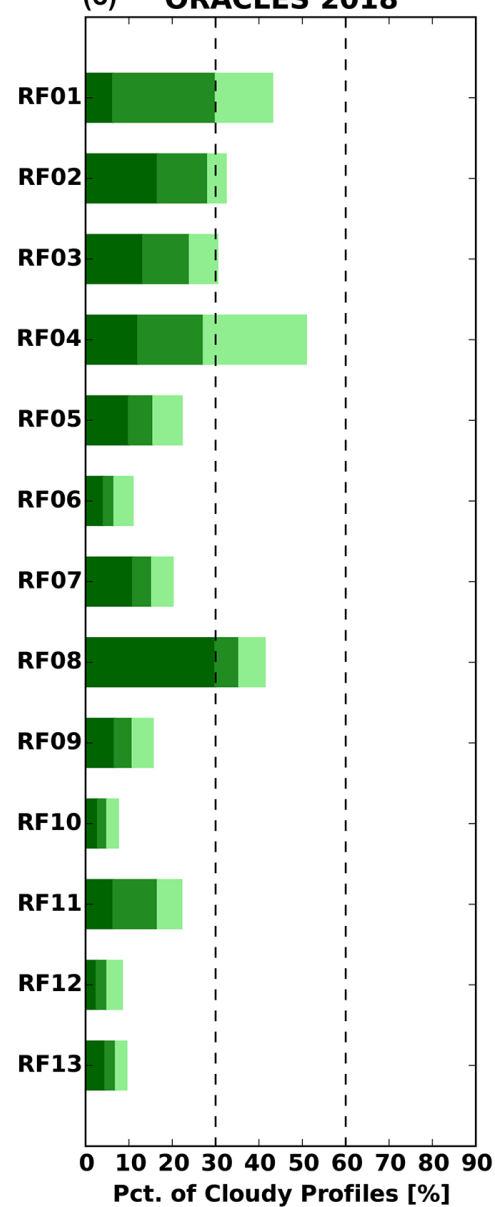

Figure 17. The fraction of clouds in which rain is possible, probable, and certain, for the ORACLES research flights in 2016 (a), 2017 (b), and 2018 (c) as detected using the APR-3 radar. Certain rain (dark green), probable rain (medium green), and possible rain or drizzle (light green) are shown left to right for each research flight, which are determined by each cloudy profile's maximum reflectivity being greater than $0,-7.5$, and $-15 \mathrm{dBZ}$ respectively (see Haynes et al., 2009, for more information).

\subsubsection{Comparisons of models and observations}

Approximately one-half of all of the flights were devoted to a routine path, motivated by a desire to facilitate model improvement through an unbiased sampling performed frequently enough to adequately capture the monthly mean (see Sect. 3.3.6). An a priori evaluation based on the random sampling of clear-sky aerosol optical depths rationalized the decision to allocate six to eight flights to a routinely sampled flight line, on random days during the deployment. The initial model-observation comparison (Shinozuka et al., 2020), which is based on the 2016 measurements only, includes model versions similar to those used for the aerosol forecasts in the field (WRF-CAM5 (Weather Research and Forecasting - Community Atmosphere Model 5) and GEOS5 (Goddard Earth Observing System, Version 5)), as well as the UK Meteorological Office Unified Model (UM), the French ALADIN-Climate (Aire Limitée Adaptation dynamique Développement InterNational - Climate, Mallet et al., 2019), the global GEOS-Chem (Goddard Earth Observing System - Chemistry) model, and the E3SM (Energy Exascale Earth System Model) Atmosphere Model (EAM). Measured variables which are compared include the aerosol layer top/bottom boundaries (as determined from lidar and in situ), aerosol extinction (lidar and in situ), black carbon and organic aerosol mass concentrations (SP2 and AMS), carbon monoxide, scattering and absorption Ångström exponents, and the single-scattering albedo (in situ). The new datasets allow an extension beyond previous assessments emphasizing the aerosol layer boundaries only (Das et al., 2017; Koffi et al., 2012). Not all of the models include all of these variables, and no effort is made to standardize model features such as the emissions databases and frequency of initialization. The project confronted the issue of how best to compare infrequently sampled but detailed measurements to frequently sampled but coarsely resolved model output, through aggregating both measured and model data into approximately 2 by $2^{\circ}$ grid boxes centered on the routine flight track 


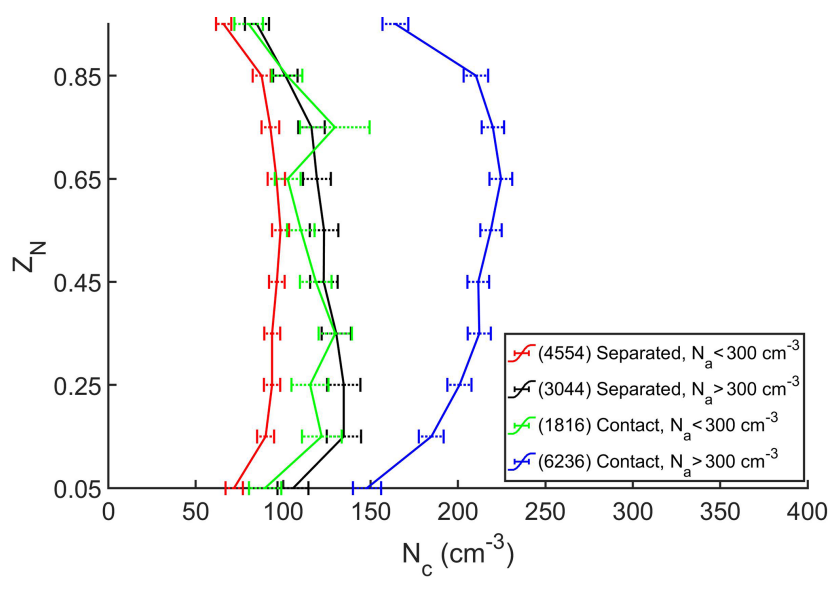

Figure 18. Mean cloud droplet number concentration $\left(N_{\mathrm{c}}\right)$ as a function of normalized cloud depth $\left(Z_{\mathrm{N}}\right)$, where the mean is computed for 397 vertical profiles flown during the three ORACLES campaigns. Different colors correspond to whether the boundary layer below cloud has average aerosol concentration $N_{\mathrm{a}}<$ $250 \mathrm{~cm}^{-3}$ or $N_{\mathrm{a}}>250 \mathrm{~cm}^{-3}$ as measured by PCASP and according to whether a layer of BB aerosol is in contact with $\left(N_{\mathrm{a}}>\right.$ $500 \mathrm{~cm}^{-3}$ within $100 \mathrm{~m}$ of cloud top) or separated from cloud top (no layer with $N_{\mathrm{a}}>500 \mathrm{~cm}^{-3}$ within $100 \mathrm{~m}$ of cloud top). Uncertainties indicated by horizontal error bars represent the $95 \%$ confidence intervals. Numbers in parentheses represent the number of $1 \mathrm{~s}$ data points included in each of the profiles. See text for details.

(see Fig. 19 for an example). This approach is similar to that applied within the AeroCom community (e.g., Katich et al., 2018; Myhre et al., 2013). The smaller grid spacings applied within a larger domain also clarify the ability of models to transport aerosol further offshore. A further study will apply a similar approach to model-observation comparisons based on the 2017 and 2018 deployments.

Shinozuka et al. (2020) assessed modeled aerosol properties through examining three separate layers and concluded that the upper 3-6 km layer generally contains less aerosol in the models than is observed, primarily because the aerosol layer tops are placed too low. Another approach, applied within Doherty et al. (2021) is examining the vertical distribution of aerosol (as in Fig. 19) and those cloud properties (cloud fraction and optical depth) important for quantifying the direct aerosol radiative effect. For example, they find significant differences in both the absolute value and vertical structure of SSA in the observations versus in the models, as well as significant differences between models. Consistent with Shinozuka et al. (2020), the model bias has an altitude dependence that results from the models generally placing the plume at too low an altitude. The covariance in the model bias in extinction and SSA with altitude affects the column SSA - the parameter of interest for determining plume aerosol direct radiative effect. Therefore Doherty et al. (2021) also compare observed to modeled extinctionweighted (or column-aerosol) SSA for the smoke plume.
This and related analyses in the paper lay the groundwork for determining which modeled parameters are contributing most to biases in modeled aerosol direct radiative effect of the smoke.

\subsubsection{Illustration of remote-sensing test bed}

As alluded to in Sect. 2.1, a subordinate, yet important objective for ORACLES was the acquisition of data that can be used for the refinement and testing of retrieval capabilities for instrument concepts that have a potential for deployment to space. Among the remote-sensing instruments participating in ORACLES, the following have a link to space-based instrument concepts: HSRL-2 (future HSRL in space), APR3 (CloudSat's CPR, GPM's DPR, RainCube's radar, EarthCARE's CPR, and candidate radars for future missions targeting clouds, convection, and precipitation), RSP (APS on Glory), AirMSPI (MAIA), and eMAS (MODIS). Examples of algorithm developments using ORACLES data include Xu et al. (2018), Segal-Rozenhaimer et al. (2018), and Miller et al. (2020), who created new cloud retrieval algorithms for the AirMSPI and RSP instruments. Additionally, the NASA Ames 4STAR instrument was used to provide AERONETlike retrievals of aerosol microphysics on the basis of sky radiance measurements from an airborne platform (Pistone et al., 2019), the SSFR instrument provided within-atmosphere spectral radiative flux observations for direct measurements of scene and cloud albedos both from the P-3 and from the ER-2 in 2016 (Cochrane et al., 2019), and HSRL-2 successfully deployed a very stable and accurate density-tuned interferometer as a prototype for spaceborne instrumentation and leveraged the resulting high accuracy in the measurements to infer aerosol microphysical properties (Burton et al., 2018). In combination, these instruments provide a powerful and unprecedented toolset for retrieving atmospheric trace gases, aerosol, and cloud properties, with simultaneous closure opportunities against the spectral radiative flux observations (see Fig. 20). The resulting dataset will be used in the testing of instrument and algorithm concepts for future satellite missions, such as the NASA Aerosol, Clouds-Convection and Precipitation (ACCP) mission, recommended by the 2018 Decadal Survey for Earth Observations from Space (National Academies of Sciences, Engineering, and Medicine, 2018) and the NASA Plankton, Aerosol, Cloud, Ocean Ecosystem (PACE) mission (Werdell et al., 2019), due for launch in 2023.

\subsection{A revised schematic view of the system}

Based on the knowledge acquired thus far from ORACLES analysis, we present a revised schematic of the system (Fig. 21) compared with what was described in Sect. 2 as the state of knowledge during ORACLES conception and planning. Smoke from biomass burning over the southern African continent in Austral winter and spring (July-October) is 


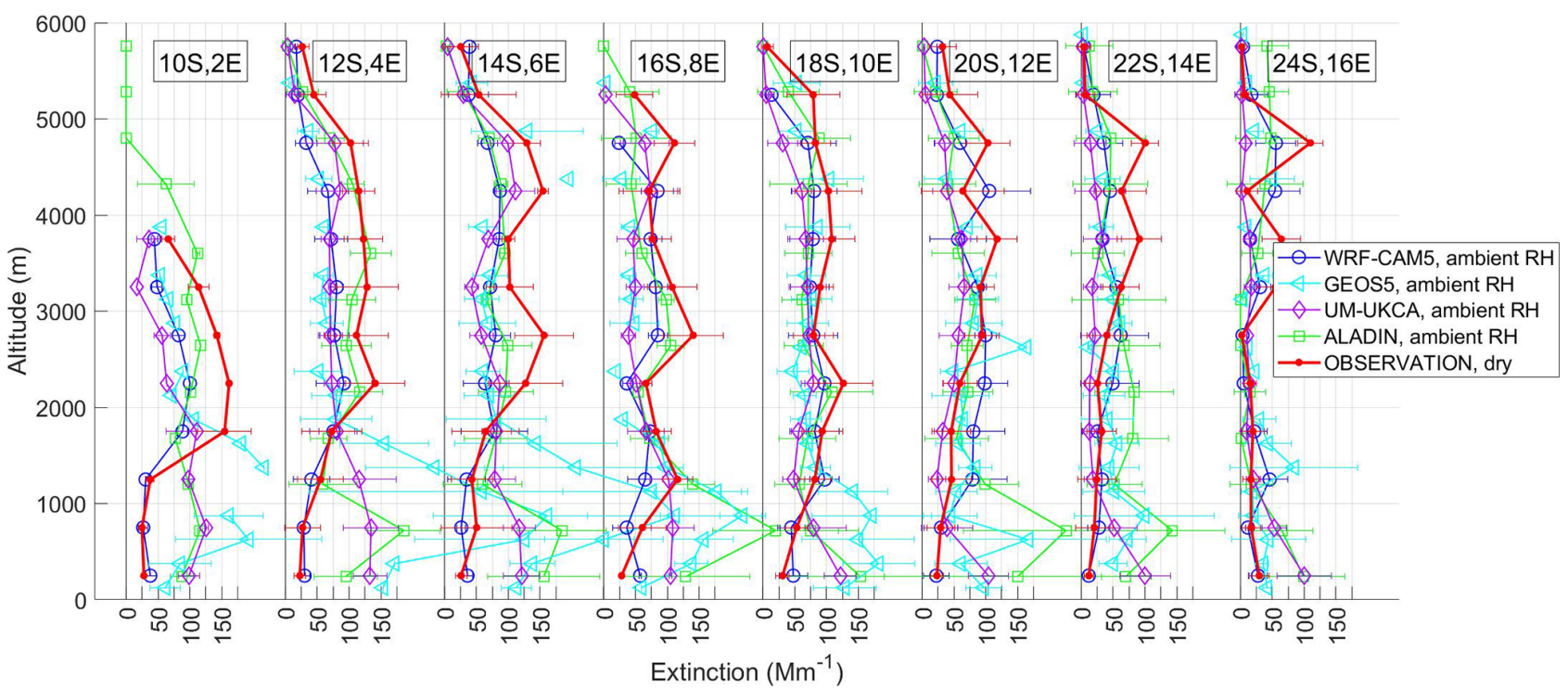

Figure 19. Vertical distribution of mid-visible ambient aerosol extinction from four models compared to dry ORACLES observations in $2 \times 2^{\circ}$ grid boxes (locations indicated) along the 2016 routine flight track.
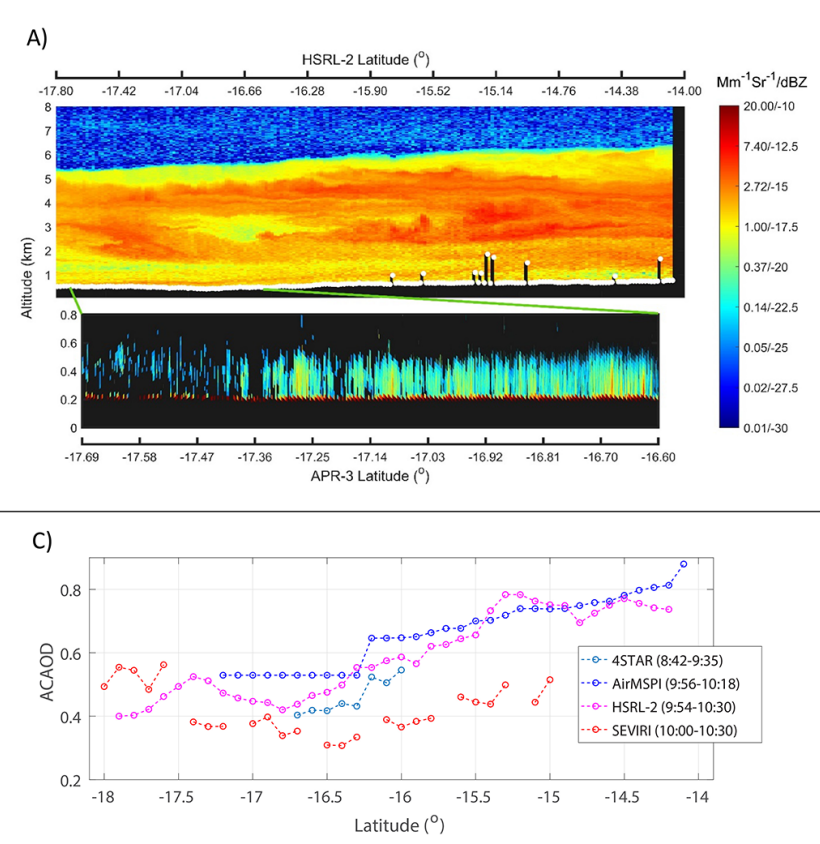

B)

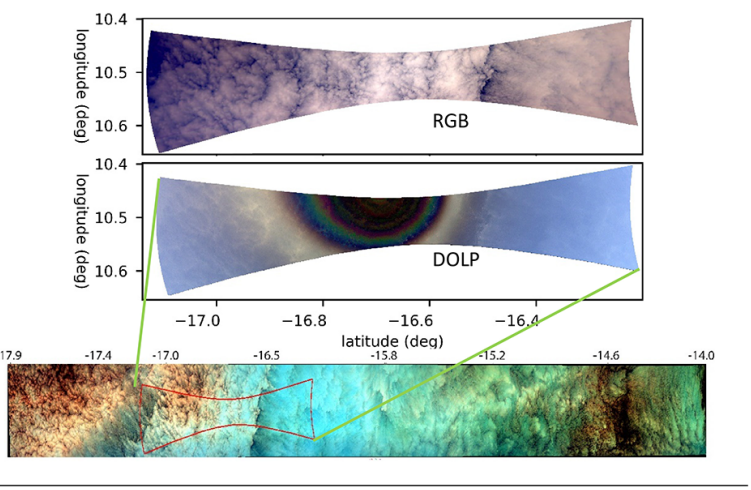

D)

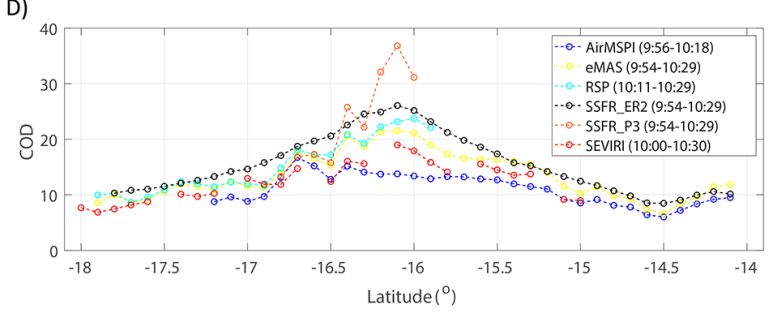

Figure 20. Illustrative remote-sensing observations in ORACLES-2016. (a) Vertical structure of aerosol backscatter and W-band reflectivity from HSRL-2 and APR-3, respectively. (b) Degree of linear polarization (DoLP) and RGB imagery from AirMSPI (bow-tie patterns) and eMAS, respectively. (c) Above-cloud AOD (ACAOD) retrievals from various P-3, ER-2, and satellite instruments. (d) COD retrievals from various P-3, ER-2, and satellite instruments.

emitted into a continental boundary layer that is potentially warmer, and therefore more buoyant, than the cold marine PBL to the west. As this smoke moves westward over the SEA, it must first cool to allow it to subside and be entrained into the PBL. In the free troposphere, clear-sky longwave cooling by emission to space helps drive large-scale subsidence. This process is slow, with typical radiatively driven subsidence rates of $200400 \mathrm{~m} \mathrm{~d}^{-1}$ (Betts and Ridgway, 1988). Solar heating by absorbing aerosol may significantly slow down this process (Sakaeda et al., 2011). As the smoke moves initially westward over the SEA, it typically takes $6-10 \mathrm{~d}$ to subside from the jet core to the top 
of the marine PBL. Typical free-tropospheric wind speeds over the SEA in the southern African Easterly Jet (SAEJ) can reach $5 \mathrm{~m} \mathrm{~s}^{-1}$, so smoke can travel hundreds to a few thousand kilometers offshore in the time taken to descend from the main smoke outflow altitude of $4-5 \mathrm{~km}$. However, FT wind speeds over the SEA are quite variable (see Fig. 15 in Adebiyi and Zuidema, 2016) and are modulated by tropical wave disturbances and by incursions of midlatitude systems into the tropics over the Southern Ocean. Depending upon winds in the FT, smoke trajectories may result in only modest horizontal displacement or may (as in the case shown in the schematic Fig. 21) be advected as far south as $30^{\circ} \mathrm{S}$, especially when midlatitude systems result in re-circulating trajectories that move air back toward the African continent after initial outflow. Thus, smoke aerosol may be entrained into the PBL over a relatively wide geographical region.

Because subsidence is strongest off the coast of Namibia and southern Angola, this makes it a favored region for entrainment of smoke into the marine PBL, especially from recirculating trajectories like the one shown in Fig. 21. This setup results in a typical (September) vertical plume structure in the ORACLES sampling region comprising relatively young aerosol aloft, more aged aerosol immediately above cloud, and the oldest aerosol typically in the marine PBL itself. However, the extensive lateral displacement of the core, and a wind structure with significant vertical shear, means that the presence of smoke immediately above cloud top is intermittent. The PBL over the SEA therefore entrains a considerable volume of clean air, especially from the Southern Ocean. Thus, mean CO levels in the PBL are lower than 100 ppm, while FT plume mean values are typically 150 200 ppm (Shinozuka et al., 2020). With typical unpolluted background levels of 50-70 ppm, this suggests that the majority of the air in the PBL has origins in regions other than those affected by biomass burning. Although this is the case, smoke plumes in the FT have very high aerosol levels (mass, concentration) compared with those in the pristine marine PBL (see Shinozuka et al., 2020), so even quite small mean elevations of $\mathrm{CO}$ in the PBL are associated with large aerosol perturbations.

\section{Discussion}

As with any significant suborbital field deployment, we expect substantial data analysis efforts to extend well beyond the nominal project end date. In this section, we describe ongoing analyses not previously mentioned. Future work that may be facilitated by ORACLES data is captured in Sect. 7 .

Science objective 1 on direct aerosol radiative effects (DAREs) is being pursued with a number of different approaches. At the finest spatiotemporal scale, these approaches entail instantaneous assessments of DAREs on the basis of very complete measurements of aerosol and cloud radiative properties from designated flight maneuvers

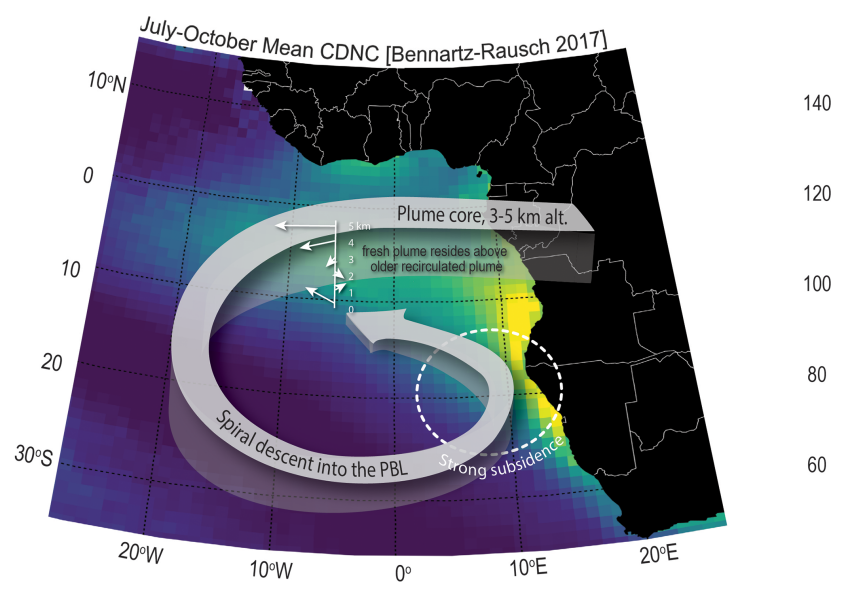

Figure 21. A schematic showing an example of a commonly occurring trajectory pathway into the marine PBL for smoke aerosol ejected from southern Africa in the core (3-5 km altitude) of the southern African Easterly Jet (SAEJ). This is overlaid onto an August-October mean climatology of cloud droplet concentration (colors) derived using MODIS (Bennartz and Rausch, 2017). Trajectories over the SEA are variable. Depending upon the winds in the FT, the trajectory may remain relatively static or may (as in the case shown here) be advected as far south as $30^{\circ} \mathrm{S}$ and back toward the African continent by the incursion of midlatitude disturbances that lead to westerly lower tropospheric winds extending into tropical latitudes.

on a particular flight day. On the larger scales, these approaches combine geostationary satellite observations of diurnally varying cloud properties and above-cloud AOD, both adjusted for aerosol radiative properties measured in situ and possibly nudged by chemical transport model outputs, with campaign-average models of aerosol intensive properties. A designated group of ORACLES scientists meets routinely to discuss the results of the DARE assessment efforts and to avoid duplication of research efforts. Participation in these teleconferences can be requested through email to the corresponding authors of this paper.

Current work on science objective 2, the semi-direct aerosol effect, focuses on understanding how the vertical structure in the SSA depicted in Fig. 14 relates to aerosol aging versus source composition (fuel type and flaming/smoldering conditions) and how the aging relates to aerosol transport patterns. Such work is primarily aimed at developing an understanding of the processes affecting the aerosol SSA and is crosscutting across the different campaigns. Other work is examining how clouds adapt to variations in the absorbing aerosol vertical structure. The discrimination between cloud adaptations to the aerosol shortwave absorption, cloud-nucleating properties, and variability in the large-scale circulation is inherently complex. While this work will assuredly require focused modeling activities that can control more easily for cause-effect relationships, ongoing analysis of ORACLES datasets will frame 
the modeling activities. In one example, the multiple routine flights along $5^{\circ} \mathrm{E}$, conducted in both August 2017 and October 2018, are being analyzed to determine the dominant thermodynamic, dynamic, and aerosol features. In another example, remote-sensing data from the ER-2 platform in September 2016 on the aerosol vertical structure and cloud properties are being constrained by sea surface temperature and location to assess liquid water path responses to aerosol loading and vertical structure.

Science objective 3 focuses on effects of smoke CCN on the microphysical properties of clouds and precipitation. Concentrations of $\mathrm{CCN}$ in the PBL are much lower than those in the FT smoke plume because (a) subsidence and entrainment of smoke into the PBL is relatively slow and (b) there are significant losses in the PBL from both dry and wet deposition. Work is currently underway to understand the transport pathways from the FT into the PBL using a combination of measurements of water vapor, tracers such as carbon monoxide (CO), and the isotopic composition of both water vapor and liquid water to understand the smoke contribution to the PBL CCN budget. Cloud droplet concentration closure is being used to quantify the efficacy with which smoke aerosols serve as nuclei for cloud droplet activation. Remote-sensing and in situ measurements are being used to understand both how smoke suppresses precipitation and the extent to which precipitation is a removal process for $\mathrm{CCN}$. The airborne polarimeter and in situ observations are being used to provide constraints to correct satellite estimates of cloud droplet concentrations that may be affected by overlying smoke. Analyses to assess the Lagrangian evolution of clouds will help quantify how entrainment of smoke aerosol can impact $\mathrm{Nd}$ and change liquid water path and cloudiness. One such Lagrangian case, observed by both the P-3 and the UK BAe-146 aircraft over several days, involved a major smoke entrainment event and is currently being used to constrain large eddy simulations to evaluate both semi-direct and indirect aerosol effects.

All of the ongoing analyses on the overarching science objectives depend critically on the comparisons of observations and models described in Sect. 5.3.6. This dependence is manifested in two separate ways. The first, and more obvious way, is that the models are being evaluated for their ability to fill in missing pieces of information required for the assessment of direct, semi-direct, or indirect aerosol radiative effects in the SE Atlantic. If models are shown to provide reasonable predictions of relevant parts of the aerosol-cloud system, the predictions of these parts can be used to extrapolate aerosol and cloud properties beyond the available spatial and temporal domains. The second, and slightly less obvious way, is that the models can be used to study the representativeness of the airborne and even some of the satellite observations. In the case of the airborne measurements, for example, the comparison of a model output averaged over all time steps coincident with the measurements to the model averaged over all times in a given month may provide an as- sessment of how representative the relatively sparse airborne observations are for a monthly mean. If the two averages vary significantly, then we may conclude that the airborne observations should not be used directly but instead should be adjusted by the model results, for the purpose of calculating monthly mean aerosol effects. Relatedly, the in situmeasured aerosol properties should only be used to evaluate model results if both the monthly average model output and the output subsampled to the airborne observations show the same discrepancy to the model, as such a consistent discrepancy is attributable to a model deficiency rather than a sampling error.

Radiative closure studies will be equally important for progress on the overarching science questions. In a broad sense, these closure studies relate the aerosol and cloud properties measured in situ on the P-3 to remotely measured radiances or irradiances, either from the ER-2 (in 2016), from satellites, or from radiation measurements on the P-3 itself. They may be as ambitious as exploring the connection between the measured aerosol chemical composition, aerosol and cloud radiative properties, and the radiation field or as simply comparing the aerosol radiative properties measured in situ to those measured from remote-sensing instruments. Either way, the knowledge gained from these closure studies will be crucial for assessing large-scale aerosol-cloudradiation interactions.

\section{Conclusions and future work}

The ORACLES project is a highly successful NASA EVS2 project that had well surpassed its Level-1 baseline science requirements upon the conclusion of its last field deployment in October 2018. We conducted a total of three flight deployments totaling 350.6 science flight hours with the NASA P3 aircraft and one flight deployment with the NASA ER-2 totaling 97.3 science flight hours, surveying, probing, and exploring the various features of the SE Atlantic aerosolcloud-climate system. The ORACLES dataset permits the study of aerosol radiative and cloud-nucleating properties, their vertical distribution relative to clouds, the locations and degree of aerosol mixing into clouds, and cloud changes in response to such mixing. Here, we have only touched upon some of the key findings, leaving the detailed exploration of the various factors determining aerosol-cloud-climate interactions in the SE Atlantic to the individual investigations being conducted as part of, or spawned by, the ORACLES project. A high-level summary of some of the main scientific findings and conclusions from our project includes the following:

- the marine boundary layer of the SE Atlantic is more frequently affected by BB aerosol than previously thought, with the variety of pathways by which BB aerosol reach the BL complex not yet fully explored (Zuidema et al., 2018); the transport and climate models 


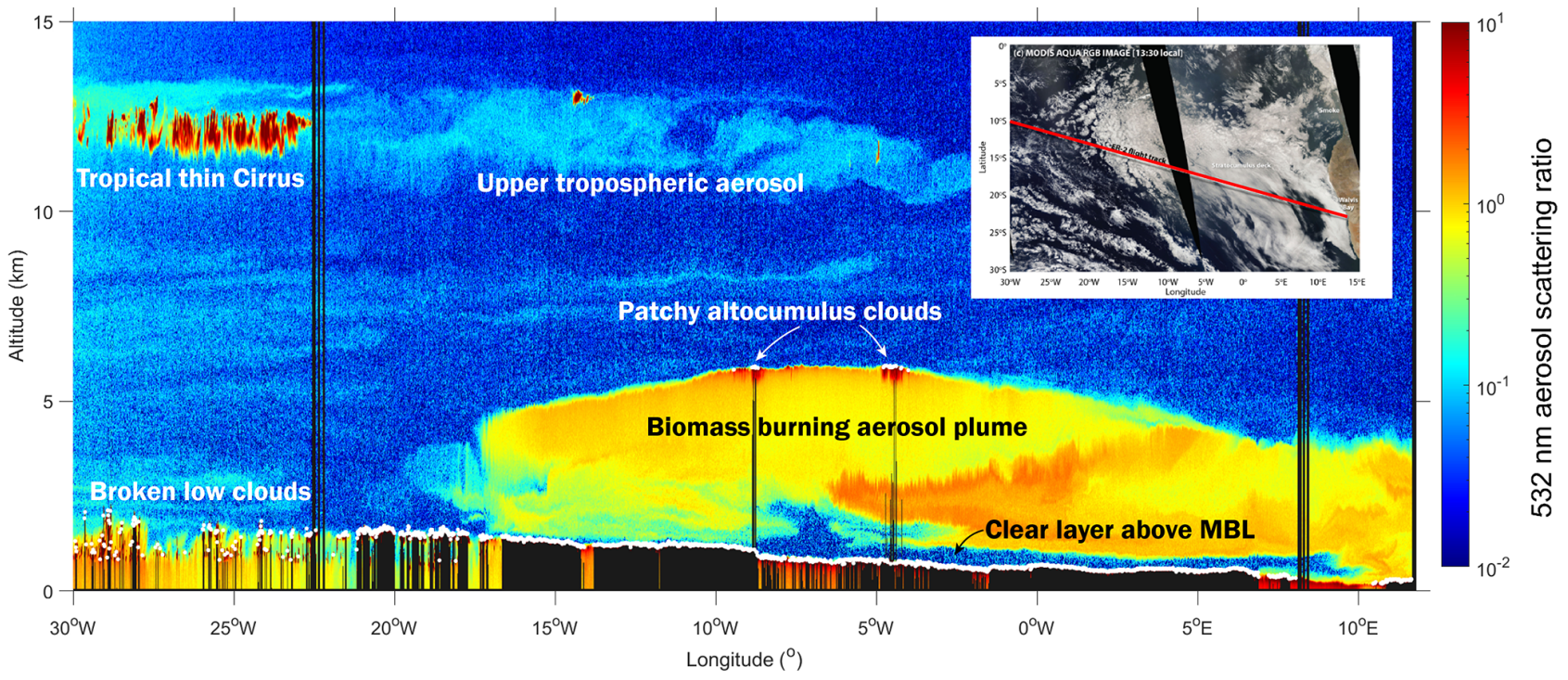

Figure 22. Longitudinal cross section of the HSRL-2 scattering ratio curtain collected during the ER-2 transit from Recife, Brazil, to Walvis Bay, Namibia, on 26 August 2016.

used in ORACLES flight planning had limited success in forecasting the locations and levels of MBL aerosol pollution;

- BB aerosol layers appear to be in much more frequent contact with the Sc cloud deck underneath than previously estimated, but the correlation of cloud droplet number concentrations with above-cloud smoke properties is weak (Diamond et al., 2018); in situ data from August 2017 suggest that cloud droplet number and above-cloud aerosol can be anticorrelated, owing to the anticorrelation of MBL aerosol with above-cloud aerosol amount (Kacarab et al., 2020);

- cloud vertical velocity tends to correlate positively with MBL aerosol number; this covariance tends to enhance cloud droplet number considerably beyond what is expected from aerosol changes alone (Kacarab et al., 2020); most of the observed droplet variability in clouds in polluted boundary layers during the August 2017 deployment appears driven by vertical velocity and its variability (Kacarab et al., 2020);

- interannual variations in the seasonal evolution of aerosol loading in the FT and cloud droplet number concentrations in the MBL over the SE Atlantic during the BB season are greater than previously appreciated (see Sect. 4.2 and 4.3); they are affected by interannual variations in BB location and strength and possibly by variations in the SAEJ (see Sect. 4.1);

- direct airborne measurements of the above-cloud AOD have shown a slight overestimation by current remote-sensing techniques from spaceborne instru- ments (MOD06ACAERO, Deep Blue MODIS, and VIIRS) and some potential difficulties in cloud masking (LeBlanc et al., 2020; Sayer et al., 2019) but a generally consistent meridionally distribution between the airborne and orbital observations;

- aerosol radiative properties, such as the singlescattering albedo and asymmetry parameter, especially in column-integrated values, show reproducible spectral dependence and a fairly-well-constrained range of absolute values in each deployment year (Pistone et al., 2019; Cochrane et al., 2020); their vertical dependence appears to be reproducible as well (see Sect. 5.2.6); overall these highlight that the aerosol is more absorbing than previously thought;

- aerosol radiative properties can correlate well to the relative proportion of $\mathrm{BC}$ and organics during plume aging (see Sect. 5.2.2 and 5.2.3), a process not previously investigated by suborbital means as it requires the sampling of smoke well beyond the near-field fire environment - this sampling of smoke properties up to 2 weeks after emission is a unique accomplishment of ORACLES;

- despite the large aerosol loadings, water vapor also contributes significantly to the total heating rate at most altitudes (Mallet et al., 2019; Cochrane et al., 2020), if less to the range in total heating rates;

- there was ample evidence for aerosol-induced modifications of Sc cloud properties (Fig. 18) and those of midlevel clouds (Adebiyi et al., 2020); 
- a new cloud/rain dataset produced by a joint multi-wavelength cloud radar and multi-angle/multiwavelength polarimeter will allow for further investigation for the suppression of drizzle by aerosol (Dzambo et al., 2019, 2020);

- chemical transport models and climate models exhibit a fairly systematic underestimation of aerosol loadings in the SE Atlantic (Shinozuka et al., 2020).

An analogous summary of lessons learned for logistics and planning of large field campaigns to address aerosol-cloudclimate interactions includes the following:

- the ORACLES science objectives and questions provided crucial guidance for flight execution in each of the deployment years;

- progress towards achieving science objectives was facilitated by the bookkeeping of flight maneuvers that relate directly to the various detailed science objectives, although such bookkeeping proved challenging in the field;

- the joint efforts in developing flight plans by scientists with nominally different flight objectives (e.g., cloud microphysics and radiation) revealed that relatively minor adjustments to flight maneuvers often resulted in datasets that are conducive to addressing a broad range of science questions, well beyond the benefits of flight plans that were developed by any one focused group in isolation;

- the scientific connection to international deployment efforts conducted by the CLARIFY and AEROCLO-sA teams in the same region and timeframe as ORACLES2017 proved a worthy investment of time - while the connecting science is ongoing, there are already measurable outcomes from the international scientific collaborations in terms of the geographic extension of datasets and related publications (e.g., Mallet et al., 2019; Formenti et al., 2019; Haywood et al., 2020);

- the routine sampling strategy for about half of the ORACLES flights allowed for a statistical assessment of climate and chemical transport models, unprecedented for suborbital efforts in this field of study;

- the involvement of the modeling community in the conception and development of the ORACLES project in general, and its flight planning specifically, proved to be invaluable for collecting a dataset that can be used for addressing model deficiencies that hamper our ability to accurately simulate aerosol-cloud-climate interactions.

Future work will likely need to focus on aspects of the science that remain poorly understood and/or physics that is well understood but not well represented in models. Such topics will likely include long-term changes in biomass burning activity, convection and FT transport in the BB source region, the location and degree of mixing of $\mathrm{BB}$ aerosols into the SE Atlantic MBL, and the separation of synoptic-scale variations in the meteorological environment from aerosolinduced changes in Sc cloud properties, to name a few.

We conclude this paper with a figure that represents the complexity of the SE Atlantic aerosol-cloud system well. Figure 22 shows the longitudinal transect of the HSRL-2 scattering ratio curtain collected during the ER-2 transit from Recife, Brazil, to Walvis Bay, Namibia, on 26 August 2016. In addition to expected features, such as an increasing MBL height with increasing distance from southern Africa, and the general dilution of the BB plume with distance from shore, the high signal-to-noise ratio in the HSRL-2 data also reveals a complexity of the layering structure within the BB plume that was previously not appreciated. The layering includes horizontal and vertical gradients in loading, and likely in microphysics, with small-scale features that bear explanation. Future studies of the SE Atlantic climate system are well advised to embrace this complexity. 


\section{Appendix A: Description of flights}

Tables A1a and A1b summarize the P-3 and ER-2 flights in 2016, respectively, while Tables A2 and A3 summarize the P3 flights in 2017 and 2018, respectively. The entries for each flight are comprised of the flight date and identifiers (format

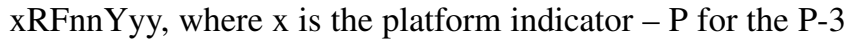
or $\mathrm{E}$ for the ER-2; RF is static and stands for research flight; yy is the flight number for this platform and year; $\mathrm{Y}$ is static and stands for year, $\mathrm{nn}$ is the numerical year $-16,17$, or 18 ) in the first column. Column 2 indicates the total flight time. Column 3 contains a brief flight synopsis and numbers that indicate the number of specific flight maneuvers indicated in each flight. 
Table A1. (a) The 2016 flight summary for the P-3 aircraft. The number of each type of flight maneuver (as given in the table header) is shown in parentheses for each flight. Flight synopsis indicates whether the flight was a designated routine or target-of-opportunity flight. (b) The 2016 flight summary for the ER-2 aircraft.

\begin{tabular}{|c|c|c|}
\hline (a) & & \\
\hline $\begin{array}{l}\text { Date } \\
\text { P-3 flight } \\
\text { no. }\end{array}$ & $\mathrm{h}$ & $\begin{array}{l}\text { Flight synopsis } \\
\text { (ramps, RA; square spirals, SS; MBL legs, ML; in-cloud legs, ICL; above-cloud legs, ACL; sawtooth legs, STL; } \\
\text { in-plume legs, IPL; above-plume legs, APL) }\end{array}$ \\
\hline $\begin{array}{l}\text { 08/27 } \\
\text { PRF00Y16 }\end{array}$ & 6.8 & $\begin{array}{l}\text { Transit: Ascension Island to Walvis Bay } \\
\text { (RA 2/SS 0/ML 1/ICL 0/ACL 0/STL 0/IPL 0/APL 2) }\end{array}$ \\
\hline $\begin{array}{l}\text { 08/30 } \\
\text { PRF01Y16 }\end{array}$ & 1.6 & $\begin{array}{l}\text { Routine (aborted): upon takeoff, P-3 climbed through overcast stratocumulus; aircraft hydraulic issue was iden- } \\
\text { tified during takeoff and the mission aborted. Some useful science measurements just offshore within the BB } \\
\text { plume at approximately } 3500 \mathrm{~m} \text { alt. } \\
\text { (RA 1/SS 0/ML 0/ICL 0/ACL 0/STL 0/IPL 2/APL 0) }\end{array}$ \\
\hline $\begin{array}{l}\text { 08/31 } \\
\text { PRF02Y16 }\end{array}$ & 8.1 & $\begin{array}{l}\text { Routine: the goal was to provide routine mapping along the NW-SE routine flight track from } 23^{\circ} \mathrm{S} / 13^{\circ} \mathrm{E} \text { to } \\
\text { as far NW as possible given flight time constraints; clouds were present along the entire routine track on the } \\
\text { outbound leg, but by the return the clouds had a clear southern edge around } 22^{\circ} \mathrm{S} \text {; typically, an aerosol-free gap } \\
\text { was present between the elevated BB layer and the cloud, corroborated by low RH values associated with clean } \\
\text { air just above cloud top. } \\
\text { (RA 7/SS 2/ML 4/ICL 3/ACL 4/STL 1/IPL 9/APL 3) }\end{array}$ \\
\hline $\begin{array}{l}\text { 09/02 } \\
\text { PRF03Y16 }\end{array}$ & 8.1 & $\begin{array}{l}\text { Target: the objective was to sample aerosol radiative effects above clouds at } 20^{\circ} \mathrm{S} / 10^{\circ} \mathrm{E} \text {, where the aerosol } \\
\text { plume concentration and low-cloud fraction are increasing towards the north, and capture a case with } 100 \% \\
\text { cloud fraction (CF). Significant in situ aerosol and cloud sampling, connection to remote sensing through Terra } \\
\text { overpass. Required no cirrus or mid-level clouds, high AOD, and solid Sc deck (all met). Performed two radia- } \\
\text { tion walls near 16S because cloud conditions were optimal. } \\
\text { (RA 9/SS 2/ML 2/ICL 2/ACL 7/STL 0/IPL 7/APL 3) }\end{array}$ \\
\hline $\begin{array}{l}\text { 09/04 } \\
\text { PRF04Y16 }\end{array}$ & 8.0 & $\begin{array}{l}\text { Routine: the objective was to reach } 10^{\circ} \mathrm{S} / 0^{\circ} \mathrm{E} \text { along routine track with two profiles outgoing and returning, } \\
\text { offset from each other. Reached } 10^{\circ} \mathrm{S} \text { with two boundary layer profiles along the way. Second BL profile at } \\
13^{\circ} \mathrm{S} \text { sampled a decoupled boundary layer reaching } 1.5 \mathrm{~km} \text { altitude with high organic/BC mass. The transit back } \\
\text { sampled a thick mid-level cloud lying above the smoke layer, with similar aerosol/black carbon concentrations. } \\
\text { (RA 4/SS 0/ML 2/ICL 2/ACL 2/STL 0/IPL 8/APL 8) }\end{array}$ \\
\hline
\end{tabular}

09/06 8.0 Target: the goal was to sample clouds and aerosols along a N-S line in what

PRF05Y16 was anticipated to be three different aerosol conditions (aged aerosols on southern end, break in aerosols in the middle of the track, and fresher aerosols towards the northern end of the track). Several in- and above-cloud legs provided some evidence of forecast conditions. Drizzle evident in APR-3 data. (RA 9/SS 0/ML 6/ICL 4/ACL 6/STL 4/IPL 4/APL 4)

09/08 $\quad 8.1 \quad$ Routine: the plan was to reach $10^{\circ} \mathrm{S}$ along routine track with a single profile out midway, and then on return at PRF06Y16 least two profiles were planned, followed by stepped ascents. The main objective was to quantify discrepancy in amount and vertical location of aerosol plumes between WRF and GEOS. Succeeded in doing three profiles. The aerosol layers were more complicated than modeled; clear slot between aerosol layers, with different aerosol composition in different layers. Some cloud work but mostly over scattered and few cloud areas. (RA 9/SS 0/ML 3/ICL 1/ACL 4/STL 1/IPL 4/APL 6)

09/10 8.1 Routine: the goal was a routine flight to $10^{\circ} \mathrm{S} / 0^{\circ} \mathrm{E}$, with planned profiling legs (below, within, above cloud, PRF07Y16 sawtooths through cloud and profiling tropospheric aerosols). Coordination with the ER-2 on the inbound leg. Some predicted Sc clouds did not materialize and some planned cloud work needed to be aborted. Aerosol conditions were cleaner than predicted. Coordination between aircraft at 11:30 UTC, with P-3 in cloud at exact ER-2 overpass time. (RA 6/SS 2/ML 4/ICL 4/ACL 4/STL 1/IPL 6/APL 2)

09/12 8.4 Routine: the plan was to transit to north and west at high altitude and then to conduct profiling on the rePRF08Y16 turn as time permitted. Loose coordination with the ER-2 on the inbound leg was envisioned. Almost reached $10^{\circ} \mathrm{S} / 0^{\circ} \mathrm{E}$ and performed cloud work after descent. ER-2 coordination attempted at $18^{\circ} \mathrm{S} / 8^{\circ} \mathrm{E}$. In general, boundary layer profiles were quite clean, and clouds and precipitation were observed to reach the ground (APR3 and in situ) towards the northern end of the track. The biomass burning plume was not being entrained into the Sc clouds.

(RA 6/SS 0/ML 3/ICL 2/ACL 2/STL 1/IPL 2/APL 6) 
Table A1. Continued.

\begin{tabular}{|c|c|c|}
\hline (a) & & \\
\hline $\begin{array}{l}\text { Date } \\
\text { P-3 flight } \\
\text { no. }\end{array}$ & $\mathrm{h}$ & $\begin{array}{l}\text { Flight synopsis } \\
\text { (ramps, RA; square spirals, SS; MBL legs, ML; in-cloud legs, ICL; above-cloud legs, ACL; sawtooth legs, STL; } \\
\text { in-plume legs, IPL; above-plume legs, APL) }\end{array}$ \\
\hline $\begin{array}{l}\text { 09/14 } \\
\text { PRF09Y16 }\end{array}$ & 8.1 & $\begin{array}{l}\text { Target: radiation focus - radiation walls at two points with contrasting cloud/aerosol conditions; achieved multi- } \\
\text { ple overflights by ER- } 2 \text { during two radiation wall segments on } \mathrm{N}-\mathrm{S} \text { legs near } 16-17^{\circ} \mathrm{S} \text {, but with moderate AOD } \\
\text { (0.4). Clouds were generally quite homogeneous and similar between radiation wall locations. Ultra-clean lay- } \\
\text { ers just above cloud top. Full square radiation spirals on leg A - preliminary results indicating significant albedo } \\
\text { differences within the spiral itself. } \\
\text { (RA 11/SS 1/ML 4/ICL 5/ACL 7/STL 0/IPL 5/APL 2) }\end{array}$ \\
\hline $\begin{array}{l}\text { 09/18 } \\
\text { PRF10Y16 }\end{array}$ & 8.2 & $\begin{array}{l}\text { Target: the goal was to study young, dense plumes. Increased likelihood of cirrus in study region near } 12- \\
14^{\circ} \mathrm{S} / 11^{\circ} \text { E. Predicted plume at about } 4 \mathrm{~km} \text {, only a few days old, was substantiated; lower parts of the plume } \\
\text { were predicted to be older. Flew one extensive radiation wall, with three in-plume legs, two legs just above } \\
\text { cloud, an extended cloud leg, an MBL leg, and one deep profile. Three ER-2 overpasses captured. Mostly } \\
\text { polluted but not decoupled MBL. } \\
\text { (RA 3/SS 1/ML 2/ICL 2/ACL 2/STL 0/IPL 5/APL 4) }\end{array}$ \\
\hline $\begin{array}{l}\text { 09/20 } \\
\text { PRF11Y16 }\end{array}$ & 8.4 & $\begin{array}{l}\text { Target: radiation flight - the objective was to sample aerosol radiative effect and aerosol and cloud properties } \\
\text { for two different types of cloud fields (in terms of albedo and/or cloud fraction) in coordination with the ER-2. } \\
\text { Very successful flight - two almost complete radiation/microphysics walls at } 10.5 \text { and } 9^{\circ} \mathrm{E} \text {; mid-level clouds } \\
\text { on 9E leg; BB plume reached highest altitudes so far }(21 \mathrm{kft} / 6.4 \mathrm{~km}) \text { and largest AOD }(\sim 0.8) \text {; apparently fresh } \\
\text { aerosol, absorption Angström exponent higher than on other flights; plume more stratified than on other days; } \\
\text { patches of drizzle found in radar and cloud probes. } \\
\text { (RA 6/SS 4/ML 4/ICL 3/ACL 5/STL 1/IPL 2/APL 4) }\end{array}$ \\
\hline $\begin{array}{l}\text { 09/24 } \\
\text { PRF12Y16 }\end{array}$ & 9.2 & $\begin{array}{l}\text { Target: the objective was another attempt to find the youngest, densest plume. Went farther north than any other } \\
\text { flight, found very polluted layers at altitude. HSRL-2 data exceedingly useful for finding layers. Penetrated } \\
\text { a couple of intermediate level clouds, able to get droplet size distributions. Confirmed the high altitude of } \\
\text { smoke plume, as predicted by WRF; GEOS-5 showed low-altitude plumes that were not there - excellent } \\
\text { model testing! One ER-2 overpass. Spent about } 30 \text { min in clouds of various sorts. AOD up to } 0.9 \text {. } \\
\text { (RA 5/SS 3/ML 4/ICL 3/ACL 3/STL 0/IPL 5/APL 5) }\end{array}$ \\
\hline $\begin{array}{l}\text { 09/25 } \\
\text { PRF13Y16 }\end{array}$ & 8.8 & $\begin{array}{l}\text { Routine: the objective was to extend routine flight to } 9 \mathrm{~h} \text { and to coordinate with ER- } 2 \text { at } 10^{\circ} \mathrm{S} / 0^{\circ} \mathrm{E} \text {. Sampled } \\
\text { BB layer at } 14 \text { and } 18 \mathrm{kft}(4.3 \text { and } 5.5 \mathrm{~km}) \text { on outbound leg; profiles on outbound legs flown as planned, with } \\
\text { extended low-level legs. AOD } 0.3-0.4 \text {, with the exception of } 0.6 \text { near turnaround point. Coordination with ER- } 2 \\
\text { at } 13: 45 \mathrm{UTC} \text {, with P-3 in cloud (after a below-cloud leg and before above-cloud legs). Very clean layer above } \\
\text { cloud top near } 20^{\circ} \mathrm{S} \text { on return leg. } \\
\text { (RA 7/SS 0/ML 2/ICL 2/ACL 5/STL 1/IPL 8/APL 5) }\end{array}$ \\
\hline $\begin{array}{l}\text { 09/27 } \\
\text { PRF14Y16 }\end{array}$ & 7.3 & $\begin{array}{l}\text { Transit: Walvis Bay to Ascension Island; mostly high-altitude flight, with some in situ MBL observations and } \\
\text { combined radar-in situ observations of precipitating clouds near Ascension Island starting at } 11^{\circ} \mathrm{S} / 10^{\circ} \mathrm{W} \text {. } \\
\text { (RA 1/SS 3/ML 1/ICL 0/ACL 2/STL 0/IPL 1/APL 2) }\end{array}$ \\
\hline 15 & & 115.2 \\
\hline
\end{tabular}


Table A1. Continued.

\begin{tabular}{|c|c|c|}
\hline \multicolumn{3}{|l|}{ (b) } \\
\hline $\begin{array}{l}\text { Date } \\
\text { ER-2 flight } \\
\text { no. }\end{array}$ & $\mathrm{h}$ & $\begin{array}{l}\text { Flight synopsis } \\
\text { (ramps, RA; square spirals, SS; MBL legs, ML; in-cloud legs, ICL; above-cloud legs, ACL; sawtooth legs, STL; } \\
\text { in-plume legs, IPL; above-plume legs, APL) }\end{array}$ \\
\hline $\begin{array}{l}\text { 08/26 } \\
\text { ERF00Y16 }\end{array}$ & 7.9 & $\begin{array}{l}\text { Transit: from Recife directly to Walvis Bay, very extensive longitudinal cross section with HSRL; RSP without } \\
\text { SWIR, eMAS collected no data as plate installed over aperture; RSP, SSFR, AirMSPI, and HSRL-2 worked } \\
\text { well. }\end{array}$ \\
\hline \multicolumn{3}{|r|}{ 08/27-09/09: waiting for ER-2 fuel to arrive } \\
\hline $\begin{array}{l}\text { 09/10 } \\
\text { ERF01Y16* }\end{array}$ & 6.3 & $\begin{array}{l}\text { Mapping routine - planned } 9 \mathrm{~h} \text { flight to survey smoke transport; high-level clouds in target area prevented } \\
\text { original plan to work with P-3; RSP, AirMSPI, eMAS, and SSFR worked well; HSRL-2 did not operate due to } \\
\text { tripped ER-2 circuit breaker/faulty ER-2 coolant pump; flight shortened to attempt coordination with P-3 and } \\
\text { allow problem troubleshooting; RSP, AirMSPI, and eMAS (including SWIR) data for cloud retrievals. }\end{array}$ \\
\hline $\begin{array}{l}09 / 12 \\
\text { ERF02Y16* }\end{array}$ & 8.7 & $\begin{array}{l}\text { Routine: planned } 9 \mathrm{~h} \text { flight to survey smoke transport ("big triangle"); mid-level clouds in target area prevented } \\
\text { original plan to work with P-3; HSRL-2, RSP, AirMSPI, eMAS, and SSFR worked well. }\end{array}$ \\
\hline $\begin{array}{l}\text { 09/14 } \\
\text { ERF03Y16* }\end{array}$ & 8.1 & $\begin{array}{l}\text { Target: planned } 8 \mathrm{~h} \text { flight with P-3 coordination along two N-S legs; RSP, AirMSPI, and SSFR worked well; } \\
\text { eMAS-VIS/NIR/SWIR worked well - LWIR compromised due to Sterling cooler's active balancer failing dur- } \\
\text { ing flight. HSRL-2 did not operate due to tripped aircraft circuit breaker. Troubleshooting found faulty aircraft } \\
\text { coolant pump which was subsequently replaced; very good Terra overpass; good flight for polarimeter cloud } \\
\text { retrievals and intercomparison with P-3 RSP and in situ. }\end{array}$ \\
\hline $\begin{array}{l}\text { 09/16 } \\
\text { ERF04Y16 }\end{array}$ & 7.7 & $\begin{array}{l}\text { Routine: mapping/survey flight "little triangle"; HSRL-2 operational again after ER-2 coolant pump replaced; } \\
\text { HSRL-2, RSP, AirMSPI, and SSFR worked well; eMAS - good data in Vis-SWIR, no LWIR data available. }\end{array}$ \\
\hline $\begin{array}{l}\text { 09/18 } \\
\text { ERF05Y } 16^{*}\end{array}$ & 8.5 & $\begin{array}{l}\text { Target: mapping plume and CALIPSO underflight; S-N leg near the coast (along } 11^{\circ} \mathrm{E} \text { ) to look at smoke } \\
\text { properties close to coast. Northern part of S-N leg (between } 10-12^{\circ} \mathrm{S}, 11.5^{\circ} \mathrm{E} \text { ) included a portion that was } \\
\text { coordinated with the P-3. Western part of plan included CALIPSO leg (overpass } \sim 13: 35 \mathrm{UT} \text { ); HSRL, RSP, } \\
\text { AirMSPI, SSFR, and eMAS worked well. }\end{array}$ \\
\hline $\begin{array}{l}\text { 09/20 } \\
\text { ERF06Y16* }\end{array}$ & 7.7 & $\begin{array}{l}\text { Target: P-3 coordination, CALIPSO underflight; coordinated S-N legs with P-3 along } 10.5^{\circ} \mathrm{E} \text { and } 9^{\circ} \mathrm{E} \text { between } \\
14-18^{\circ} \mathrm{S} \text {. Western part of plan included CALIPSO leg; HSRL, RSP, AirMSPI, SSFR, and eMAS worked well } \\
\text { (eMAS - no } 13.9 \mu \mathrm{m} \text { band data) }\end{array}$ \\
\hline $\begin{array}{l}\text { 09/22 } \\
\text { ERF07Y16 }\end{array}$ & 7.9 & $\begin{array}{l}\text { Routine and mapping: southern survey, St. Helena overflight; RSP, AirMSPI, SSFR, and HSRL-2 worked well; } \\
\text { eMAS-not operational (data system failure); southern mapping triangle; flyover of St. Helena - clouds pre- } \\
\text { vented AERONET aerosol measurements; ER-2 overflight nearly coincident with St. Helena radiosonde launch. }\end{array}$ \\
\hline $\begin{array}{l}\text { 09/24 } \\
\text { ERF08Y16* }\end{array}$ & 8.0 & $\begin{array}{l}\text { Target: RSP, AirMSPI, SSFR, and HSRL- } 2 \text { worked well; eMAS - good data in Vis-SWIR. No LWIR data } \\
\text { (bands 26-38) - aircraft pod heater failure toward end of flight. ER-2 leg along } 11^{\circ} \text { E between } 8-20^{\circ} \mathrm{S} \text { along } \\
\text { P-3 leg; ER-2 legs between } 8-12^{\circ} \mathrm{S} \text { can be used to study smoke evolution between } 11 \text { and } 3^{\circ} \mathrm{E} \text {. }\end{array}$ \\
\hline $\begin{array}{l}09 / 25 \\
\text { ERF09Y16* }\end{array}$ & 8.7 & $\begin{array}{l}\text { Routine: RSP, AirMSPI, and SSFR worked well; HSRL-2 no science data due to laser problem; eMAS - good } \\
\text { data in Vis-SWIR, no LWIR data (bands 26-38); aircraft pod heater failed. Flew "big triangle" and met P-3 on } \\
\text { return leg. }\end{array}$ \\
\hline $\begin{array}{l}\text { 09/27 } \\
\text { ERF10Y16* }\end{array}$ & 9.2 & $\begin{array}{l}\text { Routine: RSP, AirMSPI, and SSFR worked well; HSRL-2 did not collect science data due to laser problem; } \\
\text { eMAS - good data in Vis-SWIR. No LWIR data (bands 26-38) - aircraft pod heater failed. Short (10-15 min } \\
\text { leg) on return leg for Aqua overpass for eMAS. Flew "big triangle" again. }\end{array}$ \\
\hline $\begin{array}{l}\text { 09/29 } \\
\text { ERF11Y16 }\end{array}$ & 8.6 & $\begin{array}{l}\text { Transit: Walvis Bay to Recife; initial leg NW over standard leg to } 0^{\circ} \mathrm{N} / 10^{\circ} \mathrm{S} \text {, then over Ascension Island, } \\
\text { before continuing to Recife. eMAS collected no data as plate installed over aperture; HSRL-2 did not collect } \\
\text { science data due to laser problem. RSP, SSFR, and AirMSPI worked well. }\end{array}$ \\
\hline 12 & & 97.3 \\
\hline
\end{tabular}

* ER-2 flights that were closely coordinated with P-3 aircraft operations. 
Table A2. The 2017 flight summary for the P-3 aircraft.

\begin{tabular}{|c|c|c|}
\hline $\begin{array}{l}\text { Date } \\
\text { P-3 flight no. }\end{array}$ & $\mathrm{h}$ & $\begin{array}{l}\text { Flight synopsis } \\
\text { (ramps, RA; square spirals, SS; MBL legs, ML; in-cloud legs, ICL; above-cloud legs, ACL; sawtooth legs, STL; } \\
\text { in-plume legs, IPL; above-plume legs, APL) }\end{array}$ \\
\hline $\begin{array}{l}\text { 08/12 } \\
\text { PRF01Y17 }\end{array}$ & 8.5 & $\begin{array}{l}\text { Routine: the plan was to reach } 13^{\circ} \mathrm{S} \text {. Multiple layers near São Tomé; highest ACAOD of flight at } \sim 0.45 \text {. } \\
\text { During southbound transit, aerosol layer resting on cloud top and then decreasing cloud tops with separation } \\
\text { from aerosol at about } 2^{\circ} \mathrm{S} \text {. At } \sim 6^{\circ} \mathrm{S}-\text { "soft" cloud break and then solid deck of small closed cell clouds topped } \\
\text { by aerosol layer right on cloud tops. Two sets of spiral descents, cloud sawtooth patterns, sets of backtracking } \\
\text { level legs for additional cloud sampling. } \\
\text { (RA 3/SS 3/ML 3/ICL 1/ACL 2/STL 2/IPL 5/APL 2) }\end{array}$ \\
\hline
\end{tabular}

\begin{tabular}{ll}
\hline 08/13 & Target: the objective was a joint cloud-radiation flight, sampling gradient of overcast and broken clouds along \\
PRF02Y17 & the CALIPSO satellite track, aerosol radiative effects in the presence of broken clouds, and mixing of aerosols \\
into clouds. Transition between overcast and broken clouds was found along the $7-9^{\circ} \mathrm{S}$ line oriented along \\
A-train track. Line was oriented nearly parallel with surface winds. This allowed both the radiation and micro- \\
physics objectives to be addressed. Transition between homogeneous and broken clouds, and some gradient in \\
the mixing mechanism into cloud and the boundary layer. Final part involved sampling at $20 \mathrm{kft}(6.1 \mathrm{~km})$ during \\
A-train overpass to get HSRL-2/RSP curtain/comparison.
\end{tabular}
(RA 4/SS 2/ML 3/ICL 2/ACL 3/STL 1/IPL 2/APL 3)

08/15 9.2 Routine: flight to $15^{\circ} \mathrm{S}$, with main objective to sample Lagrangian start points. Flight altitude first limited due PRF03Y17 to the heavy fuel load. On way back, after waypoint 18 , the $2.5 \mathrm{~km}$ level leg was backtracked and a $3 \mathrm{~km}$ level leg stacked on top of that. This was done because of concern about the low-altitude level legs disappearing into the boundary layer before they could be sampled on subsequent flight.

(RA 2/SS 3/ML 3/ICL 1/ACL 0/STL 2/IPL 9/APL 2)

$08 / 17$

PRF04Y17

9.1 Target: suitcase flight São Tomé to Ascension Island; the objective was to resample air masses from four horizontal legs in flight PRF03Y17. Flight path connected midpoints of legs sampled in PRF03Y17 on their $48 \mathrm{~h}$ trajectories - first, overflight of parcels for lidar sampling, then re-trace of track at projected parcel height after transport, then forward run along the same track near cloud top. Low clouds had largely cleared in the region between WPs 3 and 5, precluding cloud sampling. Due to significant interest in the BL Cu near ASI, the P-3 headed west at $8^{\circ} \mathrm{S}$ (rather than planned 9.7 $\mathrm{S}$ ). Plan was to sample scattered $\mathrm{Cu}$ along $8^{\circ} \mathrm{S}$ between $\sim 8^{\circ} \mathrm{W}$ and Ascension Island. P-3 sampled the BB plume to $7.5^{\circ} \mathrm{W}$ and then descended into the MBL. Sawtooths through the boundary layer. Clouds were seen but time in cloud was insufficient for sampling. On approach to Ascension Island we overflew the ARM site.

(RA 6/SS 2/ML 4/ICL 1/ACL 1/STL 2/IPL 8/APL 2)

\begin{tabular}{lll}
\hline 08/18 $5.5 \quad$ & Target: Ascension Island local; the goal was a coordinated flight with CLARIFY Bae146 to compare aerosol \\
PRF05Y17 & and cloud in situ and radiation measurements. A highly successful coordinated flight, given the difficult cloud \\
& and aerosol forecasts. Bae146 assumed formation during initial climb-out to WP 2. Cloud conditions were very \\
& broken except for the leg between WP 4 and 5, making cloud comparisons limited. Lots of full boundary layer \\
& profiling between WP 10 and 11. Extended HSRL run over the ARM site \\
& (RA 2/SS 0/ML 2/ICL 2/ACL 0/STL 1/IPL 0/APL 2)
\end{tabular}

\begin{tabular}{|c|c|c|}
\hline $\begin{array}{l}\text { 08/19 } \\
\text { PRF06Y17 }\end{array}$ & 2.0 & $\begin{array}{l}\text { Transit: Ascension Island to São Tomé - aborted transit flight, limited set of instrumentation operated. } \\
\text { (RA 0/SS 0/ML 0/ICL 0/ACL 0/STL 0/IPL 1/APL 0) }\end{array}$ \\
\hline $\begin{array}{l}\text { 08/21 } \\
\text { PRF07Y17 }\end{array}$ & 8.3 & $\begin{array}{l}\text { Target: return suitcase flight, Ascension Island to São Tomé; the objective was to measure the west-to-east } \\
\text { transition mostly in the boundary layer. Ranging from "clean above" to "heavier free troposphere pollution } \\
\text { above (and mixing into) low cloud" to the east. Also, sampling on routine flight track. Aircraft maintenance } \\
\text { issue reduced possible flight time to } \sim 8 \mathrm{~h} \text {. Science focus was on three different plume and cloud regimes along } \\
8^{\circ} \mathrm{S} \text { and the routine track (along } 5^{\circ} \mathrm{E} \text { ). Flight featured profiles in very different conditions; low clouds were } \\
\text { more broken than forecast. Cirrus (Ci) on the } 8 \mathrm{~S} \text { track (near } 1^{\circ} \mathrm{E} \text { ). A blob of mid-level clouds and high ACAOD } \\
\left(0.73 \text { ) at } \sim 8^{\circ} \mathrm{S} / 0^{\circ} \mathrm{E} \text {. }\right. \\
\text { (RA 3/SS 3/ML 3/ICL } 2 / \mathrm{ACL} 4 / \mathrm{STL} 1 / \mathrm{IPL} 6 / \mathrm{APL} 3 \text { ) }\end{array}$ \\
\hline
\end{tabular}


Table A2. Continued.

\begin{tabular}{lcl}
\hline $\begin{array}{l}\text { Date } \\
\text { P-3 flight no. }\end{array}$ & $\mathrm{h} \quad \begin{array}{l}\text { Flight synopsis } \\
\text { (ramps, RA; square spirals, SS; MBL legs, ML; in-cloud legs, ICL; above-cloud legs, ACL; sawtooth legs, STL; } \\
\text { in-plume legs, IPL; above-plume legs, APL) }\end{array}$ \\
\hline 08/24 & $9.4 \begin{array}{l}\text { Routine: flight to } 15^{\circ} \mathrm{S} \text { along } 5^{\circ} \mathrm{E} \text { and back with some sampling of initial trajectory lines. High cloud contam- } \\
\text { ination of remote sensing on the northern part of the track. Solid deck at } 15-10^{\circ} \mathrm{S}, \text { then small popcorn Cu to } \\
5^{\circ} \mathrm{S}, \text { and then Sc followed by mid-level cloud. Lightly polluted BL. SDI inlet froze. } \\
\text { (RA 5/SS 2/ML 3/ICL 3/ACL 3/STL 1/IPL 7/APL 3) }\end{array}$ \\
\hline
\end{tabular}

$08 / 26$

PRF09Y17

9.7 Target: the focus was on radiation walls over broken cloud decks of varying albedos and relatively invariant aerosol. Targeted a region with broken low clouds, significant aerosol loading, and free of high clouds. Adjusted target area based on morning forecasts and satellite imagery high $\mathrm{Ci}$ north of $5^{\circ} \mathrm{S}$. Two successful radiation wall modules. Long transit prevented the third planned radiation wall. Many adjustments in flight for cloud conditions. During first radiation wall, low clouds were scattered to broken, no Ci. During the second wall module, significant $\mathrm{Ci}$ contamination for the center part of the legs. Good low clouds for most of the wall. In-plume legs near $2^{\circ} \mathrm{S}$ along the routine track.

(RA 2/SS 4/ML 2/ICL 2/ACL 3/STL 0/IPL 5/APL 3)

$08 / 28$

08/28
PRF10Y17

9.5 Rou

Routine: flight to $15^{\circ} \mathrm{S}$, with a simplified radiation wall, followed by cloud work and stacked aerosol sampling. Absence of $\mathrm{Ci}$ at $11^{\circ} \mathrm{S}$ allowed good square spiral maneuver over mostly solid cloud. Max ACAOD of 0.76 . Extensive cloud sampling.

(RA 3/SS 1/ML 1/ICL 2/ACL 3/STL 2/IPL 4/APL 2)

\begin{tabular}{lll}
\hline 08/30 8.9 & $\begin{array}{l}\text { Routine: the objective was routine flight, but not reaching as far south and allowing for a full radiation wall } \\
\text { PRF11Y17 }\end{array}$ \\
& (less cloud work and more above-cloud legs than on 28 August flight), and includes sampling of fresh aerosol \\
& and trajectory initialization points. HSRL-2 failure removed need for initial high-altitude leg; instead, sampled \\
& within the aerosol plume to $13^{\circ} \mathrm{S}$. Because of Ci, performed radiation wall at $8 \mathrm{~S}$. Sampled the plume south- \\
& bound between 4 and $10^{\circ} \mathrm{S}$ at $3.5 \mathrm{~km}$ altitude and northbound between 7 and $3^{\circ} \mathrm{S}$ at $3.0 \mathrm{~km}$ altitude. \\
& (RA 2/SS 3/ML 1/ICL 1/ACL $1 / \mathrm{STL} \mathrm{0/IPL} \mathrm{8/APL} \mathrm{2)}$
\end{tabular}

$09 / 02$

PRF13Y17
8.7 Transit: São Tomé to Ascension Island - the objective was to measure BB aerosol at the northern end of the study area, possibly affected by wet convection; get AERONET-like retrieval from 4STAR in a mix of biomass burning smoke and dust, supplemented with in situ and HSRL measurements. Also, sample near ASI where previously sampled air masses may be present. Got one radiation spiral each without and with some dust present. Near ASI, high-altitude HSRL legs, plume leg, and above-cloud leg. Series of legs to study cloudy region just to NE of ASI.

(RA 4/SS 6/ML 1/ICL 1/ACL 5/STL 1/IPL 6/APL 4) 
Table A3. The 2018 flight summary for the P-3 aircraft.

\begin{tabular}{|c|c|c|}
\hline $\begin{array}{l}\text { Date } \\
\text { P-3 no. }\end{array}$ & $\mathrm{h}$ & $\begin{array}{l}\text { Flight synopsis } \\
\text { (ramps, RA; square spirals, SS; MBL legs, ML; in-cloud legs, ICL; above-cloud legs, ACL; sawtooth legs, STL; } \\
\text { in-plume legs, IPL; above-plume legs, APL) }\end{array}$ \\
\hline $\begin{array}{l}\text { 09/24 } \\
\text { PRF00Y18 }\end{array}$ & 9.3 & $\begin{array}{l}\text { Transit: Cabo Verde to São Tomé; mostly transit flight at high altitude, but some in situ sampling near São } \\
\text { Tomé. } \\
\text { (RA 0/SS 2/ML 1/ICL 1/ACL 1/STL 0/IPL 1/APL 2) }\end{array}$ \\
\hline $\begin{array}{l}\text { 09/27 } \\
\text { PRF01Y18 }\end{array}$ & 8.0 & $\begin{array}{l}\text { Routine: flight along } 5^{\circ} \mathrm{E} \text { to } 13^{\circ} \mathrm{S} \text {. High-altitude transit out, square spiral down at } 13^{\circ} \mathrm{S} \text {, followed by three } \\
\text { samples of the cloudy boundary layer on the way back north, with the most northern one being at } \sim 5^{\circ} \mathrm{S} \text {. } \\
\text { Strong aerosol layering south of } 5^{\circ} \mathrm{S} \text {, fairly clean to the north. Little aerosol right above cloud top. } \\
\text { (RA 3/SS 2/ML 2/ICL 1/ACL 1/STL 3/IPL 4/APL 2) }\end{array}$ \\
\hline
\end{tabular}

\begin{tabular}{lll}
\hline 09/30 & Target: the objective was radiation work near 7-9 ${ }^{\circ} \mathrm{S}$ in radiation wall patterns over broken cloud decks of \\
PRF02Y18 & varying albedos and (nominally) relatively invariant aerosol. Coordinated with MISR local mode. Square spiral \\
& near $7.5^{\circ} \mathrm{S}$, well coordinated with MISR overpass, in an area of solid low cloud cover. Hit CALIPSO overpass \\
& for RSP; got on their track $\sim 8$ min after satellite overpass. \\
& (RA 4/SS 1/ML 3/ICL 0/ACL 1/STL 2/IPL 5/APL 4)
\end{tabular}

10/02 8.5 Routine: the goal was a flight to $10^{\circ} \mathrm{S}$, with setup of BL Lagrangian sampling in PRF04. At approximately PRF03Y18 $6.7^{\circ} \mathrm{S}$, found a transition from closed cells to pockets of open cells (POCs). AOD $\sim 0.45$. Square spiral at $10.5^{\circ} \mathrm{S}$. Boundary layer quite clean with a few big particles, low $\mathrm{CN}, \mathrm{CO}<70 \mathrm{ppb}$, and $\mathrm{O}_{3}<20 \mathrm{ppb}$. A series of 2.5 dull sawtooths, with a clean slot right above the cloud $(\sim 200 \mathrm{ft} / 0.06 \mathrm{~km})$. Several constant-altitude legs with high CCN.

(RA 3/SS 3/ML 2/ICL 1/ACL 3/STL 2/IPL 3/APL 4)

\begin{tabular}{ll}
\hline 10/03 8.5 & Target: Lagrangian resampling of POCs sampled on PRF03; closed cells present on the transit from São Tomé \\
PRF04Y18 & to $5^{\circ} \mathrm{E}, 7.5^{\circ} \mathrm{S}$. East of $6^{\circ} \mathrm{E}$ along $7.5^{\circ} \mathrm{S}$, a large region of open cells with significantly lower cloud fraction; \\
& FT plume was extensive aloft above both the POC and the surrounding closed cells. Clear evidence of smoke \\
& aerosol being present immediately above clouds in closed and open cell regions. \\
& (RA 4/SS 4/ML 2/ICL 1/ACL 2/STL 2/IPL 4/APL 2)
\end{tabular}

10/05 9.0 Target: the objective was radiation work at high solar zenith; radiation wall between $5.5^{\circ} \mathrm{E}$ and $7^{\circ} \mathrm{W}$ on $9.5^{\circ} \mathrm{S}$;

PRF05Y18 incl. high-altitude overpass; square spiral from $\sim 6 \mathrm{~km}$ to surface in mostly cloudy conditions; above-cloud, in-cloud, below-cloud leg; three vertically stacked in situ sampling legs in the plume. Second similar maneuver in almost clear conditions. Boundary layer most polluted so far in ORACLES 2018. Cloud droplet number concentrations accordingly elevated. Appeared to be a more aged plume than other days in ORACLES 2018. Good case for radiative closure: two square spirals in different conditions, the full radiation wall, moderate RH in the plume. (RA 4/SS 3/ML 4/ICL 2/ACL 3/STL 0/IPL 5/APL 5)

10/07 8.4 Routine: flight to $15^{\circ} \mathrm{S}$. During transit to $15^{\circ} \mathrm{S}$ north-south slope in Sc cloud top heights from 2 to $7^{\circ} \mathrm{S}$ with PRF06Y18 sloping aerosol layers above. From 10 to $15^{\circ} \mathrm{S}$ mid-level clouds at the top of the outflow plume, embedded in the plume. Boundary layer work between 12 and $9.5^{\circ} \mathrm{S}-$ fairly polluted BL. Extended run at $8 \mathrm{kft}(2.4 \mathrm{~km})$, clear slot at $9^{\circ} \mathrm{S}$ for square spiral and radiation work. This spiral happened in the most cloud-free conditions encountered in ORACLES-2018. Extended leg $(1 \mathrm{~h}+)$ at $8 \mathrm{kft}(2.4 \mathrm{~km})$, during transit home. (RA 6/SS 2/ML 3/ICL 1/ACL 2/STL 1/IPL 4/APL 5)

10/10 8.3 Routine: the plan was for a flight to $13^{\circ} \mathrm{S}$ along $5^{\circ} \mathrm{E}$. Three samples of polluted boundary layer allow for the PRF07Y18 possibility of Lagrangian sampling on 12 October. Square spiral nearly to surface at $13^{\circ} \mathrm{S}$. Cloud sampling south of $10^{\circ} \mathrm{S}$. Sampling aerosol layer at $13 \mathrm{kft}(4.0 \mathrm{~km})$ between 9 and $10^{\circ} \mathrm{S}$. Long boundary layer sequence, starting at $7.5^{\circ} \mathrm{S}$. Aerosol and boundary layer work near $4.5^{\circ} \mathrm{S}$. Aerosol at southern end of track up to $19.5 \mathrm{kft}$ $(5.9 \mathrm{~km})$.

(RA 6/SS 3/ML 4/ICL 2/ACL 3/STL 2/IPL 4/APL 3)

$10 / 12$

PRF08Y18
5.3 Target: the objective was Lagrangian follow-up and cloud profiling. Engine issue delayed departure; flight duration shortened by $\sim 3 \mathrm{~h}$. Outbound transit straight south of São Tomé to initial point at $2.5^{\circ} \mathrm{S}, 6.5^{\circ} \mathrm{E}$ where trajectory indicated resampling of boundary layer air. Square spiral at $2^{\circ} \mathrm{S} / 5.75^{\circ} \mathrm{E}$. Boundary layer sampling, followed by sawtooth sampling through decoupled cloud layers (stratus above $\mathrm{Cu}$ ). Cloud patch thicker and precipitating at the north end of the runs. Quite clean conditions just above cloud. More cloud work at $4.5^{\circ} \mathrm{S}$, $5.5^{\circ} \mathrm{E}$. Ensuing run northbound crossed distinct boundary between clear and polluted air, with corresponding changes in cloud properties.

(RA 2/SS 2/ML 3/ICL 1/ACL 5/STL 2/IPL 2/APL 1) 
Table A3. Continued.

\begin{tabular}{|c|c|c|}
\hline $\begin{array}{l}\text { Date } \\
\text { P-3 no. }\end{array}$ & $\mathrm{h}$ & $\begin{array}{l}\text { Flight synopsis } \\
\text { (ramps, RA; square spirals, SS; MBL legs, ML; in-cloud legs, ICL; above-cloud legs, ACL; sawtooth legs, STL; } \\
\text { in-plume legs, IPL; above-plume legs, APL) }\end{array}$ \\
\hline $\begin{array}{l}\text { 10/15 } \\
\text { PRF09Y18 }\end{array}$ & 7.8 & $\begin{array}{l}\text { Routine: the plan was for a flight to } 14^{\circ} \mathrm{S} \text {. During southbound transit, minimal direct contact between smoke } \\
\text { and Sc at } 3-9^{\circ} \mathrm{S} \text {. Heavily precipitating Sc clouds at } 5^{\circ} \mathrm{S} \text {. Two regions with plume bottom/cloud top gap }\left(8.5^{\circ} \mathrm{S}\right) \\
\text { and no gap }\left(9.5^{\circ} \mathrm{S}\right) \text { in relative close proximity. Significant drizzle between } 11 \text { and } 13^{\circ} \mathrm{S} \text {. Square spiral at } 14^{\circ} \mathrm{S} \text {; } \\
\text { geometrically thin high smoke loading layer at } 13 \mathrm{kft}(4.0 \mathrm{~km}) \text {, broken Sc. Very clean BL, low cloud bases } 500 \mathrm{ft} \\
(0.15 \mathrm{~km}) \text {. During sawtooth northbound, clouds thickening, peak above-cloud smoke at } 12.4^{\circ} \mathrm{S} \text {, dropping to the } \\
\mathrm{N} \text {. Second set of sawtooth patterns contrasting } 9.5 \text { and } 8.5^{\circ} \mathrm{S}-\text { smoke near cloud top at } 9.5 \text { and gap at } 8.5^{\circ} \mathrm{S} \text {. } \\
\text { Circular spiral descent at } 5.5^{\circ} \mathrm{S} \text {. } \\
\text { (RA 1/SS } 2 / \mathrm{ML} 2 / \mathrm{ICL} 0 / \mathrm{ACL} 3 / \mathrm{STL} 2 / \mathrm{IPL} \text { 4/APL 4) }\end{array}$ \\
\hline $\begin{array}{l}\text { 10/17 } \\
\text { PRF10Y18 }\end{array}$ & 8.5 & $\begin{array}{l}\text { Target: young plume near } 7^{\circ} \mathrm{S} / 10^{\circ} \mathrm{E} \text {. At } 10.5^{\circ} \mathrm{E}, 7^{\circ} \mathrm{S} \text { still featured mid-level clouds. Opted to change order } \\
\text { radiation wall/spiral module, aerosol in situ legs first (highest altitude layer to lowest altitude layer); then below, } \\
\text { in- and above-cloud legs; then square spiral up. Highest aerosol concentrations encountered yet, found in the } \\
\text { lower free troposphere. } \\
\text { (RA 0/SS 5/ML 1/ ICL 1/ACL 2/STL 0/IPL 9/APL 5) }\end{array}$ \\
\hline $\begin{array}{l}\text { 10/19 } \\
\text { PRF11Y18 }\end{array}$ & 8.0 & $\begin{array}{l}\text { Target: the objective was to sample young plume near the coast } 7^{\circ} \mathrm{S} / 10^{\circ} \mathrm{E} \text {. Moved north-south sampling further } \\
\text { north and west to avoid high cirrus. Evidence of very clean air directly above clouds. Did not find fresh plume } \\
\text { near Bight of Angola, ACAOD only } \sim 0.27 \text {. Two square spirals near each other, one over clear skies, the } \\
\text { other over partially cloudy. The bottom of one square spiral had a ship and its plume. Clean MBL, and ultra- } \\
\text { clean above clouds. Underflight of partial cloudy skies - high potential of 3D cloud-aerosol radiative effect. } \\
\text { Good in situ sampling, while in cloud (TDMA + CVI), indication of large aerosols. High cloud droplet number } \\
\text { concentrations were observed near cloud bases (opposite of what has been observed in the past). } \\
\text { (RA 5/SS 4/ML 3/ICL 1/ACL 5/STL 1/IPL 7/APL 6) }\end{array}$ \\
\hline $\begin{array}{l}\text { 10/21 } \\
\text { PRF12Y18 }\end{array}$ & 8.2 & $\begin{array}{l}\text { Routine: the plan was to reach as far south as possible again; during southbound transit, FT BB aerosol plume } \\
\text { tendril-like structure with numerous layers overlapping; interesting wave-like structure in low clouds from } 1.9- \\
3^{\circ} \mathrm{S} \text {, with wavelength of } \sim 100 \mathrm{~km} \text {; evidence of N-S mesoscale banding in Sc cloud layer below; at } 13.5^{\circ} \mathrm{S}- \\
\text { square spiral to } 200 \mathrm{ft}(0.06 \mathrm{~km} \text { ). Plume concentrations all around half of typical values. Ultra-large particles } \\
\text { detected on descent. Aerosol well aged in lower part of plume. Multiple sawtooth patterns for cloud work and } \\
\text { level legs in plume. } \\
\text { (RA 8/SS 1/ML 6/ICL 2/ACL 2/STL 2/ IPL 6/APL 5) }\end{array}$ \\
\hline $\begin{array}{l}\text { 10/23 } \\
\text { PRF13Y18 }\end{array}$ & 8.1 & $\begin{array}{l}\text { Target: the plan was for a survey flight going west along } 5^{\circ} \mathrm{S} \text {. Only flight with significant boundary layer cloud } \\
\text { sampling to the west of } 5^{\circ} \mathrm{E} \text {. Four sawtooths through double-layered stratocumulus in which the lower layer } \\
\text { cloud droplet number concentrations exceeded those in the upper layer. Generally low ACAOD of } 0.19 \text { max. } \\
\text { (RA 2/SS 2/ML 3/ICL 0/ACL 4/STL 3/IPL 4/APL 3) }\end{array}$ \\
\hline $\begin{array}{l}\text { 10/25 } \\
\text { PRF14Y18 }\end{array}$ & 7.8 & $\begin{array}{l}\text { Transit: São Tomé to Cabo Verde; survey flight going west. High-altitude along } 5^{\circ} \mathrm{E} \text { to } 5^{\circ} \mathrm{S} \text {, then turn west, } \\
\text { out to } 3^{\circ} \mathrm{W} \text { along } 5^{\circ} \mathrm{S} \text {. Three samples of the cloudy boundary layer on the way back. Four sawtooths through } \\
\text { double-layered stratocumulus; lower layer cloud droplet number concentrations exceeded those in the upper } \\
\text { layer. Square spiral at } 3^{\circ} \mathrm{W} \text {. } \\
\text { (RA } 1 / \mathrm{SS} 1 / \mathrm{ML} 1 / \mathrm{ICL} 0 / \mathrm{ACL} 0 / \mathrm{STL} 0 / \mathrm{IPL} \text { 0/APL 3) }\end{array}$ \\
\hline $15 / 15$ & 121.4 & \\
\hline
\end{tabular}


Figure A1 shows the distribution of flight times dedicated to the various flight maneuvers described in Table 5 in each of the three ORACLES deployments. While broadly similar, there are a few notable distinctions: 2017 and 2018 featured significantly fewer ramp descents, relatively less time just above cloud top, and more time dedicated to square spiral descents. Also, 2017 and 2018 entailed more sawtooth profiling through clouds than time spent in level legs within clouds. These changes represent an evolution in the thinking regarding the best flight maneuvers to address various cloudand radiation-related science objectives from the first to the second and third deployment.

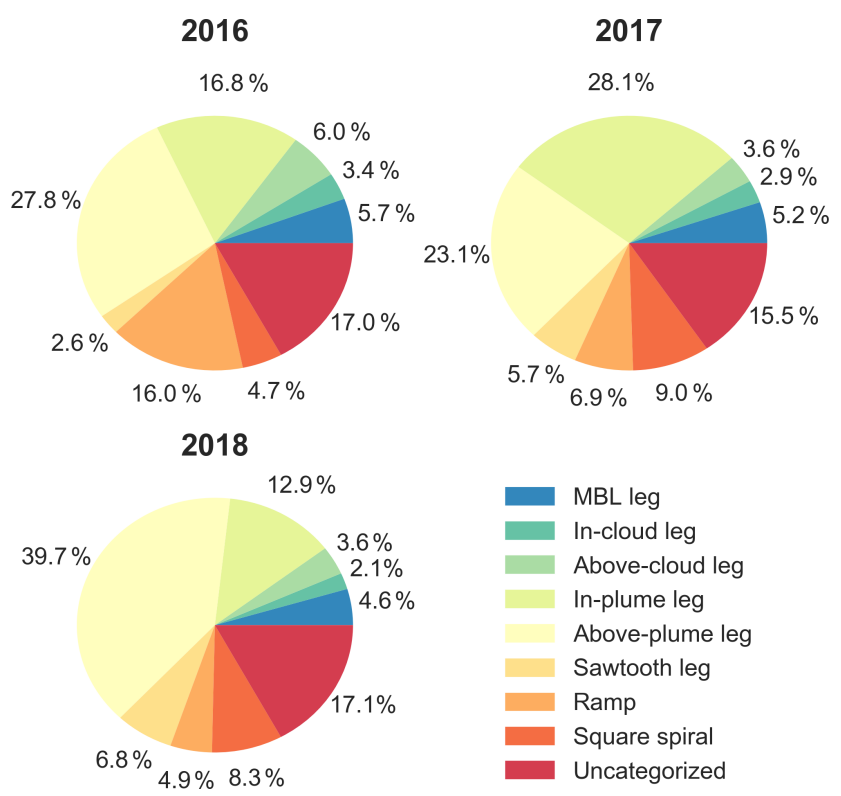

Figure A1. Distribution of flight time between flight maneuvers for each ORACLES deployment year. 


\section{Appendix B: Choice of instrumentation}

Table B1. P-3 instrumentation in ORACLES (bold entries indicate quantities submitted to the ORACLES archive; see ORACLES Science Team, 2020a-d, in the list of references).

\begin{tabular}{|c|c|c|c|}
\hline $\begin{array}{l}\text { Instrument } \\
\text { name/operating } \\
\text { organization }\end{array}$ & $\begin{array}{l}\text { Instrument description/key } \\
\text { specification }\end{array}$ & Primary measurement & $\begin{array}{l}\text { Measurements/derived quantities/inversion } \\
\text { products }\end{array}$ \\
\hline \multicolumn{4}{|l|}{ Remote sensing } \\
\hline \multirow[t]{4}{*}{ 4STAR/NASA ARC } & \multirow{4}{*}{$\begin{array}{l}\text { Hyperspectral sun/sky pho- } \\
\text { tometer }(400-1600 \mathrm{~nm}, \sim 1 \mathrm{~nm} \\
\text { res.) }\end{array}$} & \multirow{2}{*}{$\begin{array}{l}\text { 1. Direct solar beam hyperspectral transmit- } \\
\text { tance }\end{array}$} & 1. Spectral AOD \\
\hline & & & 2. Column $\mathrm{O}_{3}, \mathrm{H}_{2} \mathrm{O}, \mathrm{NO}_{2}$ \\
\hline & & 2. Sky radiance & $\begin{array}{l}\text { 3. Aerosol microphysics (e.g., size distribution, } \\
\text { refr. index, absorption, scattering phase func- } \\
\text { tion) }\end{array}$ \\
\hline & & 3. Hyperspectral cloud zenith transmittance & $\begin{array}{l}\text { 4. Cloud optical depth, } r_{\text {eff }} \text {, liquid water path, } \\
\text { thermodynamic phase }\end{array}$ \\
\hline \multirow[t]{3}{*}{ RSP/NASA GISS } & \multirow{3}{*}{$\begin{array}{l}\text { Measurements at } 410,470,555, \\
670,865,960,1590,1880, \text { and } \\
2260 \mathrm{~nm} \text { with polarimetric ac- } \\
\text { curacy of } \sim 0.15 \%\end{array}$} & Stokes parameters $I, Q$, and $U$ of reflected light & 1. Aerosol microphysics, layer height, and AOD \\
\hline & & Measurements are over $\pm 60^{\circ}$ from nadir & $\begin{array}{l}\text { 2. Water COD, droplet size distribution at cloud } \\
\text { top, bulk effective radius, top height, physical } \\
\text { thickness, } N_{\mathrm{c}}\end{array}$ \\
\hline & & & 3. Chl, CDOM conc. and backscatter coeff. \\
\hline \multirow[t]{4}{*}{ AMPR/NASA MSFC } & \multirow{4}{*}{$\begin{array}{l}\text { Advanced Microwave Precipi- } \\
\text { tation Radiometer } \\
\text { four-frequency }(10.7, \quad 19.35 \text {, } \\
37.1 \text {, and } 85.5 \mathrm{GHz}) \text {, cross- } \\
\text { track scanning, polarization- } \\
\text { variable microwave radiometer }\end{array}$} & \multirow[t]{4}{*}{ Polarized brightness temperatures } & 1. Precipitation rate \\
\hline & & & \\
\hline & & & 2. Liquid water path \\
\hline & & & 3. Ocean SST, winds \\
\hline \multirow{3}{*}{$\begin{array}{l}\text { SSFR, CG-4 } \\
\text { /NASA ARC, CU } \\
\text { LASP }\end{array}$} & \multirow{3}{*}{$\begin{array}{l}\text { Solar Spectral Flux Radiome- } \\
\text { ter }(350-2100 \mathrm{~nm} \text { shortwave ir- } \\
\text { radiance, spectral sampling } 4- \\
8 \mathrm{~nm}) \\
\text { CG-4 (longwave irradiance } 4- \\
40 \mu \mathrm{m})\end{array}$} & \multirow[t]{3}{*}{ Spectral solar irradiance } & 1. Cloud and aerosol radiative effects \\
\hline & & & $\begin{array}{l}\text { 2. Spectral and broadband absorption and heat- } \\
\text { ing rate, aerosol SSA from flux divergence }\end{array}$ \\
\hline & & & $\begin{array}{l}\text { 3. Cloud phase, OD, } r_{\text {eff }} \text { (from albedo and trans- } \\
\text { mittance) }\end{array}$ \\
\hline \multirow[t]{4}{*}{ APR3 } & \multirow[t]{4}{*}{$\begin{array}{l}\text { Three-frequency cloud and } \\
\text { precipitation Doppler scanning } \\
\text { radar }(\mathrm{Ku}, \mathrm{Ka} \text {, and } \mathrm{W} \text { band })\end{array}$} & 1. Cloud and precipitation backscatter & Rain water content and precipitation rate \\
\hline & & $\begin{array}{l}\text { 2. Cloud and precipitation differential backscat- } \\
\text { ter }\end{array}$ & Hydrometeor size (precipitation class) \\
\hline & & 3. Cloud and precipitation Doppler velocity & Hydrometeor classification (dominant) \\
\hline & & 4. Path-integrated attenuation & Vertical air velocity in precipitation \\
\hline
\end{tabular}


Table B1. Continued.

\begin{tabular}{|c|c|c|c|}
\hline $\begin{array}{l}\text { Instrument } \\
\text { name/operating } \\
\text { organization }\end{array}$ & $\begin{array}{l}\text { Instrument description/key } \\
\text { specification }\end{array}$ & Primary measurement & $\begin{array}{l}\text { Measurements/derived quantities/inversion } \\
\text { products }\end{array}$ \\
\hline \multicolumn{4}{|l|}{ Cloud in situ } \\
\hline \multirow[t]{3}{*}{ CAPS/UND } & $\begin{array}{l}\text { 1. Cloud imaging probe }- \text { op- } \\
\text { tical array probe }(25-1600 \mu \mathrm{m} \text {, } \\
25 \mu \mathrm{m} \text { res.) }\end{array}$ & Cloud particle images & $\begin{array}{l}\text { Number distribution function, nominally be- } \\
\text { tween } 25-1600 \mu \mathrm{m} \text {, particle images from which } \\
\text { other parameters can be derived: total concen- } \\
\text { tration, liquid water content, etc. }\end{array}$ \\
\hline & $\begin{array}{l}\text { 2. Cloud and Aerosol Spec- } \\
\text { trometer }(\mathrm{CAS} \text {, forward scatter- } \\
\text { ing) }(0.53-50 \mu \mathrm{m}, 1 \mu \mathrm{m} \text { nomi- } \\
\text { nal res.) }\end{array}$ & Number size distribution & $\begin{array}{l}\text { Number distribution function between } 0.53 \text { and } \\
50 \mu \mathrm{m} \text {, from which liquid water content, effec- } \\
\text { tive radius, and other parameters can be derived }\end{array}$ \\
\hline & $\begin{array}{l}\text { 3. Liquid water content (LWC) } \\
\text { sensor }\left(0-3 \mathrm{~g} \mathrm{~m}^{-3}\right) \text {, not opera- } \\
\text { tional }\end{array}$ & Liquid water content & Bulk liquid water content \\
\hline CDP/UND & $\begin{array}{l}\text { Forward scattering }(2-50 \mu \mathrm{m}, \sim \\
2 \mu \mathrm{m} \text { res. })\end{array}$ & Number size distribution & \multirow[t]{3}{*}{$\begin{array}{l}\text { Number distribution function between } 3 \text { and } \\
50 \mu \mathrm{m} \text {, from which liquid water content, effec- } \\
\text { tive radius, and other parameters can be derived }\end{array}$} \\
\hline CDP/LARC & $\begin{array}{l}\text { Cloud droplet probe } \\
\text { forward scattering }(2-50 \mu \mathrm{m}, \sim \\
2 \mu \mathrm{m} \text { res.) }\end{array}$ & Number size distribution & \\
\hline CDP/HiGEAR & $\begin{array}{l}\text { Cloud droplet probe } \\
\text { forward scattering }(2-50 \mu \mathrm{m}, \sim \\
2 \mu \mathrm{m} \text { res.) }\end{array}$ & Number size distribution & \\
\hline King/UND & $\begin{array}{l}\text { Hot wire liquid water }(0- \\
\left.5 \mathrm{~g} \mathrm{~m}^{-3}\right)\end{array}$ & Liquid water content & Bulk liquid water content \\
\hline 2-DS/ UND & $\begin{array}{l}\text { Two-dimensional stereo probe } \\
\text { optical array probe (10- } \\
1280 \mu \mathrm{m}, 10 \mu \mathrm{m} \text { res.) }\end{array}$ & Cloud particle images & $\begin{array}{l}\text { Number distribution function, nominally be- } \\
\text { tween } 10-1280 \mu \mathrm{m} \text {, and particle images from } \\
\text { which other parameters can be derived (total } \\
\text { concentration, liquid water content, etc.) }\end{array}$ \\
\hline HVPS-3/ UND & $\begin{array}{l}\text { High Volume Precipitation } \\
\text { Spectrometer } \\
\text { optical array probe (150- } \\
19200 \mu \mathrm{m}, 150 \mu \mathrm{m} \text { res.) }\end{array}$ & Cloud particle images & $\begin{array}{l}\text { Number distribution function, nominally be- } \\
\text { tween } 150-19200 \mu \mathrm{m} \text {, and particle images from } \\
\text { which total concentration and rain water content } \\
\text { can be derived }\end{array}$ \\
\hline \multirow[t]{4}{*}{$\begin{array}{l}\text { FPDR-PDI/Univ. } \\
\text { Hawaii }\end{array}$} & \multirow[t]{4}{*}{$\begin{array}{l}\text { Cloud droplet size and velocity } \\
\text { measurements }\end{array}$} & \multirow[t]{4}{*}{ Droplet size and arrival time } & 1. Droplet size $(\mu \mathrm{m})$ and arrival time $(\mu \mathrm{s})$ \\
\hline & & & 2. $N_{\mathrm{c}}\left(\# \mathrm{~cm}^{-3}\right)$ \\
\hline & & & 3. Derived LWC $\left(\mathrm{g} \mathrm{m}^{-3}\right)$ \\
\hline & & & 4. Droplet velocity $\left(\mathrm{ms}^{-1}\right)$ \\
\hline
\end{tabular}


Table B1. Continued.

\begin{tabular}{|c|c|c|c|}
\hline $\begin{array}{l}\text { Instrument } \\
\text { name/operating } \\
\text { organization }\end{array}$ & $\begin{array}{l}\text { Instrument description/key } \\
\text { specification }\end{array}$ & Primary measurement & $\begin{array}{l}\text { Measurements/derived quantities/inversion } \\
\text { products }\end{array}$ \\
\hline \multicolumn{4}{|l|}{ Aerosol in situ } \\
\hline \multirow[t]{8}{*}{ HiGEAR/Univ. Hawaii } & $\begin{array}{l}\text { TSI } 3321 \text { APS (0.8 to } 5 \mu \mathrm{m} \\
\text { aerodynamic) } \\
\text { DMT UHSAS ( } 70 \text { to } 1000 \mathrm{~nm} \\
\text { optical) } \\
\text { Modified TSI long SMPS (10- } \\
550 \mathrm{~nm}) \\
\text { Custom TSI thermal tandem } \\
\text { SMPS ( } 10 \text { to } 200 \mathrm{~nm} \text { ) }\end{array}$ & $\begin{array}{l}\text { Dry number size distributions } \\
\text { Particle volatility }\end{array}$ & \multirow[t]{2}{*}{$\begin{array}{l}\text { Number, area, volume distributions, } \mathrm{CCN} \text { con- } \\
\text { centration (indirect) }\end{array}$} \\
\hline & $\begin{array}{l}\text { TSI } 3025 \mathrm{~A} \text { ultrafine } \mathrm{CN} \\
\text { counter }(1-3000 \mathrm{~nm})\end{array}$ & Total particle concentration & \\
\hline & $\begin{array}{l}\text { TSI } 3010 \mathrm{CN} \text { counters }(3- \\
3000 \mathrm{~nm} \text {, ambient and denuded } \\
\left.\text { to } 400^{\circ} \mathrm{C}\right)\end{array}$ & Total particle concentration & Internal/external mixing \\
\hline & $\begin{array}{l}\text { TSI } 3563 \text { three-wavelength } \\
\text { nephelometers }\end{array}$ & $\begin{array}{l}\text { Dry particle scattering coefficient, backscatter- } \\
\text { ing @ } 450,550,700 \mathrm{~nm}\end{array}$ & $\begin{array}{l}\text { SSA, scat. Ångstr. exp., abs. Ångstr. exp., ex- } \\
\text { tinction (@ 470,530,660 nm) }\end{array}$ \\
\hline & $\begin{array}{l}\text { Paired Radiance Research } \\
\text { M901 nephelometers, one with } \\
\text { humidity-controlled inlet } \\
\text { Two Radiance Research } \\
\text { three-wavelength PSAPs }\end{array}$ & $\begin{array}{l}\text { Wet vs. dry scattering @ } 550 \mathrm{~nm} \\
\text { Particle light absorption }\end{array}$ & \\
\hline & \multirow[t]{2}{*}{$\begin{array}{l}\text { DMT SP2 (Single Particle Soot } \\
\text { Photometer, four-channel, } 90- \\
500 \mathrm{~nm}) 2016 \text { only }\end{array}$} & Refractory black carbon concentration, & $\mathrm{BC}$ concentration \\
\hline & & Refractory black carbon mass & $\mathrm{BC}$ mass distribution, $\mathrm{BB}$ tracer \\
\hline & $\begin{array}{l}\text { Aerodyne HR-ToF-aerosol } \\
\text { mass spectrometer (AMS) }\end{array}$ & Non-refractory aerosol composition & $\begin{array}{l}\text { Sulfates, nitrates, organics, chloride, BB tracer, } \\
\text { pollution tracer }\end{array}$ \\
\hline PCASP/UND & $\begin{array}{l}\text { Passive Cavity Aerosol Spec- } \\
\text { trometer Probe }\end{array}$ & Forward scattering $(0.1-3 \mu \mathrm{m}, \sim 0.1 \mu \mathrm{m}$ res. $)$ & $\begin{array}{l}\text { Aerosol number distribution function between } \\
0.1 \text { and } 3 \mu \mathrm{m} \text {, from which total concentration } \\
\text { can be derived }\end{array}$ \\
\hline AFS/NASA ARC & $\begin{array}{l}\text { Aerosol filter system, collecting } \\
\text { various filters for offline analy- } \\
\text { sis (2017-2018) }\end{array}$ & & $\begin{array}{l}\text { TEM-EDX/SEM-EDX analysis for single par- } \\
\text { ticle size, mixing state and elemental composi- } \\
\text { tion, bulk BrC, and bulk soluble ions }\end{array}$ \\
\hline \multirow[t]{3}{*}{ PTI/BNL } & \multirow{3}{*}{$\begin{array}{l}\text { 2016, 2018: photothermal } \\
\text { interferometer }(532 \mathrm{~nm}) \\
\text { 2017-2018: DMT Single } \\
\text { Particle Soot Photometer } \\
\text { (SP2; eight-channel, refractory } \\
\text { black carbon particle mass } \\
80-500 \mathrm{~nm} \text {, mass equivalent } \\
\text { diameter) }\end{array}$} & \multirow[t]{3}{*}{$\begin{array}{l}\text { Aerosol light absorption at } 532 \mathrm{~nm} \text {; } \\
\text { refractory black carbon }(\mathrm{rBC}) \text { particle mass }\end{array}$} & 1. Absorption coefficient $\left(\mathrm{M} \mathrm{m}^{-1}\right)$ \\
\hline & & & \\
\hline & & & $\begin{array}{l}\text { 2. Refractory black carbon (rBC) mass loading } \\
\left(\mathrm{ng} \mathrm{m}^{-3}\right) \text { and number size distributions }\end{array}$ \\
\hline GIT CCN instrument & $\begin{array}{l}\mathrm{CCN} \text { concentrations/spectra at } \\
\text { cloud-relevant supersaturation }\end{array}$ & $\begin{array}{l}\mathrm{CCN} \text { concentration }(0.15 \%-0.6 \%) \text { water vapor } \\
\text { supersaturation }\end{array}$ & $\begin{array}{l}\text { CCN spectra, cloud effective supersaturation, } \\
\text { aerosol hygroscopicity, droplet growth kinetics }\end{array}$ \\
\hline
\end{tabular}


Table B1. Continued.

\begin{tabular}{|c|c|c|c|}
\hline $\begin{array}{l}\text { Instrument } \\
\text { name/operating } \\
\text { organization }\end{array}$ & $\begin{array}{l}\text { Instrument description/key } \\
\text { specification }\end{array}$ & Primary measurement & $\begin{array}{l}\text { Measurements/derived quantities/inversion } \\
\text { products }\end{array}$ \\
\hline \multicolumn{4}{|l|}{ Gases in situ } \\
\hline COMA/NASA ARC & Trace gas detector & In situ measurement of gas-phase $\mathrm{CO}$ and $\mathrm{H}_{2} \mathrm{O}$ & $\begin{array}{l}\text { 1. } \mathrm{CO} \text { mixing ratio } \\
\text { 2. } \mathrm{H}_{2} \mathrm{O} \text { mixing ratio }\end{array}$ \\
\hline \multirow[t]{3}{*}{$\begin{array}{l}\text { WISPER/OSU } \\
\text { isotopes }\end{array}$} & $\begin{array}{l}\text { In situ gas-phase cavity ring- } \\
\text { down water vapor isotopic ana- } \\
\text { lyzers (Picarro model L2120-fi) } \\
\text { coupled to isokinetic and CVI } \\
\text { inlets. }\end{array}$ & 1. Total $\mathrm{H}_{2} \mathrm{O}$ mixing ratio, $\delta^{18} \mathrm{O}$, and $\delta \mathrm{D}$ & $\begin{array}{l}\text { 1. Cloud droplet and rain evaporation propor- } \\
\text { tion }\end{array}$ \\
\hline & & $\begin{array}{l}\text { 2. Condensed water content (liquid }+ \text { ice) } \\
\left(\mathrm{g} \mathrm{m}^{-3}\right), \delta^{18} \mathrm{O} \text {, and } \delta \mathrm{D}\end{array}$ & $\begin{array}{l}\text { 2. Bulk air mass mixing state and entrainment } \\
\text { rate. }\end{array}$ \\
\hline & & 3. CVI enhancement for residual aerosol & $\begin{array}{l}\text { 3. Cloud base and cloud top water mass flux } \\
\text { when combined with winds }\end{array}$ \\
\hline \multicolumn{4}{|l|}{ Winds } \\
\hline $\begin{array}{l}\text { Vertical winds/NASA } \\
\text { Langley }\end{array}$ & $\begin{array}{l}\text { Vertical winds calculated from } \\
\text { five hole flush port radome sys- } \\
\text { tem/aircraft inertial navigation } \\
\text { system }\end{array}$ & 1. Fast response $(20 \mathrm{~Hz})$ vertical winds & $\begin{array}{l}\text { 1. If combined with another fast response mea- } \\
\text { surement, can provide vertical fluxes of that } \\
\text { species }\end{array}$ \\
\hline
\end{tabular}


Table B2. ER-2 instruments in ORACLES 2016.

\begin{tabular}{|c|c|c|c|}
\hline $\begin{array}{l}\text { Instrument } \\
\text { name/operating } \\
\text { organization }\end{array}$ & $\begin{array}{l}\text { Instrument description } / \mathrm{k} \\
\text { specification }\end{array}$ & Primary measurement & Measurements/derived quantities \\
\hline $\begin{array}{lr}\text { eMAS } & \text { (Enhanced } \\
\text { MODIS } & \text { Airborne } \\
\text { Simulator) } & \end{array}$ & $\begin{array}{l}\text { 38-channel multi- } \\
\text { spectral line scanner }\end{array}$ & $\begin{array}{l}\text { Solar reflective and thermal emissive } \\
\text { energy in the } 0.46-14 \mu \mathrm{m} \text { range }\end{array}$ & $\begin{array}{l}\text { Cloud optical properties (phase, opti- } \\
\text { cal thickness, effective radius, and wa- } \\
\text { ter path); cloud top properties (tem- } \\
\text { perature, pressure, height, and infrared } \\
\text { phase) })^{\mathrm{a}} \text { above-cloud AOD }\end{array}$ \\
\hline \multirow[t]{2}{*}{ RSP/NASA GISS } & $\begin{array}{l}\text { Measurements at } 410, \\
470,555,670,865, \\
960,1590,1880, \text { and } \\
2260 \mathrm{~nm} \text { with polari- } \\
\text { metric accuracy of } \sim \\
0.15 \%\end{array}$ & $\begin{array}{l}\text { Stokes parameters } I, Q \text {, and } U \text { of re- } \\
\text { flected light } \\
\text { Measurements are over } \pm 60^{\circ} \text { from } \\
\text { nadir }\end{array}$ & $\begin{array}{l}\text { 1. Aerosol microphysics, layer height, } \\
\text { and AOD from inversion }\end{array}$ \\
\hline & & & $\begin{array}{l}\text { 3. Chl, CDOM conc. and backscatter } \\
\text { coeff. }\end{array}$ \\
\hline AirMSPI/JPL & $\begin{array}{l}\text { Multiangle radio- } \\
\text { metric/polarimetric } \\
\text { imager with bands } \\
\text { centered at } 355,380, \\
445,470^{*}, 555,660^{*}, \\
865^{*}, \text { and } 935 \mathrm{~nm} \\
(* \text { polarimetric). }\end{array}$ & $\begin{array}{l}\text { 1. Upwelling radiances (multispectral, } \\
\text { multiangle, spatial) }\end{array}$ & $\begin{array}{l}\text { Liquid cloud droplet effective radius } \\
\text { and COD } \\
\text { Aerosol optical depth, particle size dis- } \\
\text { tribution, single-scattering albedo, re- } \\
\text { fractive index }\end{array}$ \\
\hline \multirow[t]{3}{*}{ HSRL-2/NASA LaRC } & \multirow[t]{3}{*}{$\begin{array}{l}\text { Multi-wavelength High } \\
\text { Spectral Resolution Li- } \\
\text { dar }\end{array}$} & Particulate extinction $(355,532 \mathrm{~nm})$ & $\begin{array}{l}\text { Aerosol classification, aerosol mixing } \\
\text { layer height ( } \sim \text { PBL height), AOD } \\
\text { Aerosol microphysics from inversion } \\
\text { (e.g., N, S, V concentrations, effective } \\
\text { radius) }\end{array}$ \\
\hline & & $\begin{array}{l}\text { Particulate backscatter } \quad(355, \quad 532, \\
1064 \mathrm{~nm})\end{array}$ & \\
\hline & & $\begin{array}{l}\text { Particulate depolarization }(355,532 \text {, } \\
1064 \mathrm{~nm})\end{array}$ & \\
\hline
\end{tabular}

a eMAS-derived quantities, along with L1B data, are archived and publicly available at the LAADS DAAC (https://ladsweb.modaps.eosdis.nasa.gov/, last access: December 2020), not the ORACLES archive.

${ }^{b}$ RSP-derived quantities are publicly available at https://asdc.larc.nasa.gov (last access: December 2020). 
Table B3. Ground-based observations supported by ORACLES.

\begin{tabular}{llll}
\hline Ground-based & & & \\
\hline AERONET & $\begin{array}{l}\text { Spectral sun and sky } \\
\text { ground-based radiome- }\end{array}$ & $\begin{array}{l}\text { 1. Direct solar beam } \\
\text { transmittance } \\
\text { ter }(340 \text { to } 1640 \mathrm{~nm})\end{array}$ & $\begin{array}{l}\text { 1. Sky radiance; cloud } \\
\text { umn } \mathrm{H}_{2} \mathrm{O}\end{array}$ \\
& & $\begin{array}{l}\text { 2. Aenith transmittance AOD, col- } \\
\text { physics from inversion } \\
\text { (e.g., size distribution, }\end{array}$ \\
& & $\begin{array}{l}\text { refr. index, absorption) } \\
\text { 3. Cloud phase, OD, } \\
\end{array}$ \\
& & $r_{\text {eff (inversion) }}$ \\
\hline
\end{tabular}


Appendix C: Acknowledgement of all participants

Table C1. Participants in the ORACLES project, 2014-2019, not co-authoring this paper.

\begin{tabular}{|c|c|c|}
\hline Last name & First middle & Organization \\
\hline Adebiyi & Adeyemi A. & University of Miami \\
\hline Alexandrov & Mikhail & NASA Goddard Institute for Space Studies, Columbia University \\
\hline Allison & Quincy & Bay Area Environmental Research Institute \\
\hline Alugodhi & Mercy-Thea & \\
\hline Anderson & Bruce Eldon & NASA Langley Research Center \\
\hline Arnold & George Thomas & NASA Goddard Space Flight Center, Science Systems and Applications, Inc. \\
\hline Barrett & Paul Alan & UK Met Office \\
\hline Barrick & John & NASA Langley Research Center \\
\hline Bauer & Susanne & NASA Goddard Institute for Space Studies, Columbia University \\
\hline Beach Jr. & Harry Lee & AMA Inc \\
\hline Bennett & Joseph Ryan & National Suborbital Research Center \\
\hline Biswas & Sayak Krishna & Aerospace Corporation, NASA Marshall Space Flight Center \\
\hline Broccardo & Stephen Paul & NASA Ames Research Center \\
\hline Cantrell & Alvin Eric & NASA Marshall Space Flight Center \\
\hline Carnes & Steve Raymond & Jet Propulsion Laboratory \\
\hline Chirica & Dan C. & Bay Area Environmental Research Institute \\
\hline Chowdhary & Jacek & NASA Goddard Institute for Space Studies, Columbia University \\
\hline Chun & William & Jet Propulsion Laboratory \\
\hline Clarke & Antony David & University of Hawai'i at Mānoa \\
\hline Colarco & Peter Richard & NASA Goddard Space Flight Center \\
\hline Cook & Anthony L & NASA Langley Research Center \\
\hline Dahlgren & Robert Paul & California State University, Monterey Bay \\
\hline Das & Sampa & NASA Goddard Space Flight Center \\
\hline Delaney Jr. & Michael McFadyen & National Suborbital Research Center \\
\hline Delene & David & University of North Dakota \\
\hline Dobrowalski & Gregg Charles & Jet Propulsion Laboratory \\
\hline Dominguez & Roseanne & University of California, Santa Cruz \\
\hline Drouet & Jeffrey Thomas & University of Colorado, Boulder \\
\hline Dunagan & Stephen & NASA Ames Research Center \\
\hline Dunwoody & Kent Nelson & NASA Armstrong Flight Research Center, USRA \\
\hline Durden & Stephen L. & Jet Propulsion Laboratory \\
\hline Eck & Thomas Frank & NASA Goddard Space Flight Center \\
\hline Ellis & Thomas Ashly & University of California, Santa Cruz \\
\hline Everson & Chad Michael & University of North Dakota \\
\hline Fenn & Marta Angeline & NASA Langley Research Center, Science Systems and Applications, Inc. \\
\hline Finch & Patrick Eugene & Bay Area Environmental Research Institute \\
\hline Fraim & Eric & NASA Ames Research Center, Universities Space Research Association \\
\hline Garay & Michael Joseph & Jet Propulsion Laboratory \\
\hline Garland Jr. & Rebecca Maureen & Council for Scientific and Industrial Research \\
\hline Geogdzhayev & Igor & NASA Goddard Institute for Space Studies, Columbia University \\
\hline Giles & David Matthew & NASA Goddard Space Flight Center, Science Systems and Applications, Inc. \\
\hline Grant & Patrick Steven & NASA Ames Research Center, University of California, Santa Cruz \\
\hline Gray & Ellen Theresa & NASA Goddard Space Flight Center \\
\hline Hambloch & Patrick & University of Alabama in Huntsville \\
\hline Harper & David B. & NASA Langley Research Center \\
\hline Heikkila & Ashley Creta & University of Hawai'i at Mānoa \\
\hline Henze & Dean & Oregon State University \\
\hline Hildum & Edward Ames & Universities Space Research Association \\
\hline Howes & Calvin Tucker & University of California, Los Angeles \\
\hline Ibrahim & Hani Halim & SpecTIR LLC \\
\hline James & Mark W. & NASA Marshall Space Flight Center \\
\hline Johnson & Roy Robert & NASA Ames Research Center \\
\hline Johnson & Matthew & NASA Ames Research Center \\
\hline
\end{tabular}


Table C1. Continued.

\begin{tabular}{|c|c|c|}
\hline Last name & First middle & Organization \\
\hline Jordan & David Everet & NASA Ames Research Center \\
\hline Kangueehi & Ismael & Stellenbosch University \\
\hline Karol & Yana & NASA Ames Research Center \\
\hline Kindel & Bruce & University of Colorado, Boulder \\
\hline Kittelman & Alan Scott & University of Colorado, Boulder \\
\hline Kraft & Jason Michael & NASA Goddard Space Flight Center \\
\hline Klopper & Danitza & North-West University \\
\hline Lebsock & Matthew David & Jet Propulsion Laboratory \\
\hline Lee & Joseph William & NASA Langley Research Center \\
\hline Lightbourn & Frank & NASA Armstrong (Dryden) Flight Research Center \\
\hline Mace Jr. & Gerald Grant & University of Utah \\
\hline Yang Martin & Meiying Melissa & National Suborbital Research Center \\
\hline McFadden & Susan Kimi & NASA Ames Research Center, Bay Area Environmental Research Institute \\
\hline McIlhattan & Elin Arwen & University of Wisconsin-Madison \\
\hline Miller & Rose Marie & University of Illinois at Urbana-Champaign \\
\hline Miller & Daniel John & NASA Goddard Space Flight Center/UMBC Joint Center for Earth Systems Technology \\
\hline Mohrmann & Johannes & University of Washington \\
\hline Nathanael & Benjamin & National Commission on Research, Science and Technology (Namibia) \\
\hline Nghiyalwa & Hilma & Geography Department, University of Namibia \\
\hline Nicholas & Sommer Lynne & Bay Area Environmental Research Institute \\
\hline Olson & Jennifer & NASA Langley Research Center \\
\hline Ottaviani & Matteo & NASA Goddard Institute for Space Studies, Terra Research Inc \\
\hline Purdue & Sara Kisa & University of Miami \\
\hline Quigley & Emmett & NASA Ames Research Center \\
\hline Rheingans & Brian Eugene & Jet Propulsion Laboratory \\
\hline Rodriguez Monje & Raquel & Jet Propulsion Laboratory \\
\hline Schafer & Joel Shannon & NASA Goddard Space Flight Center \\
\hline Schaller & Emily Lauren & National Suborbital Research Center \\
\hline Seidel Caprez & Felix Clemens & NASA Headquarters, now JPL \\
\hline Shimhanda & Senior & Kiyushu Institute of Technology, Japan \\
\hline Shingler & Taylor & NASA Langley Research Center, Science Systems and Applications, Inc. \\
\hline Shipepe & David Michael & Namibia University of Science and Technology \\
\hline Simmons & David Earl & University of Alabama in Huntsville \\
\hline Sims & W. Herb & University of Alabama in Huntsville \\
\hline Sinclair & Kenneth Allan & Columbia University \\
\hline Sinyuk III & Aliaksandr & NASA Goddard Space Flight Center \\
\hline Slutsker & Ilya & NASA Goddard Space Flight Center \\
\hline Smirnov & Alexander & NASA Goddard Space Flight Center, Science Systems and Applications, Inc. \\
\hline Smirnow & Nikolai Brown & University of Hawai'i at Mānoa \\
\hline Sorokin & Mikhail Grigorievich & NASA Goddard Space Flight Center, Science Systems and Applications, Inc. \\
\hline Stamnes & Snorre & NASA Langley Research Center \\
\hline Swap & Robert John & University of Virginia, NASA Headquarters \\
\hline Tan & Qian & Bay Area Environmental Research Institute \\
\hline Thompson & Andrew & Bay Area Environmental Research Institute \\
\hline Tosca & Mika & School of the Art Institute of Chicago \\
\hline van Diedenhoven & Bastiaan & NASA Goddard Institute for Space Studies, Columbia University \\
\hline Van Gilst & David Patrick & National Suborbital Research Center \\
\hline van Harten & Gerrit & Jet Propulsion Laboratory \\
\hline Vasques & Marilyn & NASA Ames Research Center \\
\hline Wasilewski & Andrzej Piotr & SciSpace, NASA Goddard Institute for Space Studies \\
\hline Williams & Brent Allan & Bay Area Environmental Research Institute \\
\hline Winchester & Cody & University of Hawai'i at Mānoa \\
\hline $\mathrm{Xu}$ & Feng & JPL, now University of Oklahoma \\
\hline Yates & Brian Avery & NASA GSFC Wallops Flight Facility, Pinnacle/AMOC \\
\hline Zavaleta & Jhony Ronald & NASA Ames Research Center \\
\hline Zhang & Jianhao & University of Miami \\
\hline Zhang & Qin & Bay Area Environmental Research Institute \\
\hline
\end{tabular}


Data availability. All ORACLES data are accessible via the digital object identifiers (DOIs) provided under ORACLES Science Team (2020a-d) references: https://doi.org/10.5067/Suborbital/ORACLES/P3/2018_V2

(ORACLES Science Team, 2020a), https://doi.org/10.5067/Suborbital/ORACLES/P3/2017_V2

(ORACLES Science Team, 2020b), https://doi.org/10.5067/Suborbital/ORACLES/P3/2016_V2 (ORACLES Science Team, 2020c), and https://doi.org/10.5067/Suborbital/ORACLES/ER2/2016_V2 (ORACLES Science Team, 2020d). The only exceptions are noted as footnotes to Table B2.

Author contributions. JR, RW, and PZ, designed the original ORACLES observational concept and co-led the 5-year investigation. SJD was instrumental in conducting the ORACLES investigation. BL coordinated all project management. JMH and PF led the CLARIFY and AEROCLO-sA field experiments, respectively, and their coordination with ORACLES deployments. SEL, MSD, YS, RU, JMR, AND, AMdS, KML, MSK, CJF, KP, ASA, SEB, AMF, GRC, PES, GAF, SF, BC, BNH, KDK, ST, TSL, AMD, OOS, GMM, MRP, SG, JRO, AN, MK, JPSW, JDSG, KLT, DN, JRP, KSS, PP, HC, SPC, AJS, TJL, ES, MSR, RAF, SPB, CAH, DJD, FCS, SEP, JSM, KGM, and DAS made critical contributions to the field deployments and post-campaign data analyses. SGH made vital contributions to the experimental design and execution. MM and PS led formal modeling analyses in the post-campaign stage. NMK and SJP coordinated the outreach and scientific efforts by Namibian and South African partner institutions. IYC and LG created and visualized results for portions of this paper. HM provided crucial administrative support to enable ORACLES field operations.

Competing interests. Paquita Zuidema, Paola Formenti, and James M. Haywood are guest editors for the ACP Special Issue "New observations and related modeling studies of the aerosolcloud-climate system in the Southeast Atlantic and southern Africa regions", to which this paper has been submitted. The remaining authors declare that they have no conflicts of interest.

Special issue statement. This article is part of the special issue "New observations and related modeling studies of the aerosolcloud-climate system in the Southeast Atlantic and southern Africa regions (ACP/AMT inter-journal SI)". It is not associated with a conference.

Acknowledgements. ORACLES is a NASA Earth Venture Suborbital-2 investigation managed through the Earth System Science Pathfinder Office. The team is equally grateful for the tireless contributions by the NASA Wallops and NASA Johnson P-3 and NASA Armstrong ER-2 pilots, flight crews, and their management, as well as air traffic control at Walvis Bay airport (Namibia) and the airport in São Tomé. Local authorities in Namibia and São Tomé beyond the ones mentioned in Sect. 3.3.7 and 3.5 played important roles as well, for which the project would like to express their gratitude. Philip Stier acknowledges funding from the UK
NERC project CLARIFY (NE/L013479/1) and the European Research Council (ERC) project RECAP under the European Union's Horizon 2020 research and innovation program with grant agreement 724602. Part of this work was performed at the Jet Propulsion Laboratory, California Institute of Technology, under a contract with the National Aeronautics and Space Administration (80NM0018D0004).

The ORACLES project, in spirit and execution, was very much a collaborative effort. It entailed contributions small and large, with many of the smaller and short-term contributions equally crucial to the execution of the project. In Table $\mathrm{C} 1$ in Appendix $\mathrm{C}$ we list all participants in the ORACLES project that are not co-authors of this paper. The ORACLES leadership, and indeed NASA as a whole, owe sincere gratitude to any and all of the participants listed there.

Financial support. This research has been supported by NASA through the Earth Venture Suborbital-2 (EVS-2) program (grant no. 13-EVS2-13-0028).

Review statement. This paper was edited by Frank Eckardt and reviewed by Armin Sorooshian and one anonymous referee.

\section{References}

Ackerman, A. S., Toon, O. B., Stevens, D. E., Heymsfield, A. J., Ramanathan, V., and Welton, E. J.: Reduction of tropical cloudiness by soot, Science, 288, 1042-1047, 2000.

Ackerman, A. S., Kirkpatrick, M. P., Stevens, D. E., and Toon, O. B.: The impact of humidity above stratiform clouds on indirect aerosol climate forcing, Nature, 432, 1014-1017, https://doi.org/10.1038/nature03174, 2004.

Adebiyi, A. and Zuidema, P.: The Role of the Southern African Easterly Jet in Modifying the Southeast Atlantic Aerosol and Cloud Environments, Q. J. Roy. Meteor. Soc., 697, 1574-89, https://doi.org/10.1002/qj.2765, 2016.

Adebiyi, A. A. and Zuidema, P.: Low Cloud Cover Sensitivity to Biomass-Burning Aerosols and Meteorology over the Southeast Atlantic, J. Climate, 31, 4329-4346, 2018.

Adebiyi, A., Zuidema, P., and Abel, S.: The convolution of dynamics and moisture with the presence of shortwave absorbing aerosols over the southeast Atlantic, J. Climate, 28, 1997-2024, https://doi.org/10.1175/JCLI-D-14-00352.1, 2015.

Adebiyi, A. A., Zuidema, P., Chang, I., Burton, S. P., and Cairns, B.: Mid-level clouds are frequent above the southeast Atlantic stratocumulus clouds, Atmos. Chem. Phys., 20, 11025-11043, https://doi.org/10.5194/acp-20-11025-2020, 2020.

Albrecht, B. A.: Aerosols, cloud microphysics, and fractional cloudiness, Science, 245, 1227-1230, 1989.

Andela, N., Morton, D. C., Giglio, L., Chen, Y., van der Werf, G. R., Kasibhatla, P. S., DeFries, R. S., Collatz, G. L., Hantson, S., Kloster, S., Bachelet, D., Forrest, M., Lasslop, G., Li, F., Mangeon, S., Melton, J. R., Yue, C., and Randerson, J. T.: A humandriven decline in global burned area, Science, 356, 1356-1362, 2017. 
Annegarn, H. J. and Swap, R. J.: SAFARI 2000: A Southern African Example of Science Diplomacy, Science and Diplomacy, 1, 4, 2012.

Bennartz, R. and Rausch, J.: Global and regional estimates of warm cloud droplet number concentration based on 13 years of AQUA-MODIS observations, Atmos. Chem. Phys., 17, 98159836, https://doi.org/10.5194/acp-17-9815-2017, 2017.

Betts, A. K. and Ridgway, W.: Coupling of the Radiative, Convective, and Surface Fluxes over the Equatorial Pacific, J. Atmos. Sci., 45, 522-36, https://doi.org/10.1175/15200469(1988)045\%3C0522:COTRCA\%3E2.0.CO;2, 1988.

Bond, T. C., Doherty, S. J., Fahey, D. W., Forster, P. M. Berntsen, T., DeAngelo, B. J., Flanner, M. G., Ghan, S., Kärcher, B., Koch, D., Kinne, S., Kondo, Y., Quinn, P. K., Sarofim, M. C., Schultz, M. G., Schulz, M., Venkataraman, C., Zhang, H., Zhang S., Bellouin, N., Guttikunda, S. K., Hopke, P. K., Jacobson, M. Z., Kaiser, J. W., Klimont, Z., Lohmann, U., Schwarz, J. P., Shindell, D., Storelvmo, T., Warren, S. G., and Zender, C. S.: Bounding the role of black carbon in the climate system: A scientific assessment, J. Geophys. Res.-Atmos., 118, 5380-5552, https://doi.org/10.1002/jgrd.50171, 2013.

Bony, S. and Dufresne, J. L.: Marine boundary layer clouds at the heart of tropical cloud feedback uncertainties in climate models, Geophys. Res. Lett., 32, L20806, https://doi.org/10.1029/2005GL023851, 2005.

Burton, S., Hostetler, C., Cook, A., Hair, J., Seaman, S., Scola, S., Harper, D., Smith, J., Fenn, M., Ferrare, R., Saide, P. E., Chemyakin, E. V., and Müller, D.: Calibration of a high spectral resolution lidar using a Michelson interferometer, with data examples from ORACLES, Appl. Optics, 57, 6061, https://doi.org/10.1364/AO.57.006061, 2018.

Chand, D., Wood, R., Anderson, T., Satheesh, S. K., and Charlson, R. J.: Satellite-derived direct radiative effect of aerosols dependent on cloud cover, Nat. Geosci., 2, 181-184, 2009.

Chatfield, R. B., Guo, Z., Sachse, G. W., Blake, D. R., and Blake, N. J.: The subtropical global plume in the Pacific Exploratory Mission-Tropics A (PEM-Tropics A), PEM-Tropics B, and the Global Atmospheric Sampling Program (GASP): How tropical emissions affect the remote Pacific, J. Geophys. Res., 107, 4278, https://doi.org/10.1029/2001JD000497, 2002.

Coakley, J. and Chylek, P.: The two-stream approximation in radiative transfer including the angle of the incident radiation, J. Atmos. Sci., 32, 409-418, 1975.

Cochrane, S. P., Schmidt, K. S., Chen, H., Pilewskie, P., Kittelman, S., Redemann, J., LeBlanc, S., Pistone, K., Kacenelenbogen, M., Segal Rozenhaimer, M., Shinozuka, Y., Flynn, C., Platnick, S., Meyer, K., Ferrare, R., Burton, S., Hostetler, C., Howell, S., Freitag, S., Dobracki, A., and Doherty, S.: Above-cloud aerosol radiative effects based on ORACLES 2016 and ORACLES 2017 aircraft experiments, Atmos. Meas. Tech., 12, 65056528, https://doi.org/10.5194/amt-12-6505-2019, 2019.

Coddington, O. M., Pilewskie, P., Redemann, J., Platnick, S., Russell, S. P. B., Schmidt, K. S., Gore, W. J., Livingston, J., Wind, G., and Vukicevic, T.: Examining the impact of overlying aerosols on the retrieval of cloud optical properties from passive remote sensing, J. Geophys. Res., 115, D10211, https://doi.org/10.1029/2009JD012829, 2010.

Costantino, L. and Bréon, F.-M.: Satellite-based estimate of aerosol direct radiative effect over the South-East At- lantic, Atmos. Chem. Phys. Discuss., 13, 23295-23324, https://doi.org/10.5194/acpd-13-23295-2013, 2013.

Das, S., Harshvardhan, H., Bian, H., Chin, M., Curci, G., Protonotariou, A. P. T., Mielonen, K., Zhang, H., Wang, H., and Liu, X.: Biomass burning aerosol transport and vertical distribution over the South African-Atlantic region, J. Geophys. Res.-Atmos., 122, 6391-6415, https://doi.org/10.1002/2016JD026421, 2017.

Davies, N. W., Fox, C., Szpek, K., Cotterell, M. I., Taylor, J. W., Allan, J. D., Williams, P. I., Trembath, J., Haywood, J. M., and Langridge, J. M.: Evaluating biases in filter-based aerosol absorption measurements using photoacoustic spectroscopy, Atmos. Meas. Tech., 12, 3417-3434, https://doi.org/10.5194/amt12-3417-2019, 2019.

Deaconu, L. T., Waquet, F., Josset, D., Ferlay, N., Peers, F., Thieuleux, F., Ducos, F., Pascal, N., Tanré, D., Pelon, J., and Goloub, P.: Consistency of aerosols above clouds characterization from A-Train active and passive measurements, Atmos. Meas. Tech., 10, 3499-3523, https://doi.org/10.5194/amt10-3499-2017, 2017.

Deaconu, L. T., Ferlay, N., Waquet, F., Peers, F., Thieuleux, F., and Goloub, P.: Satellite inference of water vapour and abovecloud aerosol combined effect on radiative budget and cloudtop processes in the southeastern Atlantic Ocean, Atmos. Chem. Phys., 19, 11613-11634, https://doi.org/10.5194/acp-19-116132019, 2019.

De Graaf, M., Bellouin, N., Tilstra, L. G., Haywood, J., and Stammes, P.: Aerosol direct radiative effect of smoke over clouds over the southeast Atlantic Ocean from 2006 to 2009, Geophys. Res. Lett., 41, 7723-7730, https://doi.org/10.1002/2014GL061103, 2014.

Diamond, M. S., Dobracki, A., Freitag, S., Small Griswold, J. D., Heikkila, A., Howell, S. G., Kacarab, M. E., Podolske, J. R., Saide, P. E., and Wood, R.: Time-dependent entrainment of smoke presents an observational challenge for assessing aerosolcloud interactions over the southeast Atlantic Ocean, Atmos. Chem. Phys., 18, 14623-14636, https://doi.org/10.5194/acp-1814623-2018, 2018.

Doherty, S. J., Saide, P., Zuidema, P., Shinozuka, Y., Ferrada, G., Mallet, M., Meyer, K., Painemal, D., Howell, S. G., Freitag, S., Smirnow, N.,Dobracki, A., Podolske, J., Ferrare, R., Burton, S., Nabat, P., Wood, R., and Redemann, J.: Modeled and observed vertically-resolved aerosol and cloud properties related to the direct aerosol radiative effect in the Southeast Atlantic, in preparation, 2021.

Dubovik, O. and King, M. D.: A flexible inversion algorithm for retrieval of aerosol optical properties from sun and sky radiance measurements, J. Geophys. Res., 105, 20673-20696, 2000.

Dzambo, A. M., L'Ecuyer, T., Sy, O. O., and Tanelli, S.: The Observed Structure and Precipitation Characteristics of Southeast Atlantic Stratocumulus from Airborne Radar During ORACLES 2016-17, J. Appl. Meteorol. Clim., 58, 2197-2215, https://doi.org/10.1175/jamc-d-19-0032.1, 2019.

Dzambo, A. M., L'Ecuyer, T., Sinclair, K., van Diedenhoven, B., Gupta, S., McFarquhar, G., O'Brien, J. R., Cairns, B., Wasilewski, A. P., and Alexandrov, M.: Joint Cloud Water Path and Rain Water Path Retrievals from ORACLES Observations, Atmos. Chem. Phys. Discuss., https://doi.org/10.5194/acp-2020849, in review, 2020. 
Eastman, R. and Wood, R. K. T. O: The subtropical stratocumulustopped planetary boundary layer: A climatology and the Lagrangian evolution, J. Atmos. Sci., 74, 2633-2656, https://doi.org/10.1175/JAS-D-16-0336.1, 2017.

Eck, T. F., Holben, B. N., Reid, J. S., Mukelabai, M. M., Piketh, S. J., Torres, O., Jethva, H. T., Hyer, E. J., Ward, D. E., Dubovik, O., Sinyuk, A., Schafer, J. S., Giles, D. M., Sorokin, M., Smirnov, A., and Slutsker, I.: A seasonal trend of single scattering albedo in southern African biomass-burning particles: Implications for satellite products and estimates of emissions for the world's largest biomass-burning source, J. Geophys. Res. Atmos., 118, 6414-6432, https://doi.org/10.1002/jgrd.50500, 2013.

ECMWF: Describing ECMWF's forecasts and forecasting system, Newsletter Feature Article, ECMWF, availabel at: https://www.ecmwf.int/sites/default/files/elibrary/2012/ 17412-describing-ecmwfs-forecasts-and-forecasting-system. pdf (last access: December 2013), 2012.

Fishman, J., Hoell, J. M., Bendura, R. D., McNeal, R. J., and Kirchhoff, V. W. J. H.: NASA GTE TRACE-A Experiment (September-October 1992), Overview, J. Geophys. Res., 101, 23865-23880, 1996.

Formenti, P., D’Anna, B., Flamant, C., Mallet, M., Piketh, S. J., Schepanski, K., Waquet, F., Auriol, F., Brogniez, G., Burnet, F., Chaboureau, J., Chauvigné, A., Chazette, P., Denjean, C., Desboeufs, K., Doussin, J., Elguindi, N., Feuerstein, S., Gaetani, M., Giorio, C., Klopper, D., Mallet, M. D., Nabat, P., Monod, A., Solmon, F., Namwoonde, A., Chikwililwa, C., Mushi, R., Welton, E. J., and Holben, B.: The Aerosols, Radiation and Clouds in Southern Africa Field Campaign in Namibia: Overview, illustrative observations, and way forward, B. Am. Meteor. Soc., 100, 1277-1298, https://doi.org/10.1175/BAMS-D-17-0278.1, 2019.

Grell, G. A., Peckham, S. E., Schmitz, R., McKeen, S. A., Frost, G., Skamarock, W. C., and Eder, B.: Fully coupled "online" chemistry within the WRF model, Atmos. Environ., 39, 6957-6975, https://doi.org/10.1016/j.atmosenv.2005.04.027, 2005.

Gupta, S., McFarquhar, G. M., O’Brien, J. R., Delene, D. J., Poellot, M. R., Dobracki, A., Podolske, J. R., Redemann, J., LeBlanc, S. E., Segal-Rozenhaimer, M., and Pistone, K.: Impact of the Variability in Vertical Separation between Biomass-Burning Aerosols and Marine Stratocumulus on Cloud Microphysical Properties over the Southeast Atlantic, Atmos. Chem. Phys. Discuss. [preprint], https://doi.org/10.5194/acp-2020-1039, in review, 2020.

Haynes, J. M., L’Ecuyer, T. S., Stephens, G. L., Miller, S. D., Mitrescu, C., Wood, N. B., and Tanelli, S.: Rainfall retrieval over the ocean with spaceborne W-band radar, J. Geophys. Res., 114, D00A22, https://doi.org/10.1029/2008JD009973, 2009.

Haywood, J., Francis, P., Dubovik, O., Glew, M., and Holben, B.: Comparison of aerosol size distributions, radiative properties, and optical depths determined by aircraft observations and Sun photometers during SAFARI 2000, J. Geophys. Res., 108, 8471, https://doi.org/10.1029/2002JD002250, 2003.

Haywood, J. M., Osborne, S. R., and Abel, S. J.: The effect of overlying absorbing aerosol layers on remote sensing retrievals of cloud effective radius and cloud optical depth, Q. J. Roy. Meteor. Soc., 130, 779-800, 2004.

Haywood, J. M., Abel, S. J., Barrett, P. A., Bellouin, N., Blyth, A., Bower, K. N., Brooks, M., Carslaw, K., Che, H., Coe, H., Cotterell, M. I., Crawford, I., Cui, Z., Davies, N., Dingley, B.,
Field, P., Formenti, P., Gordon, H., de Graaf, M., Herbert, R., Johnson, B., Jones, A. C., Langridge, J. M., Malavelle, F., Partridge, D. G., Peers, F., Redemann, J., Stier, P., Szpek, K., Taylor, J. W., Watson-Parris, D., Wood, R., Wu, H., and Zuidema, P.: Overview: The CLoud-Aerosol-Radiation Interaction and Forcing: Year-2017 (CLARIFY-2017) measurement campaign, Atmos. Chem. Phys. Discuss., https://doi.org/10.5194/acp-2020729, in review, 2020.

Herman, J., Cede, A., Spinei, E., Mount, G., Tzortziou, M., and Abuhassan, N.: $\mathrm{NO}_{2}$ column amounts from groundbased Pandora and MFDOAS spectrometers using the direct-sun DOAS technique: Intercomparisons and application to OMIvalidation, J. Geophys. Res., 114, D13307, https://doi.org/10.1029/2009JD011848, 2009.

Herman, J., Evans, R., Cede, A., Abuhassan, N., Petropavlovskikh, I., and McConville, G.: Comparison of ozone retrievals from the Pandora spectrometer system and Dobson spectrophotometer in Boulder, Colorado, Atmos. Meas. Tech., 8, 3407-3418, https://doi.org/10.5194/amt-8-3407-2015, 2015.

Holben, B. N., Eck, T. F., Slutsker, I., Tanre, D., Buis, J. P., Setzer, A., Vermote, E., Reagan, J. A., Kaufman, Y., Nakajima, T., Lavenu, F., Jankowiak, I., and Smirnov, A.: AERONET - A federated instrument network and data archive for aerosol characterization, Remote Sens. Environ., 66, 1-16, 1998.

Holben, B. N., Kim, J., Sano, I., Mukai, S., Eck, T. F., Giles, D. M., Schafer, J. S., Sinyuk, A., Slutsker, I., Smirnov, A., Sorokin, M., Anderson, B. E., Che, H., Choi, M., Crawford, J. H., Ferrare, R. A., Garay, M. J., Jeong, U., Kim, M., Kim, W., Knox, N., Li, Z., Lim, H. S., Liu, Y., Maring, H., Nakata, M., Pickering, K. E., Piketh, S., Redemann, J., Reid, J. S., Salinas, S., Seo, S., Tan, F., Tripathi, S. N., Toon, O. B., and Xiao, Q.: An overview of mesoscale aerosol processes, comparisons, and validation studies from DRAGON networks, Atmos. Chem. Phys., 18, 655-671, https://doi.org/10.5194/acp-18-655-2018, 2018.

Huffman, G. J., Adler, R. F., Bolvin, D. T., Gu, G., Nelkin, E. J., Bowman, K. P., Hong, Y., Stocker, E. F., Wolff, D. B.: The TRMM Multi-satellite Precipitation Analysis: Quasi-Global, Multi-Year, Combined-Sensor Precipitation Estimates at Fine Scale, J.Hydrometeor., 8, 38-55, 2007.

IPCC: Climate Change 2013: The Physical Science Basis. Contribution of Working Group I to the Fifth Assessment Report of the Intergovernmental Panel on Climate Change, edited by: Stocker, T. F., Qin, D., Plattner, G.-K., Tignor, M., Allen, S. K., Boschung, J., Nauels, A., Xia, Y., Bex, V. and Midgley, P. M., Cambridge University Press, Cambridge, UK and New York, USA, 2013.

Jethva, H., Torres, O., Waquet, F., Chand, D., and Hu, Y.: How do A-train sensors intercompare in the retrieval of above-cloud aerosol optical depth? A case study-based assessment, Geophys. Res. Lett., 41, 186-192, https://doi.org/10.1002/2013GL058405, 2014.

Jethva, H., Torres, O., Remer, L., Redemann, J., Livingston, J., Dunagan, S., Shinozuka, Y., Kacenelenbogen, M., Rosenheimer, M. S., and Spurr, R.: Validating MODIS abovecloud aerosol optical depth retrieved from "color ratio" algorithm using direct measurements made by NASA's airborne AATS and 4STAR sensors, Atmos. Meas. Tech., 9, 5053-5062, https://doi.org/10.5194/amt-9-5053-2016, 2016.

Jethva, H., Torres, O., and Ahn, C.: A 12-year long global record of optical depth of absorbing aerosols above the clouds de- 
rived from the OMI/OMACA algorithm, Atmos. Meas. Tech., 11, 5837-5864, https://doi.org/10.5194/amt-11-5837-2018, 2018.

Kacarab, M., Thornhill, K. L., Dobracki, A., Howell, S. G., O'Brien, J. R., Freitag, S., Poellot, M. R., Wood, R., Zuidema, P., Redemann, J., and Nenes, A.: Biomass burning aerosol as a modulator of the droplet number in the southeast Atlantic region, Atmos. Chem. Phys., 20, 3029-3040, https://doi.org/10.5194/acp20-3029-2020, 2020.

Kacenelenbogen, M. S., Vaughan, M. A., Redemann, J., Young, S. A., Liu, Z., Hu, Y., Omar, A. H., LeBlanc, S., Shinozuka, Y., Livingston, J., Zhang, Q., and Powell, K. A.: Estimations of global shortwave direct aerosol radiative effects above opaque water clouds using a combination of A-Train satellite sensors, Atmos. Chem. Phys., 19, 4933-4962, https://doi.org/10.5194/acp19-4933-2019, 2019.

Katich, J. M., Samset, B. H., Bui, T. P., Dollner, M., Froyd, K. D., Campuzano-Jost, P., Nault, B. A., Schroder, J. C., Weinzierl, B., and Schwarz, J. P.: Strong contrast in remote black carbon aerosol loadings between the Atlantic and Pacific basins, J. Geophys. Res.-Atmos.,123, 13386-13395, https://doi.org/10.1029/2018JD029206, 2018.

Keil, A. and Haywood, J. M.: Solar radiative forcing by BB aerosol particles during SAFARI 2000: A case study based on measured aerosol and cloud properties, J. Geophys. Res., 108, 8467, https://doi.org/10.1029/2002JD002315, 2003.

Knobelspiesse, K., Cairns, B., Jethva, H., Kacenelenbogen, M., Segal-Rosenheimer, M., and Torres, O.: Remote sensing of above cloud aerosols, in: Light Scattering Reviews 9, edited by: Kokhanovsky, A., Springer Praxis Books, Springer, Berlin, Heidelberg, https://doi.org/10.1007/978-3-642-37985-7_5, 2015.

Koch, D. and Del Genio, A. D.: Black carbon semi-direct effects on cloud cover: review and synthesis, Atmos. Chem. Phys., 10, 7685-7696, https://doi.org/10.5194/acp-10-7685-2010, 2010.

Koffi, B., Schulz, M., Bréon, F., Griesfeller, J., Winker, D., Balkanski, Y., Bauer, S., Berntsen, T., Chin, M., Collins, W. D., Dentener, F., Diehl, T., Easter, R., Ghan, S., Ginoux, P., Gong, S., Horowitz, L. W., Iversen, T., Kirkevåg, A., Koch, D., Krol, M., Myhre, G., Stier, P., and Takemura, T.: Application of the CALIOP layer product to evaluate the vertical distribution of aerosols estimated by global models: AeroCom phase I results, J. Geophys. Res., 117, D10201, https://doi.org/10.1029/2011JD016858, 2012.

LeBlanc, S.: Moving Lines: NASA airborne research flight planning tool release (Version v1.21), Zenodo, https://doi.org/10.5281/zenodo.1478126, 2018.

LeBlanc, S. E., Redemann, J., Flynn, C., Pistone, K., Kacenelenbogen, M., Segal-Rosenheimer, M., Shinozuka, Y., Dunagan, S., Dahlgren, R. P., Meyer, K., Podolske, J., Howell, S. G., Freitag, S., Small-Griswold, J., Holben, B., Diamond, M., Wood, R., Formenti, P., Piketh, S., Maggs-Kölling, G., Gerber, M., and Namwoonde, A.: Above-cloud aerosol optical depth from airborne observations in the southeast Atlantic, Atmos. Chem. Phys., 20, 1565-1590, https://doi.org/10.5194/acp-20-1565-2020, 2020.

Ma, P.-L., Rasch, P. J., Fast, J. D., Easter, R. C., Gustafson Jr., W. I., Liu, X., Ghan, S. J., and Singh, B.: Assessing the CAM5 physics suite in the WRF-Chem model: implementation, resolution sensitivity, and a first evaluation for a regional case study, Geosci. Model Dev., 7, 755-778, https://doi.org/10.5194/gmd-7755-2014, 2014.
Mallet, M., Nabat, P., Zuidema, P., Redemann, J., Sayer, A. M., Stengel, M., Schmidt, S., Cochrane, S., Burton, S., Ferrare, R., Meyer, K., Saide, P., Jethva, H., Torres, O., Wood, R., Saint Martin, D., Roehrig, R., Hsu, C., and Formenti, P.: Simulation of the transport, vertical distribution, optical properties and radiative impact of smoke aerosols with the ALADIN regional climate model during the ORACLES-2016 and LASIC experiments, Atmos. Chem. Phys., 19, 4963-4990, https://doi.org/10.5194/acp19-4963-2019, 2019.

Mallet, M., Solmon, F., Nabat, P., Elguindi, N., Waquet, F., Bouniol, D., Sayer, A. M., Meyer, K., Roehrig, R., Michou, M., Zuidema, P., Flamant, C., Redemann, J., and Formenti, P.: Direct and semi-direct radiative forcing of biomass-burning aerosols over the southeast Atlantic (SEA) and its sensitivity to absorbing properties: a regional climate modeling study, Atmos. Chem. Phys., 20, 13191-13216, https://doi.org/10.5194/acp-20-131912020, 2020.

Martin, G. M., Johnson, D. W., and Spice, A.: The measurement and parameterization of effective radius of droplets in warm stratiform clouds, J. Atmos. Sci., 51, 1823-1842, 1994.

Mauger, G. and Norris, J.: Meteorological bias in satellite estimates of aerosol-cloud relationships, Geophys. Res. Lett., 34, https://doi.org/10.1029/2007GL029952, 2007.

Meyer, K., Platnick, S., Oreopoulos, L., and Lee, D.: Estimating the direct radiative effect of absorbing aerosols overlying marine boundary layer clouds in the southeast Atlantic using MODIS and CALIOP, J. Geophys. Res.-Atmos., 118, 48014815, https://doi.org/10.1002/jgrd.50449, 2013.

Meyer, K., Platnick, S., and Zhang, Z.: Simultaneously inferring above-cloud absorbing aerosol optical thickness and underlying liquid phase cloud optical and microphysical properties using MODIS, J. Geophys. Res.-Atmos., 120, 2015JD023128, https://doi.org/10.1002/2015JD023128, 2015.

Miles, N. L., Verlinde, J., and Clothiaux, E. E.: Cloud droplet size distributions in low-level stratiform clouds, J. Atmos. Sci., 57, 295-311, 2000.

Miller, D. J., Segal-Rozenhaimer, M., Knobelspiesse, K., Redemann, J., Cairns, B., Alexandrov, M., van Diedenhoven, B., and Wasilewski, A.: Low-level liquid cloud properties during ORACLES retrieved using airborne polarimetric measurements and a neural network algorithm, Atmos. Meas. Tech., 13, 3447-3470, https://doi.org/10.5194/amt-13-3447-2020, 2020.

Minnis, P., Nguyen, L., Palikonda, R., Heck, P. W., Spangenberg, D. A., Doelling, D. R., Ayers, J. K., Smith Jr., W. L., Khaiyer, M. M., Trepte, Q. Z., Avey, L. A., Chang, F.-L., Yost, C. R., Chee, T. L., and Sun-Mack, S.: Near-real time cloud retrievals from operational and research meteorological satellites, Proceedings of the SPIE Europe Remote Sens., Cardiff, UK, 15-18 September 2008, 7107-2, 2008.

Minnis, P., Sun-Mack, S., Chen, Y., Chang, F.-L., Yost, C. R., Smith Jr., W. L., Heck, P. W., Arduini, R. F., Bedka, S. T., Yi, Y., Hong, G., Jin, Z., Painemal, D., Palikonda, R., Scarino, B., Spangenberg, D. A., Smith, R. A., Trepte, Q. Z., Yang, P., and Xie, Y.: CERES MODIS cloud product retrievals for Edition 4, Part I: Algorithm changes, IEEE Trans. Geosci. Remote Sens., https://doi.org/10.1109/TGRS.2020.3008866, 2020.

Molod, A., Takacs, L., Suarez, M., Bacmeister, J., Song, I.-S., and Eichmann, A.: The GEOS-5 Atmospheric General Circulation Model: Mean Climate and Development from MERRA to For- 
tuna, Technical Report Series on Global Modeling and Data Assimilation, NASA, Washington, D.C., USA, 28, 124 pp., 2012.

Myhre, G., Samset, B. H., Schulz, M., Balkanski, Y., Bauer, S., Berntsen, T. K., Bian, H., Bellouin, N., Chin, M., Diehl, T., Easter, R. C., Feichter, J., Ghan, S. J., Hauglustaine, D., Iversen, T., Kinne, S., Kirkevåg, A., Lamarque, J.-F., Lin, G., Liu, X., Lund, M. T., Luo, G., Ma, X., van Noije, T., Penner, J. E., Rasch, P. J., Ruiz, A., Seland, Ø., Skeie, R. B., Stier, P., Takemura, T., Tsigaridis, K., Wang, P., Wang, Z., Xu, L., Yu, H., Yu, F., Yoon, J.-H., Zhang, K., Zhang, H., and Zhou, C.: Radiative forcing of the direct aerosol effect from AeroCom Phase II simulations, Atmos. Chem. Phys., 13, 1853-1877, https://doi.org/10.5194/acp13-1853-2013, 2013.

National Academies of Sciences, Engineering, and Medicine: Thriving on Our Changing Planet: A Decadal Strategy for Earth Observation from Space, The National Academies Press, Washington, DC, USA, https://doi.org/10.17226/24938, 2018.

Nicholls, S. and Leighton, J.: An observational study of the structure of stratiform cloud sheets, Part I: Structure, Q. J. Roy. Meteor. Soc., 112, 431-460, 1986.

ORACLES Science Team: Suite of Aerosol, Cloud, and Related Data Acquired Aboard P3 During ORACLES 2018, Version 2, NASA Ames Earth Science Project Office, https://doi.org/10.5067/Suborbital/ORACLES/P3/2018_V2, 2020a.

ORACLES Science Team: Suite of Aerosol, Cloud, and Related Data Acquired Aboard P3 During ORACLES 2017, Version 2, NASA Ames Earth Science Project Office, https://doi.org/10.5067/Suborbital/ORACLES/P3/2017_V2, 2020b.

ORACLES Science Team: Suite of Aerosol, Cloud, and Related Data Acquired Aboard P3 During ORACLES 2016, Version 2, NASA Ames Earth Science Project Office, https://doi.org/10.5067/Suborbital/ORACLES/P3/2016_V2, 2020c.

ORACLES Science Team: Suite of Aerosol, Cloud, and Related Data Acquired Aboard ER2 During ORACLES 2016, Version 2, NASA Ames Earth Science Project Office, https://doi.org/10.5067/Suborbital/ORACLES/ER2/2016_V2, 2020d.

Painemal, D. and Zuidema, P.: Microphysical variability in southeast Pacific Stratocumulus clouds: synoptic conditions and radiative response, Atmos. Chem. Phys., 10, 6255-6269, https://doi.org/10.5194/acp-10-6255-2010, 2010.

Painemal, D. and Zuidema, P.: Assessment of MODIS cloud effective radius and optical thickness retrievals over the Southeast Pacific with VOCALS-REx in situ measurements, J. Geophys. Res., 116, D24206, https://doi.org/10.1029/2011JD016155, 2011.

Pappenberger, F., Scipal, K., and Buizza, R.: Hydrological aspects of meteorological verification, Atmospheric Sci. Lett., 9, 43-52, 2008.

Peers, F., Francis, P., Fox, C., Abel, S. J., Szpek, K., Cotterell, M. I., Davies, N. W., Langridge, J. M., Meyer, K. G., Platnick, S. E., and Haywood, J. M.: Observation of absorbing aerosols above clouds over the south-east Atlantic Ocean from the geostationary satellite SEVIRI - Part 1: Method description and sensitivity, Atmos. Chem. Phys., 19, 9595-9611, https://doi.org/10.5194/acp19-9595-2019, 2019.
Pistone, K., Redemann, J., Doherty, S., Zuidema, P., Burton, S., Cairns, B., Cochrane, S., Ferrare, R., Flynn, C., Freitag, S., Howell, S. G., Kacenelenbogen, M., LeBlanc, S., Liu, X., Schmidt, K. S., Sedlacek III, A. J., Segal-Rozenhaimer, M., Shinozuka, Y., Stamnes, S., van Diedenhoven, B., Van Harten, G., and $\mathrm{Xu}, \mathrm{F}$.: Intercomparison of biomass burning aerosol optical properties from in situ and remote-sensing instruments in ORACLES-2016, Atmos. Chem. Phys., 19, 9181-9208, https://doi.org/10.5194/acp-19-9181-2019, 2019.

Rajapakshe, C., Zhang, Z., Yorks, J. E., Yu, H., Tan, Q., Meyer, K., Platnick, S., and Winker, D. M.: Seasonally transported aerosol layers over southeast Atlantic are closer to underlying clouds than previously reported, Geophys. Res. Lett., 44, 5818-5825, https://doi.org/10.1002/2017GL073559, 2017.

Ran, Q., Fu, W., Liu, Y., Li, T. Shi, K., and Sivakumar, B.: Evaluation of Quantitative Precipitation Predictions by ECMWF, CMA, and UKMO for Flood Forecasting: Application to Two Basins in China, Nat. Hazards Rev., 19, 05018003, https://doi.org/10.1061/(ASCE)NH.1527-6996.0000282, 2018.

Rouault, M.: Bi-annual intrusion of tropical water in the northern Benguela upwelling, Geophys. Res. Lett., 39, L12606, https://doi.org/10.1029/GL052099, 2012.

Saide, P. E., Thompson, G., Eidhammer, T., da Silva, A. M., Pierce, R. B., and Carmichael, G. R.: Assessment of biomass burning smoke influence on environmental conditions for multi-year tornado outbreaks by combining aerosol-aware microphysics and fire emission constraints, J. Geophys. Res.-Atmos., 121, 1029410311, https://doi.org/10.1002/2016JD025056, 2016.

Sakaeda, N., Wood, R., and Rasch, P. J.: Direct and semidirect aerosol effects of southern African biomass burning aerosol, J. Geophys. Res.-Atmos., 116, D12205, https://doi.org/10.1029/2010JD015540, 2011.

Sayer, A. M., Hsu, N. C., Bettenhausen, C., Lee, J., Redemann, J., Schmid, B., and Shinozuka, Y.: Extending "Deep Blue" aerosol retrieval coverage to cases of absorbing aerosols above clouds: Sensitivity analysis and first case studies, J. Geophys. Res.Atmos., 121, 4830-4854, 2016.

Sayer, A. M., Hsu, N. C., Lee, J., Kim, W. V., Burton, S., Fenn, M. A., Ferrare, R. A., Kacenelenbogen, M., LeBlanc, S., Pistone, K., Redemann, J., Segal-Rozenhaimer, M., Shinozuka, Y., and Tsay, S.-C.: Two decades observing smoke above clouds in the south-eastern Atlantic Ocean: Deep Blue algorithm updates and validation with ORACLES field campaign data, Atmos. Meas. Tech., 12, 3595-3627, https://doi.org/10.5194/amt12-3595-2019, 2019.

Schulz, M., Textor, C., Kinne, S., Balkanski, Y., Bauer, S., Berntsen, T., Berglen, T., Boucher, O., Dentener, F., Guibert, S., Isaksen, I. S. A., Iversen, T., Koch, D., Kirkevåg, A., Liu, X., Montanaro, V., Myhre, G., Penner, J. E., Pitari, G., Reddy, S., Seland, Ø., Stier, P., and Takemura, T.: Radiative forcing by aerosols as derived from the AeroCom present-day and pre-industrial simulations, Atmos. Chem. Phys., 6, 5225-5246, https://doi.org/10.5194/acp6-5225-2006, 2006

Segal-Rozenhaimer, M., Miller, D., Knobelspiesse, K., Redemann, J., Cairns, B., and Alexandrov, M.: Development of neural network retrievals of liquid cloud properties from multi-angle polarimetric observations, J. Quant. Spectrosc. Ra., 220, 39-51, 2018. 
Shinozuka, Y. and Redemann, J.: Horizontal variability of aerosol optical depth observed during the ARCTAS airborne experiment, Atmos. Chem. Phys., 11, 8489-8495, https://doi.org/10.5194/acp-11-8489-2011, 2011.

Shinozuka, Y., Saide, P. E., Ferrada, G. A., Burton, S. P., Ferrare, R., Doherty, S. J., Gordon, H., Longo, K., Mallet, M., Feng, Y., Wang, Q., Cheng, Y., Dobracki, A., Freitag, S., Howell, S. G., LeBlanc, S., Flynn, C., Segal-Rosenhaimer, M., Pistone, K., Podolske, J. R., Stith, E. J., Bennett, J. R., Carmichael, G. R., da Silva, A., Govindaraju, R., Leung, R., Zhang, Y., Pfister, L., Ryoo, J.-M., Redemann, J., Wood, R., and Zuidema, P.: Modeling the smoky troposphere of the southeast Atlantic: a comparison to ORACLES airborne observations from September of 2016, Atmos. Chem. Phys., 20, 11491-11526, https://doi.org/10.5194/acp-20-11491-2020, 2020.

Simpson, J. and Wiggert, V.: Models of precipitating cumulus towers, Mon. Weather Rev., 97, 471-489, 1969.

Skamarock, W. C., Klemp, J., Dudhia, J., Gill, D. O., Barker, D., Wang, W., and Powers, J. G.: A Description of the Advanced Research, WRF, Version 3.27.3-27, NCAR Technical Notes, NCAR/TN-4751STR, available at: https://opensky.ucar.edu/ islandora/object/technotes:500/datastream/PDF/view (last access: December 2020), 2008.

Sorooshian, A., Feingold, G., Lebsock, M. D., Jiang, H., and Stephens, G. L.: On the Precipitation Susceptibility of Clouds to Aerosol Perturbations, Geophys. Res. Lett., 36, 13, https://doi.org/10.1029/2009GL038993, 2009.

Stier, P., Schutgens, N. A. J., Bellouin, N., Bian, H., Boucher, O., Chin, M., Ghan, S., Huneeus, N., Kinne, S., Lin, G., Ma, X., Myhre, G., Penner, J. E., Randles, C. A., Samset, B., Schulz, M., Takemura, T., Yu, F., Yu, H., and Zhou, C.: Host model uncertainties in aerosol radiative forcing estimates: results from the AeroCom Prescribed intercomparison study, Atmos. Chem. Phys., 13, 3245-3270, https://doi.org/10.5194/acp-13-3245-2013, 2013.

Swap, R. J., Annegarn, H. J., Suttles, J. T., King, M. D., Platnick, S., Privette, J. L., and Scholes, R. J.: Africa burning: A thematic analysis of the Southern African Regional Science Initiative (SAFARI 2000), J. Geophys. Res., 108, 8465, https://doi.org/10.1029/2003JD003747, 2003.

Szczodrak, M., Austin, P. H., and Krummel, P. B.: Variability of Optical Depth and Effective Radius in Marine Stratocumulus Clouds, J. Atmos. Sci., 58, 2912-2926, https://doi.org/10.1175/15200469(2001)058<2912:VOODAE >2.0.CO;2, 2001.

Twomey, S.: Pollution and the planetary albedo, Atmos. Environ., 8, 1251-1256, 1974.

Tzortziou, M., Herman, J. R., Cede, A., and Abuhassan, N.: High precision, absolute total column ozone measurements from the Pandora spectrometer system: Comparisons with data from a Brewer double monochromator and AuraOMI, J. Geophys. Res., 117, D16303, https://doi.org/10.1029/2012JD017814, 2012.

van der Werf, G. R., Randerson, J. T., Giglio, L., Collatz, G. J., Mu, M., Kasibhatla, P. S., Morton, D. C., DeFries, R. S., Jin, Y., and van Leeuwen, T. T.: Global fire emissions and the contribution of deforestation, savanna, forest, agricultural, and peat fires (1997-2009), Atmos. Chem. Phys., 10, 11707-11735, https://doi.org/10.5194/acp-10-11707-2010, 2010.

Watson-Parris, D., Schutgens, N., Winker, D., Burton, S., Ferrare, R., Stier, P.: On the Limits of CALIOP for Constraining Modeled
Free Tropospheric Aerosol, Geophys. Res. Lett., 45, 9260-9266, 2018.

Werdell, P. J., Behrenfeld, M. J., Bontempi, P. S., Boss, E., Cairns, B., Davis, G. T., Franz, B. A., Gliese, U. B., Gorman, E. T., Hasekamp, O., Knobelspiesse, K. D., Mannino, A., Martins, J. V., McClain, C. R., Meister, G., and Remer, L. A.: The Plankton, Aerosol, Cloud, ocean Ecosystem (PACE) mission: Status, science, advances, B. Am. Meteorol. Soc., 100, 1775-1794 https://doi.org/10.1175/bams-d-18-0056.1, 2019.

Wilcox, E. M.: Direct and semi-direct radiative forcing of smoke aerosols over clouds, Atmos. Chem. Phys., 12, 139-149, https://doi.org/10.5194/acp-12-139-2012, 2012.

Wood, R.: Cancellation of aerosol indirect effects in marine stratocumulus through cloud thinning, J. Atmos. Sci., 64, 26572669, 2007.

Wood, R.: Stratocumulus clouds, Mon. Weather Rev., 140, 2373 2423, https://doi.org/10.1175/MWR-D-11-00121.1, 2012.

Wood, R., Leon, D., Lebsock, M., Snider, J., and Clarke, A. D.: Precipitation Driving of Droplet Concentration Variability in Marine Low Clouds: PRECIPITATION DRIVING OF DROP CONC, J. Geophys. Res.-Atmos., 117, D19, https://doi.org/10.1029/2012JD018305, 2012.

Wu, H., Taylor, J. W., Szpek, K., Langridge, J. M., Williams, P. I., Flynn, M., Allan, J. D., Abel, S. J., Pitt, J., Cotterell, M. I., Fox, C., Davies, N. W., Haywood, J., and Coe, H.: Vertical variability of the properties of highly aged biomass burning aerosol transported over the southeast Atlantic during CLARIFY-2017, Atmos. Chem. Phys., 20, 12697-12719, https://doi.org/10.5194/acp-20-12697-2020, 2020.

Xu, F., van Harten, G., Diner, D., Davis, A., Seidel, F., Rheingans, B., Tosca, M., Alexandrov, M., Cairns, B., Ferrare, R., Burton, S., Fenn, M. A., Hostetler, C. A., Wood, R., and Redemann, J.: Coupled Retrieval of Liquid Water Cloud and Above-Cloud Aerosol Properties using the Airborne Multiangle SpectroPolarimetric Imager (AirMSPI), J. Geophys. Res.-Atmos., 123, 31753204, 2018.

Ye, J., He, Y., Pappenberger, F., Cloke, H. L., Manful, D. Y., and Li, Z.: Evaluation of ECMWF medium-range ensemble forecasts of precipitation for river basins, Q. J. R. Meteor. Soc., 140, 16151628, 2014.

Yu, H. and Zhang, Z.: New Directions: Emerging satellite observations of above-cloud aerosols and direct radiative forcing, Atmos. Environ., 72, 36-40, 2013.

Yu, H., Zhang, Y., Chin, M., Liu, Z., Omar, A., Remer, L. A., Yang, Y., Yuan, T., and Zhang, J.: An Integrated Analysis of Aerosol above Clouds from A-Train Multisensor Measurements, Rem. Sens. Environ., 121, 125-131, https://doi.org/10.1016/j.rse.2012.01.011, 2012.

Zhang, J. and Zuidema, P.: The diurnal cycle of the smoky marine boundary layer observed during August in the remote southeast Atlantic, Atmos. Chem. Phys., 19, 14493-14516, https://doi.org/10.5194/acp-19-14493-2019, 2019.

Zhang, Z., Meyer, K., Yu, H., Platnick, S., Colarco, P., Liu, Z., and Oreopoulos, L.: Shortwave direct radiative effects of above-cloud aerosols over global oceans derived from 8 years of CALIOP and MODIS observations, Atmos. Chem. Phys., 16, 2877-2900, https://doi.org/10.5194/acp-16-2877-2016, 2016.

Zuidema, P., Painemal, D., deSzoeke, S., and Fairall, C.: Stratocumulus cloud top height estimates and 
their climatic implications, J. Climate, 22, 4652-4666, https://doi.org/10.1175/2009JCLI2708.1, 2009.

Zuidema, P., Chiu, C., Fairall, C. W., Ghan, S. J., Kollias, P., McFarguhar, G. M., Mechem, D. B., Romps, D. M., Wong, H., Yuter, S. E., Alvarado, M. J., DeSzoeke, S. P., Feingold, G., Haywood, J. M., Lewis, E. R., McComiskey, A., Redemann, J., Turner, D. D., Wood, R., and Zhu, P.: Layered Atlantic Smoke Interactions with Clouds (LASIC) Science Plan, DOE/SC-ARM-14-037, availabe at: http://www.osti.gov/scitech/servlets/purl/1232658 (last access: December 2018), 2015.
Zuidema, P., Redemann, J., Haywood, J., Wood, R., Piketh, S., Hipondoka, M., and Formenti, P.: Smoke and Clouds above the Southeast Atlantic: Upcoming Field Campaigns Probe Absorbing Aerosol's Impact on Climate, B. Am. Meteorol. Soc., 97, 1131-1135, https://doi.org/10.1175/BAMS-D-15-00082.1, 2016.

Zuidema, P., Sedlacek III, A. J., Flynn, C., Springston, S., Delgadillo, R., Zhang, J., Aiken, A. C., Koontz, A., and Muradyan, P.: The Ascension Island boundary layer in the remote southeast Atlantic is often smoky, Geophys. Res. Lett., 45, 4456-4465, https://doi.org/10.1002/2017GL076926, 2018. 